\title{
Naphthalimide Scaffold Provides Versatile Platform for Selective Thiol Sensing and Protein Labeling
}

Pengcheng Zhou, Juan Yao, Guodong Hu, and Jianguo Fang*

State Key Laboratory of Applied Organic Chemistry and College of Chemistry and Chemical Engineering, Lanzhou University, Lanzhou 730000, China

*Corresponding author, Email: fangjg@|zu.edu.cn.

\section{Contents}

Experimental section: Materials and methods

Table S1. Reaction of the substituted naphthalimides with ethyl mercaptan (EtSH).

Figure S1. Selective recognition of thiols by MSBN.

Figure S2-82. Original spectra of the compounds.

Figure S83. Cytotoxicity of MSBN to HeLa cells and HepG2 cells.

Figure S84. Mass spectra of E. Coli Trx and adduct of E. Coli Tra with MSBN-TPP. References. 


\section{Experimental Section}

Materials and Instruments HeLa cells and HepG2 cells were obtained from the Shanghai Institute of Biochemistry and Cell Biology, Chinese Academy of Sciences. Dulbecco's modified Eagle's medium (DMEM), GSH, diamide, TCEP, DTNB, 3-(4,5-Dimethyl-2-thiazolyl)-2,5-diphenyl-2H-tetrazolium bromide (MTT) and dimethyl sulfoxide (DMSO) were obtained from Sigma-Aldrich. Fetal bovine serum (FBS) was obtained from SiJiqing. Human cytosolic Trx and E. coli Trx were prepared in our lab. ${ }^{1}$ Penicillin, streptomycin, coomassie blue (CB) and anti-Trx antibody were obtained from Sangon Biotec. SNOC was prepared freshly by mixing $\mathrm{NaNO}_{2}$ and Cys under acidic solutions according to the published procedures. ${ }^{2}$ All other reagents were of analytical grade and were purchased from commercial supplies. Absorption spectra were recorded on UV-vis spectrometer evolution 200 (Thermo Scientific). Fluorescence studies were carried out using a LUMINA fluorescence spectrofluorometer (Thermo Scientific). The absolute quantum yields $(\phi)$ of MSBN $(5 \mu M)$ in PBS with and without Cys $(1 \mathrm{mM})$ were determined on FLS920 spectrometer (Edinburgh Instruments) with $\lambda_{\mathrm{ex}}=390$ nm. MS spectra were recorded on Trace DSQ GC-MS spectrometer or Bruker Daltonics esquire 6000 mass spectrometer. HRMS was obtained on Orbitrap Elite (Thermo Scientific). ${ }^{1} \mathrm{H}$ and ${ }^{13} \mathrm{C}$ NMR spectra were recorded on Bruker Advance 400, and tetramethylsilane (TMS) was used as a reference. Melting points were determined on WRS-2 Melting Point Apparatus (Shanghai Precision \& Scientific Instrument) and were uncorrected. The following buffers were used for the biochemical experiments: Buffer A: $50 \mathrm{mM}$ PBS $(\mathrm{pH}=7.4$, containing 1\% SDS); Buffer B: $50 \mathrm{mM}$ PBS $(\mathrm{pH}=7.4$, containing $1 \%$ SDS, $1 \mathrm{mM}$ EDTA and $0.1 \mathrm{mM}$ Neocuproine); Buffer C: $50 \mathrm{mM}$ Tris $\bullet \mathrm{Cl}(\mathrm{pH}=8.0$, containing $0.1 \%$ SDS); Cell fixation solution A: 70\% EtOH (v/v, containing $0.1 \mathrm{mM}$ NEM); Cell fixation solution $\mathrm{B}: 70 \% \mathrm{EtOH}(\mathrm{v} / \mathrm{v}$, containing $0.1 \mathrm{mM}$ NEM, $1 \mathrm{mM}$ EDTA and $0.1 \mathrm{mM}$ Neocuproine).

\section{Chemical syntheses}

4-Nitro-1,8-naphthalic Anhydride (1, Scheme 2A): ${ }^{3}$ 4-Nitroacenaphthene (10 g, $\left.0.05 \mathrm{~mol}\right)$ was dissolved in glacial acetic acid $(150 \mathrm{ml})$. Then sodium dichromate $(60 \mathrm{~g}, 0.2 \mathrm{~mol})$ was added gradually with string at room temperature. The resulting mixture was heated at gentle reflux for $5 \mathrm{~h}$. After cooling, the mixture was poured into ice water to give yellow precipitate, which was filtered and recrystallized from acetic acid to afford 4-nitro-1,8-naphthalic anhydride (8.5 g, 70\%). ${ }^{1} \mathrm{H}$ NMR $\left(400 \mathrm{MHz}, \mathrm{CDCl}_{3}\right): \delta(\mathrm{ppm}) 8.75(\mathrm{~d}, \mathrm{~J}=8.4 \mathrm{~Hz}, 1 \mathrm{H}), 8.64$ $(\mathrm{m}, 2 \mathrm{H}), 8.56(\mathrm{~d}, J=2.4 \mathrm{~Hz}, 1 \mathrm{H}), 8.12\left(\mathrm{dd}, J_{1}=8.8 \mathrm{~Hz}, J_{2}=1.2 \mathrm{~Hz}, 1 \mathrm{H}\right) ;{ }^{13} \mathrm{C} \mathrm{NMR}\left(100 \mathrm{MHz}, \mathrm{CDCl}_{3}\right): \delta(\mathrm{ppm})$ 
160.0, 159.4, 149.5, 133.2, 131.1, 130.6, 130.3, 129.8, 124.3, 124.0, 122.8, 120.0; El-MS m/z (\%): $243\left(\mathrm{M}^{+}\right.$, 38), 199 (35), 153 (32), 125 (39); mp: $237-238{ }^{\circ} \mathrm{C}$

4-Nitro-N-n-butyl-1,8-naphthalimide (2, Scheme $2 \mathrm{~A}):{ }^{3} \mathrm{~A}$ mixture of $1(2.43 \mathrm{~g}, 10 \mathrm{mmol})$ and $n$-butylamine $(1.1 \mathrm{~g}, 15 \mathrm{mmol})$ in ethanol $(150 \mathrm{ml})$ was refluxed for $4 \mathrm{~h}$. After cooling, the mixture was concentrated in vacuum to give crude compound, which was purified by recrystallized to afford 2 as a yellow solid (2.38 g, $80 \%)$. ${ }^{1} \mathrm{H}$ NMR (400 MHz, CDCl3): $\delta(\mathrm{ppm}) 8.84(\mathrm{dd}, J 1=8.8 \mathrm{~Hz}, J 2=7.6 \mathrm{~Hz}, 1 \mathrm{H}), 8.74\left(\mathrm{dd}, J_{1}=7.2 \mathrm{~Hz}, J_{2}=6.0 \mathrm{~Hz}, 1 \mathrm{H}\right)$, $8.69(\mathrm{~d}, J=8.0 \mathrm{~Hz}, 1 \mathrm{H}), 8.41(\mathrm{~d}, J=8.0 \mathrm{~Hz}, 1 \mathrm{H}), 7.99\left(\mathrm{dd}, J_{1}=8.8 \mathrm{~Hz}, J_{2}=1.6 \mathrm{~Hz}, 1 \mathrm{H}\right), 4.20(\mathrm{t}, J=7.6 \mathrm{~Hz}, 2 \mathrm{H}), 1.73$ (m, 2H), $1.46(\mathrm{~m}, 2 \mathrm{H}), 0.99(\mathrm{t}, 3 \mathrm{H}) ;{ }^{13} \mathrm{C}$ NMR $\left(100 \mathrm{MHz}, \mathrm{CDCl}_{3}\right): \delta(\mathrm{ppm}) 163.5,162.7,149.8,132.6,130.1$, 129.9, 129.5, 129.3, 127.3, 124.1, 123.9, 123.3, 40.9, 30.3, 20.6, 14.0; El-MS m/z (\%): 298 (M+, 93), 243 (85), 153 (12), 125 (16); mp: $95-96{ }^{\circ} \mathrm{C}$

General procedure for preparation of 3a-3c (Scheme 2A). ${ }^{4,5}$ 4-Nitro-N-n-butyl-1,8-naphthalimide (2) (894 mg, $3 \mathrm{mmol})$, corresponding thiols $(9 \mathrm{mmol})$ and TEA (303 $\mathrm{mg}, 3 \mathrm{mmol})$ were mixed in DMF $(30 \mathrm{ml})$. Then the reaction mixture was stirring for $2 \mathrm{~h}$ at room temperature. The solvent was removed in vacuum and the crude products were purified by silica gel column chromatography to afford the corresponding products.

4-Methylthio-N-n-butyl-1,8-naphthalimide (3a): yellow solid (854 mg, 95\%); ${ }^{1} \mathrm{H} \mathrm{NMR}\left(400 \mathrm{MHz}, \mathrm{CDCl}_{3}\right): \delta$ (ppm) $8.76(\mathrm{~d}, J=7.6 \mathrm{~Hz}, 1 \mathrm{H}), 8.63(\mathrm{~d}, J=7.6 \mathrm{~Hz}, 1 \mathrm{H}), 8.38(\mathrm{~d}, J=7.6 \mathrm{~Hz}, 1 \mathrm{H}), 8.25(\mathrm{~d}, J=8.4 \mathrm{~Hz}, 1 \mathrm{H}), 7.83(\mathrm{t}$ $J=8.0 \mathrm{~Hz}, 1 \mathrm{H}), 4.14(\mathrm{t}, J=7.6 \mathrm{~Hz}, 2 \mathrm{H}), 2.87(\mathrm{~s}, 3 \mathrm{H}), 1.68(\mathrm{~m}, 2 \mathrm{H}), 1.41(\mathrm{~m}, 2 \mathrm{H}), 0.94(\mathrm{t}, J=7.6 \mathrm{~Hz}, 3 \mathrm{H}) ;{ }^{13} \mathrm{C}$ NMR $\left(100 \mathrm{MHz}, \mathrm{CDCl}_{3}\right): \delta(\mathrm{ppm}) 163.5,163.4,149.1,131.7,130.9,128.3,128.3,127.2,127.1,125.1,123.8,123.0$, 43.5, 40.6, 30.2, 20.4, 13.9; ESI-MS (m/z): $[\mathrm{M}+\mathrm{H}]^{+} 299.9 ; \mathrm{mp}: 119-121^{\circ} \mathrm{C}$.

4-Ethylthio-N-n-butyl-1,8-naphthalimide (3b): yellow solid (890 mg, 93\%); ${ }^{1} \mathrm{H} \mathrm{NMR}\left(400 \mathrm{MHz}, \mathrm{CDCl}_{3},\right): \delta$ (ppm) $8.58\left(\mathrm{dd}, J_{1}=7.2 \mathrm{~Hz}, J_{2}=6.0 \mathrm{~Hz}, 1 \mathrm{H}\right), 8.50\left(\mathrm{dd}, J_{1}=8.8 \mathrm{~Hz}, J_{2}=7.6 \mathrm{~Hz}, 1 \mathrm{H}\right), 8.43(\mathrm{~d}, J=8.0 \mathrm{~Hz}, 1 \mathrm{H}), 7.71$ (dd, $\left.J_{1}=8.4 \mathrm{~Hz}, J_{2}=1.2 \mathrm{~Hz}, 1 \mathrm{H}\right), 7.50(\mathrm{~d}, J=8.0 \mathrm{~Hz}, 1 \mathrm{H}), 4.16(\mathrm{t}, J=7.6 \mathrm{~Hz}, 2 \mathrm{H}), 3.18\left(\mathrm{dd}, J_{1}=14.8 \mathrm{~Hz}, J_{2}=7.6 \mathrm{~Hz}\right.$, 2H), $1.71(\mathrm{~m}, 2 \mathrm{H}), 1.46(\mathrm{~m}, 5 \mathrm{H}), 0.98(\mathrm{t}, \mathrm{J}=7.6 \mathrm{~Hz}, 3 \mathrm{H}) ;{ }^{13} \mathrm{C}$ NMR $\left(100 \mathrm{MHz}, \mathrm{CDCl}_{3}\right): \delta(\mathrm{ppm}) 164.2,164.2$ 145.3, 131.6, 130.9, 130.2, 129.7, 128.5, 126.7, 123.4, 122.8, 119.3, 40.4, 30.4, 26.6, 20.6, 14.0, 13.7; ESI-MS $(\mathrm{m} / \mathrm{z}):[\mathrm{M}+\mathrm{H}]^{+} 313.9 ; \mathrm{mp}: 96-98^{\circ} \mathrm{C}$.

4-Phenylthio- $N$ - $n$-butyl-1,8-naphthalimide (3c): yellow solid (1.03 g, 96\%); ${ }^{1} \mathrm{H} \mathrm{NMR}\left(400 \mathrm{MHz}, \mathrm{CDCl}_{3}\right): \delta$ (ppm) $8.56\left(\mathrm{dd}, J_{1}=7.2 \mathrm{~Hz}, J_{2}=6.0 \mathrm{~Hz}, 2 \mathrm{H}\right), 8.29(\mathrm{~d}, J=8.0 \mathrm{~Hz}, 1 \mathrm{H}), 7.71(\mathrm{t}, J=7.8 \mathrm{~Hz}, 1 \mathrm{H}), 7.51(\mathrm{~m}, 2 \mathrm{H}), 7.43(\mathrm{t}$, $J=3.2 \mathrm{~Hz}, 3 \mathrm{H}), 7.22(\mathrm{~d}, J=8.0 \mathrm{~Hz}, 1 \mathrm{H}), 4.14(\mathrm{t}, J=7.6 \mathrm{~Hz}, 2 \mathrm{H}), 1.70(\mathrm{~m}, 2 \mathrm{H}), 1.44(\mathrm{~m}, 2 \mathrm{H}), 0.97$ (t, J=7.6 Hz, 3H); 
${ }^{13} \mathrm{C} \mathrm{NMR}\left(100 \mathrm{MHz}, \mathrm{CDCl}_{3}\right): \delta$ (ppm) 164.2, 164.0, 145.1, 134.2, 131.8, 131.3, 130.9, 130.4, 130.2, 129.6, 129.4, 128.6, 127.1, 126.3, 123.4, 120.5, 40.4, 30.4, 20.6, 14.0; ESI-MS(m/z): [M+H] $362.3 ; \mathrm{mp}: 93-94{ }^{\circ} \mathrm{C}$.

General procedure for preparation of $\mathbf{4 a - 4 c}$ (Scheme $2 \mathrm{~A}){ }^{5}$ To a solution of $3 \mathrm{a}-3 \mathrm{c}(2 \mathrm{mmol})$ in $60 \mathrm{ml} \mathrm{DCM}$ at 0 ${ }^{\circ} \mathrm{C}$ was added $m$-CPBA (516 mg, $3 \mathrm{mmol}$ ) gradually. Then, the reaction was stirred for $2 \mathrm{~h}$ at room temperature. The solvent was removed in vacuum and the crude products were purified by silica gel column chromatography to afford the corresponding products.

4-Methylsulfinyl-N-n-butyl-1,8-naphthalimide (4a): pale yellow solid (548 mg, 87\%); ${ }^{1} \mathrm{H}$ NMR (400 MHz, $\left.\mathrm{CDCl}_{3}\right): \delta(\mathrm{ppm}) 8.59(\mathrm{~d}, J=7.2 \mathrm{~Hz}, 1 \mathrm{H}), 8.45\left(\mathrm{dd}, J_{1}=8.4 \mathrm{~Hz}, J_{2}=4.8 \mathrm{~Hz}, 2 \mathrm{H}\right), 7.71(\mathrm{t}, J=8.0 \mathrm{~Hz}, 1 \mathrm{H}), 7.41$ (d, $J=8.0 \mathrm{~Hz}, 1 \mathrm{H}), 4.16(\mathrm{t}, J=7.6 \mathrm{~Hz}, 2 \mathrm{H}), 2.68(\mathrm{~s}, 3 \mathrm{H}), 1.71(\mathrm{~m}, 2 \mathrm{H}), 1.45(\mathrm{~m}, 2 \mathrm{H}), 0.98(\mathrm{t}, J=7.2 \mathrm{~Hz}, 3 \mathrm{H}) ;{ }^{13} \mathrm{C} N M R$ $\left(100 \mathrm{MHz}, \mathrm{CDCl}_{3}\right): \delta(\mathrm{ppm}) 164.2,164.2,146.4,131.6,131.0,129.7,129.1,128.3,126.7,123.4,121.1,119.0$, 40.4, 30.4, 20.6, 15.0, 14.0; ESI-MS(m/z): $[\mathrm{M}+\mathrm{H}]^{+} 316.1 ; \mathrm{mp}: 115-117^{\circ} \mathrm{C}$.

4-Ethylsulfinyl-N-n-butyl-1,8-naphthalimide (4b): pale yellow solid (590 mg, 90\%); ${ }^{1} \mathrm{H}$ NMR (400 MHz, $\left.\mathrm{CDCl}_{3}\right): \delta(\mathrm{ppm}) 8.75(\mathrm{~d}, J=7.6 \mathrm{~Hz}, 1 \mathrm{H}), 8.67(\mathrm{~d}, J=7.2 \mathrm{~Hz}, 1 \mathrm{H}), 8.35(\mathrm{~d}, J=7.6 \mathrm{~Hz}, 1 \mathrm{H}), 8.29(\mathrm{~d}, J=8.4 \mathrm{~Hz}, 1 \mathrm{H})$, $7.85(\mathrm{~d}, J=7.6 \mathrm{~Hz}, 1 \mathrm{H}), 4.19(\mathrm{t}, \mathrm{J}=7.6 \mathrm{~Hz}, 2 \mathrm{H}), 3.16(\mathrm{~m}, 1 \mathrm{H}), 2.88(\mathrm{~m}, 1 \mathrm{H}), 1.72(\mathrm{~m}, 2 \mathrm{H}), 1.45(\mathrm{~m}, 2 \mathrm{H}), 1.25(\mathrm{t}$, $J=7.6 \mathrm{~Hz}), 0.98(\mathrm{t}, J=7.6 \mathrm{~Hz}, 3 \mathrm{H}) ;{ }^{13} \mathrm{C}$ NMR $\left(100 \mathrm{MHz}, \mathrm{CDCl}_{3}\right): \delta$ (ppm) 163.6, 163.4, 146.6, 131.6, 130.5, 128.3, $128.1,127.5,127.4,125.0,124.2,123.8,49.4,40.6,30.3,20.5,13.9,6.2 ; \mathrm{ESI}-\mathrm{MS}(\mathrm{m} / \mathrm{z}):[\mathrm{M}+\mathrm{H}]^{+} 330.1 ; \mathrm{mp}$ : $113-114^{\circ} \mathrm{C}$.

4-Phenylsulfinyl-N-n-butyl-1,8-naphthalimide (4c): pale yellow solid (688 mg, 92\%); ${ }^{1} \mathrm{H}$ NMR (400 MHz, $\left.\mathrm{CDCl}_{3}\right): \delta(\mathrm{ppm}) 8.75(\mathrm{~d}, J=7.6 \mathrm{~Hz}, 1 \mathrm{H}), 8.63(\mathrm{~d}, J=7.2 \mathrm{~Hz}, 1 \mathrm{H}), 8.56(\mathrm{~d}, J=8.4 \mathrm{~Hz}, 1 \mathrm{H}), 8.50(\mathrm{~d}, J=7.6 \mathrm{~Hz}, 1 \mathrm{H})$, 7.80 (dd, $\left.J_{1}=8.0 \mathrm{~Hz}, J_{2}=0.8 \mathrm{~Hz}, 1 \mathrm{H}\right), 7.7(\mathrm{~m}, 2 \mathrm{H}), 7.43$ (t, J=3.2 Hz, 3H), 4.17 (t, J=7.6 Hz, 2H), 1.70 (m, 2H), $1.44(\mathrm{~m}, 2 \mathrm{H}), 0.97(\mathrm{t}, J=7.6,3 \mathrm{H}) ;{ }^{13} \mathrm{C}$ NMR $\left(100 \mathrm{MHz}, \mathrm{CDCl}_{3}\right): \delta(\mathrm{ppm}) 163.7,163.5,148.0,144.4,132.0,131.8$, 130.8, 129.9, 128.7, 128.4, 128.3, 127.8, 125.6, 125.4, 124.2, 123.8, 40.6, 30.3, 20.5, 14.0; ESI-MS (m/z): $[\mathrm{M}+\mathrm{H}]^{+} 378.1 ; \mathrm{mp}: 144-145^{\circ} \mathrm{C}$.

General procedure for preparation of $\mathbf{5 a - 5 c}($ Scheme $2 \mathrm{~A}) .{ }^{5} \mathrm{~A}$ mixture of $\mathbf{4 a}-\mathbf{4 c}(1 \mathrm{mmol})$ and $\mathrm{m}$-CPBA (516 $\mathrm{mg}, 3 \mathrm{mmol}$ ) in $30 \mathrm{ml} \mathrm{DCM}$ was refluxed for $3 \mathrm{~h}$. After cooling, the solvent was removed in vacuum and the crude products were purified by silica gel column chromatography to afford the corresponding products.

4-Methylsulfonyl-N-n-butyl-1,8-naphthalimide (MSBN, 5a): white solid (282 mg, 85\%); ${ }^{1} \mathrm{H}$ NMR (400 MHz, $\left.\mathrm{CDCl}_{3}\right): \delta(\mathrm{ppm}) 9.12\left(\mathrm{dd}, J_{1}=8.8 \mathrm{~Hz}, J_{2}=8.0 \mathrm{~Hz}, 1 \mathrm{H}\right), 8.73(\mathrm{~m}, 2 \mathrm{H}), 8.57(\mathrm{~d}, J=7.6 \mathrm{~Hz}, 1 \mathrm{H}), 7.99\left(\mathrm{dd}, J_{1}=8.8 \mathrm{~Hz}\right.$, 
$\left.J_{2}=1.2 \mathrm{~Hz}, 1 \mathrm{H}\right), 4.20(\mathrm{t}, J=7.6 \mathrm{~Hz}, 2 \mathrm{H}), 3.27(\mathrm{~s}, 3 \mathrm{H}), 1.73(\mathrm{~m}, 2 \mathrm{H}), 1.46(\mathrm{~m}, 2 \mathrm{H}), 0.99(\mathrm{t}, J=7.6 \mathrm{~Hz}, 3 \mathrm{H}) ;{ }^{13} \mathrm{C} N M R$ $\left(100 \mathrm{MHz}, \mathrm{CDCl}_{3}\right): \delta$ (ppm) 163.6, 163.0, 140.9, 132.1, 130.2, 130.0, 129.9, 129.6, 129.2, 127.9, 127.7, 123.8, 45.0, 40.8, 30.3, 20.6, 14.0; HRMS (ESI) calculated for $[\mathrm{C} 17 \mathrm{H} 17 \mathrm{NO} 4 \mathrm{SH}]^{+}(\mathrm{M}+\mathrm{H})^{+}$requires $\mathrm{m} / \mathrm{z}=332.0951$, found 332.0946; mp: $164-165^{\circ} \mathrm{C}$.

4-Ethylsulfonyl-N-n-butyl-1,8-naphthalimide (5b): white solid (280 mg, 81\%); $\left.{ }^{1} \mathrm{H} \mathrm{NMR} \mathrm{(400} \mathrm{MHz,} \mathrm{CDCl}_{3}\right): \delta$ (ppm) 9.12 (d, J=8.8 Hz, 1H), 8.72 (d, J=7.6 Hz, 2H), 8.52 (d, J=7.6 Hz, 2H), 7.96 (t, 1H), 4.19 (t, J=7.6 Hz, 2H), $3.34\left(\mathrm{dd}, J_{1}=14.8 \mathrm{~Hz}, J_{2}=7.6 \mathrm{~Hz}, 2 \mathrm{H}\right), 1.73(\mathrm{~m}, 2 \mathrm{H}), 1.46(\mathrm{~m}, 2 \mathrm{H}), 1.29(\mathrm{t}, J=7.6 \mathrm{~Hz}, 3 \mathrm{H}) ;{ }^{13} \mathrm{C} \mathrm{NMR}(100 \mathrm{MHz}$, $\left.\mathrm{CDCl}_{3}\right): \delta(\mathrm{ppm}) 163.6,163.0,139.1,132.1,131.2,130.4,129.7,129.4,129.2,128.0,127.9,123.8,51.2,40.8$, 30.3, 20.5, 14.0, 7.5; ESI-MS (m/z): [M+H $]^{+} 346.13 ; \mathrm{mp}: 179-181{ }^{\circ} \mathrm{C}$.

4-Phenylsulfonyl-N-n-butyl-1,8-naphthalimide (5c): white solid (322 mg, 82\%); ${ }^{1} \mathrm{H} \mathrm{NMR}\left(400 \mathrm{MHz}, \mathrm{CDCl}_{3}\right): \delta$ (ppm) 9.08 (d, J=8.4 Hz, 1H), $8.73(\mathrm{~d}, J=7.6 \mathrm{~Hz}, 1 \mathrm{H}), 8.66$ (dd, $\left.J_{1}=10.4 \mathrm{~Hz}, J_{2}=2.4 \mathrm{~Hz}, 2 \mathrm{H}\right), 8.01$ (d, J=7.6 Hz, 2H), 7.87 (t, J=7.2 Hz, 1H), 7.54 (t, J=7.6 Hz, 2H), 4.18 (t, J=7.6 Hz, 2H), 1.70 (m, 2H), $1.44(\mathrm{~m}, 2 \mathrm{H}), 0.98$ (t, $J=7.2,3 \mathrm{H}) ;{ }^{13} \mathrm{C}$ NMR $\left(100 \mathrm{MHz}, \mathrm{CDCl}_{3}\right): \delta$ (ppm) 163.6, 163.0, 141.8, 140.9, 134.1, 132.0, 130.6, 129.9, 129.8, 129.7, 129.2, 129.2, 127.9, 127.7, 127.4, 123.6, 40.8, 29.9, 20.5, 14.0; ESI-MS (m/z): $[M+H]^{+} 394.1 ; m p:$ $184-185^{\circ} \mathrm{C}$.

4-Bromo-N-n-butyl-1,8-naphthalimide (6, Scheme $2 \mathrm{~B}):^{6} \mathrm{~A}$ mixture of 4-bromo-1,8-naphthalic anhydride $(2.77 \mathrm{~g}, 10 \mathrm{mmol})$ and $n$-butylamine $(1.1 \mathrm{~g}, 15 \mathrm{mmol})$ in ethanol $(150 \mathrm{~mL})$ was refluxed for $4 \mathrm{~h}$. After cooling, the mixture was concentrated in vacuum to give crude product, which was purified by recrystallization to give 6 as a yellow solid $(2.65 \mathrm{~g}, 80 \%) .{ }^{1} \mathrm{H}$ NMR $\left(400 \mathrm{MHz}, \mathrm{CDCl}_{3}\right): \delta(\mathrm{ppm}) 8.63(\mathrm{~d}, J=7.6 \mathrm{~Hz}, 1 \mathrm{H}), 8.54(\mathrm{~d}, \mathrm{~J}=8.4 \mathrm{~Hz}, 1 \mathrm{H})$, $8.39(\mathrm{~d}, J=7.6 \mathrm{~Hz}, 1 \mathrm{H}), 8.02(\mathrm{~d}, J=8.0 \mathrm{~Hz}, 1 \mathrm{H}), 7.83\left(\mathrm{dd}, J_{1}=8.4 \mathrm{~Hz}, J_{2}=0.8 \mathrm{~Hz}, 1 \mathrm{H}\right), 4.17(\mathrm{t}, J=7.6 \mathrm{~Hz}, 2 \mathrm{H}), 1.72$ $(\mathrm{m}, 2 \mathrm{H}), 1.45$ (m, 2H), $0.98(\mathrm{t}, \mathrm{J}=7.6 \mathrm{~Hz}, 3 \mathrm{H}) ;{ }^{13} \mathrm{C} \mathrm{NMR}\left(100 \mathrm{MHz}, \mathrm{CDCl}_{3}\right): \delta$ (ppm) 163.8, 163.7, 133.3, 132.2, 131.3, 131.2, 130.8, 130.3, 129.1, 128.2, 123.3, 122.5, 40.6, 30.4, 20.6, 14.0; ESI-MS (m/z): [M+H] $]^{+} 332.3 ; \mathrm{mp}:$ $99-101^{\circ} \mathrm{C}$.

4-Methoxy-N-n-butyl-1, 8-naphthalimide (7, Scheme 2B): ${ }^{6}$ Compound 6 (1.66 g, $5 \mathrm{mmol}$ ), sodium methoxide $(2.16 \mathrm{~g}, 40 \mathrm{mmol})$ and copper sulphate $(160 \mathrm{mg}, 1 \mathrm{mmol})$ were mixed in dry methanol $(50 \mathrm{ml})$. The reaction mixture was refluxed under argon for $10 \mathrm{~h}$. After cooling, the resulting mixture was filtered to give pale yellow solid, which was washed with $10 \%$ hydrochloric acid and water to afford 7 as a pale green needle-shaped crystal $(1.17 \mathrm{~g}, 82 \%) .{ }^{1} \mathrm{H}$ NMR $\left(400 \mathrm{MHz}, \mathrm{CDCl}_{3}\right): \delta(\mathrm{ppm}) 8.54(\mathrm{~d}, \mathrm{~J}=7.2 \mathrm{~Hz}, 1 \mathrm{H}), 8.49(\mathrm{~d}, J=8.4$ 
$\mathrm{Hz}, 2 \mathrm{H}), 7.65(\mathrm{t}, \mathrm{J}=8.0 \mathrm{~Hz}, 1 \mathrm{H}), 6.99(\mathrm{~d}, \mathrm{~J}=8.4 \mathrm{~Hz}, 1 \mathrm{H}), 4.15(\mathrm{t}, \mathrm{J}=7.6 \mathrm{~Hz}, 2 \mathrm{H}), 4.10(\mathrm{~s}, 3 \mathrm{H}), 1.71(\mathrm{~m}, 2 \mathrm{H}), 1.44$ (m, 2H), 0.97 (t, J=7.2 Hz, 3H); ${ }^{13} \mathrm{C}$ NMR $\left(100 \mathrm{MHz}, \mathrm{CDCl}_{3}\right): \delta(\mathrm{ppm}) 164.6,164.1,160.9,133.5,131.6,129.5$, 128.7, 126.0, 123.6, 122.6, 115.3, 105.3, 56.3, 40.3, 30.5, 20.6, 14.0; ESI-MS (m/z): $[\mathrm{M}+\mathrm{H}]^{+} 284.1 ; \mathrm{mp}:$ $113-114{ }^{\circ} \mathrm{C}$

4-Hydroxy-N-n-butyl-1, 8-naphthalimide (8, Scheme 2B): ${ }^{6}$ A mixture of $7(2.08 \mathrm{~g}, 7.3 \mathrm{mmol})$ and $57 \%$ hydroiodic acid (100 ml) was refluxed under argon for $14 \mathrm{~h}$. After cooling, the resulting mixture was filtered, and the crude product was washed with water to afford yellow-green solid, which was further purified by silica gel column chromatography to afford compound 8 as a pale yellow solid $(845 \mathrm{mg}, 43 \%) .{ }^{1} \mathrm{H}$ NMR $(400 \mathrm{MHz}$, DMSO-d6): $\delta$ (ppm) 11.87 (s, 1H), $8.50(\mathrm{~d}, J=7.2 \mathrm{~Hz}, 1 \mathrm{H}), 8.32$ (d, J=8.0 Hz, 1H), $7.73(\mathrm{t}, J=7.2 \mathrm{~Hz}, 1 \mathrm{H}), 7.13$ (d, $J=8.4 \mathrm{~Hz}, 1 \mathrm{H}), 4.00(\mathrm{t}, J=7.6 \mathrm{~Hz}, 2 \mathrm{H}), 1.58(\mathrm{~m}, 2 \mathrm{H}), 1.33(\mathrm{~m}, 2 \mathrm{H}), 0.91(\mathrm{t}, J=7.6 \mathrm{~Hz}, 3 \mathrm{H}) ;{ }^{13} \mathrm{C} \mathrm{NMR}(100 \mathrm{MHz}$, DMSO-d6): $\delta$ (ppm) 163.6, 162.9, 160.2, 133.5, 131.0, 129.1, 128.8, 125.5, 122.3, 121.8, 112.68, 109.9, 40.1, 29.7, 19.8, 13.7; ESI-MS (m/z): [M-H] 268.1; mp: 219-221 ${ }^{\circ} \mathrm{C}$.

General procedure for preparation of $9 a$ and $9 b$ (Scheme 2B). Compound 8 (134.5 mg, $0.5 \mathrm{mmol}$ ), methanesulfonyl chloride or $p$-toluenesulfonyl chloride $(1 \mathrm{mmol})$ and TEA $(101 \mathrm{mg}, 1 \mathrm{mmol})$ were mixed in DCM $(30 \mathrm{ml})$. Then the reaction mixture was stirring for $4 \mathrm{~h}$ at room temperature. The solvent was removed in vacuum and the solid was purified by column chromatography to afford products.

4-[(methylsulfonyl)oxy]-N-n-butyl-1,8-naphthalimide (9a): white solid (135 mg, 78\%); ${ }^{1} \mathrm{H}$ NMR (400 MHz, $\left.\mathrm{CDCl}_{3}\right): \delta(\mathrm{ppm}) 8.66\left(\mathrm{dd}, J_{1}=7.2 \mathrm{~Hz}, J_{2}=6.4 \mathrm{~Hz}, 1 \mathrm{H}\right), 8.61(\mathrm{~d}, J=8.0 \mathrm{~Hz}, 1 \mathrm{H}), 8.46\left(\mathrm{dd}, J_{1}=8.4 \mathrm{~Hz}, J_{2}=7.6 \mathrm{~Hz}\right.$ $1 \mathrm{H}), 7.85\left(\mathrm{dd}, J_{1}=8.4 \mathrm{~Hz}, J_{2}=0.8 \mathrm{~Hz}, 1 \mathrm{H}\right), 7.75(\mathrm{~d}, J=8 \mathrm{~Hz}, 1 \mathrm{H}), 4.18(\mathrm{t}, J=7.6 \mathrm{~Hz}, 2 \mathrm{H}), 3.38(\mathrm{~s}, 3 \mathrm{H}), 1.71(\mathrm{~m}, 2 \mathrm{H})$, $1.45(\mathrm{~m}, 2 \mathrm{H}), 0.98(\mathrm{t}, \mathrm{J}=7.2 \mathrm{~Hz}, 3 \mathrm{H}) ;{ }^{13} \mathrm{C}$ NMR $\left(100 \mathrm{MHz}, \mathrm{CDCl}_{3}\right): \delta(\mathrm{ppm}) 163.9,163.3,149.6,132.2,131.7$, 129.7, 128.2, 128.1, 125. 8, 123.2, 121.9, 119.4, 40.6, 38.9, 30.4, 20.6, 14.0; HRMS (ESI) calculated for $[\mathrm{C} 17 \mathrm{H} 17 \mathrm{NO} 5 \mathrm{SH}]^{+}(\mathrm{M}+\mathrm{H})^{+}$requires $\mathrm{m} / \mathrm{z}=348.0900$, found 348.0903; mp: 100-102 ${ }^{\circ} \mathrm{C}$.

4-[(p-toluenesulfonyl)oxy]-N-n-butyl-1,8-naphthalimide (9b): white solid (178 mg, 84\%); ${ }^{1} \mathrm{H} \mathrm{NMR} \mathrm{(400} \mathrm{MHz,}$ $\left.\mathrm{CDCl}_{3}\right): \delta(\mathrm{ppm}) 8.56\left(\mathrm{dd}, J_{1}=7.2 \mathrm{~Hz}, J_{2}=6.4 \mathrm{~Hz}, 1 \mathrm{H}\right), 8.48(\mathrm{~d}, J=8.4 \mathrm{~Hz}, 1 \mathrm{H}), 8.23\left(\mathrm{dd}, J_{1}=8.4 \mathrm{~Hz}, J_{2}=7.6 \mathrm{~Hz}\right.$ 1H), $7.78(\mathrm{~d}, J=8.4 \mathrm{~Hz}, 2 \mathrm{H}), 7.68\left(\mathrm{dd}, J_{1}=8.4 \mathrm{~Hz}, J_{2}=1.2 \mathrm{~Hz}, 1 \mathrm{H}\right), 7.41(\mathrm{~d}, J=8.0 \mathrm{~Hz}, 1 \mathrm{H}), 7.32(\mathrm{~d}, J=8.0 \mathrm{~Hz}, 2 \mathrm{H})$, 4.14 (t, J=7.6 Hz, 2H), $2.43(\mathrm{~s}, 3 \mathrm{H}), 1.68(\mathrm{~m}, 2 \mathrm{H}), 1.42(\mathrm{~m}, 2 \mathrm{H}), 0.96(\mathrm{t}, J=7.6 \mathrm{~Hz}, 3 \mathrm{H}) ;{ }^{13} \mathrm{C}$ NMR (400 MHz, $\left.\mathrm{CDCl}_{3}\right): \delta(\mathrm{ppm}) 164.0,163.4,150.3,146.4,132.2,132.0,131.5,130.4,130.3,129.5,128.7,128.4,127.7$ 127.2, 125.9, 122.9, 121.5, 119.5, 40.5, 30.3, 21.9, 20.5, 14.0; HRMS (ESI) calculated for [C23H21NO5SH] $(\mathrm{M}+\mathrm{H})^{+}$requires $\mathrm{m} / \mathrm{z}=424.1213$, found $424.1217 ; \mathrm{mp}: 96-97^{\circ} \mathrm{C}$. 
4-Carbonitrile-N-n-butyl-1,8-naphthalimide (10, Scheme 2C): ${ }^{7}$ Compound 6 (219 mg, $\left.0.66 \mathrm{mmol}\right)$ and CuCN (200 mg, $2.23 \mathrm{mmol}$ ) were added into $5 \mathrm{ml} \mathrm{N}$-methylpyrrolidone (NMP). The mixture was stirred for $14 \mathrm{~h}$ at $140{ }^{\circ} \mathrm{C}$. After cooling to room temperature, the reaction mixture was poured into $100 \mathrm{~mL}$ water. The aqueous layer was extracted with ethyl acetate and then the combined organic layer was washed by brine, dried over $\mathrm{Na}_{2} \mathrm{SO}_{4}$. The solvent was removed in vacuum, and the crude product was purified by silica gel column chromatography (petroleum ether/DCM, v:v,1:1) to give compound $\mathbf{1 0}(94 \mathrm{mg}, 51 \%)$ as a pale yellow solid. ${ }_{1} \mathrm{H}$ $\operatorname{NMR}\left(400 \mathrm{MHz}, \mathrm{CDCl}_{3}\right): \delta(\mathrm{ppm}) 8.71(\mathrm{~d}, J=7.2 \mathrm{~Hz}, 1 \mathrm{H}), 8.63(\mathrm{~d}, J=7.6 \mathrm{~Hz}, 1 \mathrm{H}), 8.57(\mathrm{~d}, J=8.4 \mathrm{~Hz}, 1 \mathrm{H}), 8.16(\mathrm{~d}$, $J=7.6 \mathrm{~Hz}, 1 \mathrm{H}), 7.98(\mathrm{t}, J=7.6 \mathrm{~Hz}, 1 \mathrm{H}), 4.18(\mathrm{t}, \mathrm{J}=7.2 \mathrm{~Hz}, 2 \mathrm{H}), 1.71(\mathrm{~m}, 2 \mathrm{H}), 1.45(\mathrm{~m}, 2 \mathrm{H}), 0.98(\mathrm{t}, J=7.2 \mathrm{~Hz}, 3 \mathrm{H})$; ${ }^{13} \mathrm{C}$ NMR $\left(100 \mathrm{MHz}, \mathrm{CDCl}_{3}\right): \delta(\mathrm{ppm}) 162.1,162.8,132.8,132.4,130.9,130.8,129.5,129.4,127.7,126.4$, 123.3, 116.2, 115.3, 40.6, 30.1, 20.3, 13.8; ESI-MS (m/z): $[\mathrm{M}+\mathrm{H}]^{+} 278.9 ; \mathrm{mp:} 149-151^{\circ} \mathrm{C}$.

5-Acetylacenaphthen (11, Scheme 2C): ${ }^{8}$ In a three-neck round-bottom flask with condenser, $\mathrm{AlCl}_{3}(2.4 \mathrm{~g}$ $18 \mathrm{mmol})$, dry DCM $(24 \mathrm{ml})$ and acetyl chloride $(0.8 \mathrm{ml}, 11.2 \mathrm{mmol})$ were added under ice-bath. The mixture was stirred for $15 \mathrm{~min}$, after which acenaphthene $(2.08 \mathrm{~g}, 13.5 \mathrm{mmol})$ dissolved in dry DCM (12 ml) was dropped into the flask slowly. Then the ice-bath was removed and the mixture was stirred at $20{ }^{\circ} \mathrm{C}$ for $35 \mathrm{~min}$. Ice-water was added into the flask to terminate the reaction, the DCM layer was isolated and washed two times by saturated $\mathrm{Na}_{2} \mathrm{CO}_{3}$ solution and water. The DCM layer was dried with anhydrous magnesium sulphate. After filtration, the organic solvent was evaporated and the crude product was purified by silica gel column chromatography (petroleum ether/EtOAc, v:v, 8:1) to give compound $11(1.94 \mathrm{~g}, 73 \%) .{ }^{1} \mathrm{H}$ NMR $(400 \mathrm{MHz}$, $\left.\mathrm{CDCl}_{3}\right): \delta(\mathrm{ppm}) 8.74(\mathrm{~d}, \mathrm{~J}=8.4 \mathrm{~Hz}, 1 \mathrm{H}), 8.07$ (d, J=7.2 Hz, 1H), $7.61(\mathrm{dd}, \mathrm{J} 1=8.4 \mathrm{~Hz}, \mathrm{~J} 2=1.2 \mathrm{~Hz}, 1 \mathrm{H}), 7.37(\mathrm{~d}$, $\mathrm{J}=6.8 \mathrm{~Hz}, 1 \mathrm{H}), 7.35(\mathrm{~d}, \mathrm{~J}=7.2 \mathrm{~Hz}, 1 \mathrm{H}), 3.41(\mathrm{~m}, 4 \mathrm{H}), 2.74(\mathrm{~s}, 3 \mathrm{H}) ;{ }^{13} \mathrm{C}$ NMR $\left(100 \mathrm{MHz}, \mathrm{CDCl}_{3}\right): \delta(\mathrm{ppm}) 200.2$, 153.0, 145.9, 139.6, 132.8, 130.4, 130.0, 129.2, 122.4, 120.3, 118.0, 30.4, 30.3, 28.9; ESI-MS (m/z): $[\mathrm{M}+\mathrm{H}]^{+}$ 197.1; mp: $55-56{ }^{\circ} \mathrm{C}$.

4-Acetyl-1,8-naphthalic anhydride (12, Scheme 2C): To a stirred solution of sodium dichromate (744 mg, $2.5 \mathrm{mmol}$ ) and acetic acid $(2 \mathrm{ml})$ was added the solution of compound 11 (196 $\mathrm{mg}, 1 \mathrm{mmol}$ in $3 \mathrm{ml}$ acetic acid). After refluxing for $10 \mathrm{~h}$, the solution was mixed with cold water $(50 \mathrm{ml})$ at $0{ }^{\circ} \mathrm{C}$ and then filtered and washed with water until the filtrate was neutral. The residue was dried in vacuum to afford the product $12(180 \mathrm{mg}, 75 \%) .{ }^{1} \mathrm{H}$ NMR (400 MHz, DMSO-d6): $\delta(\mathrm{ppm}) 8.85\left(\mathrm{dd}, J_{1}=8.4 \mathrm{~Hz}, J_{2}=7.6 \mathrm{~Hz}, 1 \mathrm{H}\right), 8.55(\mathrm{~m}, 2 \mathrm{H}), 8.38(\mathrm{~d}, J=7.6 \mathrm{~Hz}, 1 \mathrm{H})$ 7.97 (dd, $J_{1}=8.4 \mathrm{~Hz}, J_{2}=1.2 \mathrm{~Hz}, 1 \mathrm{H}$ ), 2.81 (s, 3H); ${ }^{13} \mathrm{C}$ NMR (100 MHz, DMSO-d6): $\delta$ (ppm) 201.5, 160.5, 160.1, 
$141.1,133.1,132.4,131.3,130.2,128.8,128.5,127.7,121.9,119.4,30.3 ;$ ESI-MS (m/z): $[M+H]^{+} 241.0$; Elemental analysis: $\mathrm{N}: 7.01 \%, \mathrm{C}: 72.45 \%, \mathrm{H}: 4.50 \%$; mp: $203-205^{\circ} \mathrm{C}$.

4-Acetyl-N-n-butyl-1, 8-naphthalimide (13, Scheme 2C): N-butylamine $(0.15 \mathrm{ml}, 1.5 \mathrm{mmol})$ was quickly added to a cloudy solution of compound $12(180 \mathrm{mg}, 0.75 \mathrm{mmol})$ in ethanol $(10 \mathrm{ml})$. After refluxing for $6 \mathrm{~h}$, the solvent was removed in vacuum, and the crude product was purified by silica gel column chromatography (petroleum ether/EtOAc, v:v, 4:1) to give compound 13 (190 mg, 86\%) as a pale yellow solid. ${ }^{1} \mathrm{H}$ NMR (400 $\left.\mathrm{MHz}, \mathrm{CDCl}_{3}\right): \delta(\mathrm{ppm}) 8.97\left(\mathrm{dd}, J_{11}=8.4 \mathrm{~Hz}, J_{2}=7.6 \mathrm{~Hz}, 1 \mathrm{H}\right), 8.65(\mathrm{~m}, 2 \mathrm{H}), 8.13(\mathrm{~d}, J=7.6 \mathrm{~Hz}, 1 \mathrm{H}), 7.85(\mathrm{dd}$, $\left.J_{1}=8.4 \mathrm{~Hz}, J_{2}=1.2 \mathrm{~Hz}, 1 \mathrm{H}\right), 4.20$ (t, J=7.6 Hz, 2H), $2.82(\mathrm{~s}, 3 \mathrm{H}), 1.74(\mathrm{~m}, 2 \mathrm{H}), 1.46(\mathrm{~m}, 2 \mathrm{H}), 0.99$ (t, J=7.2 Hz. $3 \mathrm{H}) ;{ }^{13} \mathrm{C}$ NMR $\left(100 \mathrm{MHz}, \mathrm{CDCl}_{3}\right): \delta$ (ppm) 200.9, 163.9, 163.4, 140.1, 132.4, 131.5, 129.8, 128.8, 128.6, 128.5, 128.0, 125.6, 122.7, 40.4, 30.2, 30.1, 20.4, 13.8; ESI-MS (m/z): [M+H] $]^{+} 296.1$; Elemental analysis: N: 4.71\%, C: 72.97\%, H: 5.82\%; mp: $106-107^{\circ} \mathrm{C}$.

4-Bromo-N-hexanoic acid -1, 8-naphthalimide (14, Scheme 3): ${ }^{9}$ In a $250 \mathrm{ml}$ round-bottom flask, 4-bromo-1, 8-naphthalic anhydride $(3.0 \mathrm{~g}, 10.8 \mathrm{mmol})$ and 6-aminohexanoic acid $(1.43 \mathrm{~g}, 10.9 \mathrm{mmol})$ were refluxed in 100 $\mathrm{ml}$ of ethanol. The reaction is complete when the initially milky suspension becomes a brown clear solution. Upon cooling, crystals of the product were formed. The gathered crystals were purified through recrystallization in ethanol to give $14(2.12 \mathrm{~g}, 50 \%) .{ }^{1} \mathrm{H}$ NMR $\left(400 \mathrm{MHz}, \mathrm{CDCl}_{3}\right): \delta(\mathrm{ppm}) 12.03(\mathrm{~s}, 1 \mathrm{H}), 8.34(\mathrm{~d}, J=7.2 \mathrm{~Hz}, 1 \mathrm{H})$, 8.27 (d, J=8.4 Hz, 1H), 8.08 (d, J=7.6 Hz, 1H), 7.99 (d, J=7.6 Hz, 1H), 7.80 (t, J=8.0 Hz, 1H), 3.91 (t, J=7.6 Hz, 2H), 2.21 (t, J=7.2 Hz, 2H), $1.56(\mathrm{~m}, 4 \mathrm{H}), 1.32(\mathrm{~m}, 2 \mathrm{H}) ;{ }^{13} \mathrm{C} \mathrm{NMR}\left(100 \mathrm{MHz}, \mathrm{CDCl}_{3}\right): \delta(\mathrm{ppm})$ 174.5, 162.6, 162.5, 132.3, 131.4, 131.1, 130.7, 129.4, 129.0, 128.5, 127.9, 122.4, 121.6, 33.5, 27.2, 26.1, 24.2 ; El-MS m/z (\%): $391\left(\mathrm{M}^{+}, 59\right), 389\left(\mathrm{M}^{+}, 59\right), 260(51), 258(53)$; mp 157-158 ${ }^{\circ} \mathrm{C}$.

4-Methylthio-N-hexanoic acid-1, 8-naphthalimide (15, Scheme 3): ${ }^{4}$ Compound 14 (1.209 g, $\left.3 \mathrm{mmol}\right)$, sodium methanethiolate $(630 \mathrm{mg}, 9 \mathrm{mmol})$ were mixed in DMF $(30 \mathrm{ml})$. Then the reaction mixture was stirring for $8 \mathrm{~h}$ at $60{ }^{\circ} \mathrm{C}$. Then the solvent was removed under reduced pressure and the residue was subjected to column chromatography on silica gel. The product was separated with $\mathrm{DCM} / \mathrm{MeOH}(50 / 1, \mathrm{v} / \mathrm{v})$ to give 15 (803 $\mathrm{mg}, 75 \%)$ as a yellow powder. ${ }^{1} \mathrm{H}$ NMR $(400 \mathrm{MHz}, \mathrm{DMSO}-\mathrm{d} 6): \delta(\mathrm{ppm}) 12.00(\mathrm{~s}, 1 \mathrm{H}), 8.39(\mathrm{t}, 1 \mathrm{H}), 8.33(\mathrm{t}, 1 \mathrm{H})$, $8.23(\mathrm{~d}, J=8.0 \mathrm{~Hz}, 1 \mathrm{H}), 7.76\left(\mathrm{dd}, J_{1}=7.6 \mathrm{~Hz}, J_{2}=8.4 \mathrm{~Hz}, 1 \mathrm{H}\right), 7.51(\mathrm{~d}, J=8.4 \mathrm{HZ}, 1 \mathrm{H}), 3.96(\mathrm{t}, J=7.2 \mathrm{~Hz}, 2 \mathrm{H}), 2.68$ (s, 3H), 2.21 (t, J=7.2 Hz, 2H), $1.57(\mathrm{~m}, 4 \mathrm{H}), 1.33$ (m, 2H); ${ }^{13} \mathrm{C}$ NMR (100 MHz, DMSO-d6): $\delta$ (ppm) 174.4, 163.0, 163.0, 145.8, 130.8, 130.4, 129.0, 127.9, 127.1, 126.9, 122.4, 121.2, 117.8, 33.5, 27.2, 26.0, 24.2, 14.0; ESI-MS (m/z): $[\mathrm{M}+\mathrm{H}]^{+}$358.3; Elemental analysis: $\mathrm{N}: 3.66 \%$, C: $63.78 \%, \mathrm{H}: 5.38 \%$; mp: $160-161{ }^{\circ} \mathrm{C}$. 
4-Methylthio-N-succinimidyl hexanoate-1,8-naphthalimide (16, Scheme 3$):{ }^{10}$ To a solution of 15 (714 mg, $2.0 \mathrm{mmol})$ in DCM $(30 \mathrm{ml})$ was added $\mathrm{N}$-hydroxysuccinimide (NHS) $(280 \mathrm{mg}, 2.4 \mathrm{mmol})$ and $\mathrm{N}$-ethyl-N'-(3-dimethylaminopropyl)carbodiimide hydrochloride (EDAC) $(460 \mathrm{mg}, 2.4 \mathrm{mmol})$. The mixture was stirred at room temperature overnight. Then the solvent was removed under reduced pressure and the residue was subjected to column chromatography on silica gel. The product was separated with $\mathrm{DCM} / \mathrm{MeOH}(50 / 1, \mathrm{v} / \mathrm{v})$ to give $16(636 \mathrm{mg}, 70 \%)$ as a yellow powder. ${ }^{1} \mathrm{H}$ NMR $\left(400 \mathrm{MHz}, \mathrm{CDCl}_{3}\right): \delta(\mathrm{ppm}) 8.62(\mathrm{~d}, \mathrm{~J}=6.8 \mathrm{~Hz}, 1 \mathrm{H}), 8.50$ (t, 2H), 7.75 (t, J=8.0 Hz, 1H), 7.45 (d, J=8.0 Hz, 1H), 4.19 (t, J=7.6 Hz, 2H), 2.87 (s, 4H), 2.70 (s, 3H), 2.64 (t, $J=7.6 \mathrm{~Hz}, 2 \mathrm{H}), 1.81(\mathrm{~m}, 4 \mathrm{H}), 1.55(\mathrm{~m}, 2 \mathrm{H}) ;{ }^{13} \mathrm{C} \mathrm{NMR}\left(100 \mathrm{MHz}, \mathrm{CDCl}_{3}\right): \delta(\mathrm{ppm}) 169.3,169.2,168.7,164.3$, $164.2,146.6,131.7,131.1,129.9,129.2,128.4,126.8,123.3,121.2,118.9,40.1,31.0,27.8,26.4,25.8,25.6$, 24.5, 15.1; HRMS $(\mathrm{ESI})$ calculated for $[\mathrm{C} 17 \mathrm{H} 17 \mathrm{NO} 5 \mathrm{SNa}]^{+}(\mathrm{M}+\mathrm{Na})^{+}$requires $\mathrm{m} / \mathrm{z}=477.1091$, found 477.1097; $\mathrm{mp}: 52-54^{\circ} \mathrm{C}$.

Compound 17 (Scheme 3): ${ }^{10}$ To a solution of 16 (454 mg, $\left.1 \mathrm{mmol}\right)$ and 6-aminohexanoic acid (656 mg, 5 $\mathrm{mmol})$ in $50 \mathrm{ml}$ DCM was added TEA $(0.72 \mathrm{ml}, 5 \mathrm{mmol})$. The reaction was stirred at room temperature overnight. Then $1 \mathrm{ml}$ of concentrated hydrochloric acid was added. Then the solvent was removed under reduced pressure and the residue was subjected to column chromatography on silica gel. The product was separated with $\mathrm{DCM} / \mathrm{MeOH}(30 / 1, \mathrm{v} / \mathrm{v})$ to give 17 (329 mg, 70\%) as a yellow powder. ${ }^{1} \mathrm{H} \mathrm{NMR}(400 \mathrm{MHz}$, DMSO-d6 ): $\delta$ (ppm) 8.48 (dd, $\left.J_{1}=10.0 \mathrm{~Hz}, J_{2}=2.8 \mathrm{~Hz}, 2 \mathrm{H}\right), 8.35$ (d, J=7.6 Hz, 1H), 7.85 (t, J=8.0 Hz, 1H), $7.72(\mathrm{t}$, $J=5.6 \mathrm{~Hz}, 1 \mathrm{H}), 7.63(\mathrm{~m}, J=8.0 \mathrm{~Hz}, 1 \mathrm{H}), 4.00(\mathrm{t}, J=7.6 \mathrm{~Hz}, 2 \mathrm{H}), 2.97\left(\mathrm{dd}, J_{1}=12.4 \mathrm{~Hz}, J_{2}=6.0 \mathrm{~Hz}, 2 \mathrm{H}\right), 2.72(\mathrm{~s}$, 3H), $2.16(\mathrm{t}, \mathrm{J}=7.6 \mathrm{~Hz}, 2 \mathrm{H}), 2.04(\mathrm{t}, \mathrm{J}=7.6 \mathrm{~Hz}, 2 \mathrm{H}), 1.61(\mathrm{~m}, 2 \mathrm{H}), 1.51(\mathrm{~m}, 2 \mathrm{H}), 1.44(\mathrm{~m}, 2 \mathrm{H}), 1.32(\mathrm{~m}, 4 \mathrm{H}), 1.23$ (m, 2H); ${ }^{13} \mathrm{C}$ NMR (100 MHz, DMSO-d6): $\delta$ (ppm) 174.4, 171.8, 163.0, 163.0, 145.8, 130.8, 130.3, 129.0, 127.9, 127.0, 126.9, 122.4, 121.2, 117.8, 38.2, 35.3, 33.6, 28.9, 27.4, 26.2, 26.0, 25.1, 24.2, 14.0 ; ESI-MS (m/z): $[\mathrm{M}+\mathrm{H}]^{+}$471.0; Elemental analysis: N: 5.66\%, C: 63.61\%, H: 6.16\%; mp: $175-177^{\circ} \mathrm{C}$.

Compound 18 (Scheme 3): To a solution of $17(235 \mathrm{mg}, 0.5 \mathrm{mmol})$ in $60 \mathrm{ml} \mathrm{DCM}$ at $0{ }^{\circ} \mathrm{C}$ was added $m$-CPBA (258 mg, $1.5 \mathrm{mmol}$ ) gradually. Then, the reaction was stirred for $5 \mathrm{~h}$ at room temperature. Then the solvent was removed under reduced pressure and the residue was subjected to column chromatography on silica gel. The product was separated with $\mathrm{DCM} / \mathrm{MeOH}(30 / 1, \mathrm{v} / \mathrm{v})$ to give $18(201 \mathrm{mg}, 80 \%)$ as a white powder. ${ }^{1} \mathrm{H}$ NMR (400 MHz, DMSO-d6): $\delta$ (ppm) 11.97 (s, 1H), 9.03 (dd, $\left.J_{1}=8.8 \mathrm{~Hz}, J_{2}=8.0 \mathrm{~Hz}, 1 \mathrm{H}\right), 8.62(\mathrm{~m}, 2 \mathrm{H}), 8.48$ (d, J=7.6 Hz, 1H), 8.08 (dd, $J_{1}=8.8 \mathrm{~Hz}, J_{2}=1.2 \mathrm{~Hz}, 1 \mathrm{H}$ ), 7.72 (t, J=5.6 Hz, 1H), 4.02(t, J=7.2 Hz, 2H), 3.48 (s, 3H), $2.98\left(\mathrm{dd}, J_{1}=12.8 \mathrm{~Hz}, J_{2}=6.0 \mathrm{~Hz}, 2 \mathrm{H}\right), 2.17(\mathrm{t}, J=7.6 \mathrm{~Hz}, 2 \mathrm{H}), 2.04(\mathrm{t}, J=7.6 \mathrm{~Hz}, 2 \mathrm{H}), 1.63(\mathrm{~m}, 2 \mathrm{H}), 1.49(\mathrm{~m}$, 
4H), $1.32(\mathrm{~m}, 4 \mathrm{H}), 1.21$ (m, 2H); ${ }^{13} \mathrm{C}$ NMR (100 MHz, DMSO-d6): $\delta$ (ppm) 174.4, 171.7, 162.9, 162.4, 140.8, 131.2, 130.2, 129.4, 129.3, 128.3, 127.0, 126.6, 123.1, 56.0, 44.1, 38.2, 35.2, 33.6, 28.9, 27.2, 26.2, 25.9, 25.0, 24.2, 18.5; ESI-MS (m/z): 503.2; Elemental analysis: N: 5.42\%, C: $59.49 \%, \mathrm{H}: 5.85 \% ; \quad \mathrm{mp}: 210-212{ }^{\circ} \mathrm{C}$.

Compound 19 (Scheme 3): ${ }^{11}$ To a round-bottom flask triphenylphosphine $(1.0 \mathrm{~g}, 3.82 \mathrm{mmol})$, 3-bromopropylamine hydrobromide $(0.836 \mathrm{~g}, 3.82 \mathrm{mmol})$, and acetonitrile $(5 \mathrm{ml})$ were added. The resulting suspension was heated to reflux for $16 \mathrm{~h}$. The reaction was cooled to room temperature, and hexane (10 ml) was added. The resulting solid was separated, washed with hexane $(10 \mathrm{ml})$, dissolved in $100 \mathrm{ml}$ of isopropanol and precipitated with diethyl ether $(75 \mathrm{ml})$, affording crude product 19 , which was further recrystallized from isopropanol/diethyl ether to give 19 (0.840 g, 46\%). ${ }^{1} \mathrm{H}$ NMR (400 MHz, DMSO-d6): $\delta(p p m) 7.92(\mathrm{~m}, 4 \mathrm{H}), 7.85$ $(\mathrm{m}, 4 \mathrm{H}), 7.80(\mathrm{~m}, 7 \mathrm{H}), 3.80\left(\mathrm{dd}, J_{1}=14.4 \mathrm{~Hz}, J_{2}=1.6 \mathrm{~Hz}, 2 \mathrm{H}\right), 3.01(\mathrm{t}, J=7.2 \mathrm{~Hz}, 2 \mathrm{H}), 1.86(\mathrm{~m}, 2 \mathrm{H}) ;^{13} \mathrm{C}$ NMR (100 MHz, DMSO-d6): $\delta$ (ppm) 135.1, 133.6,133.5, 130.4, 130.3, 118.4, 117.6, 20.0, 18.6, 18.1; ESI-MS (m/z): 319.4; mp: $276-279^{\circ} \mathrm{C}$.

Compound 20 (MSBN-TPP, Scheme 3): To a solution of 18 (251 mg, $0.5 \mathrm{mmol})$ in anhydrous DCM (50 ml) was added DMAP (244 $\mathrm{mg}, 2.0 \mathrm{mmol})$ and EDAC $(95.5 \mathrm{mg}, 0.5 \mathrm{mmol})$. The mixture was stirred at room temperature for $30 \mathrm{~min}$. Then 19 (192 $\mathrm{mg}, 0.6 \mathrm{mmol}$ ) was added to the solution and left to stir for $24 \mathrm{~h}$ at room temperature. Then the solvent was removed under reduced pressure and the residue was subjected to column chromatography on silica gel. The product was separated with DCM/MeOH (10/1, v/v) to give 20 (636 mg, $70 \%)$ as a white powder. $1 \mathrm{H} \mathrm{NMR}\left(400 \mathrm{MHz}, \mathrm{CDCl}_{3}\right): \delta(\mathrm{ppm}) 9.05\left(\mathrm{dd}, J_{1}=8.6 \mathrm{~Hz}, J_{2}=7.6 \mathrm{~Hz}, 1 \mathrm{H}\right), 8.65(\mathrm{~m}, 2 \mathrm{H})$, $8.49(\mathrm{~d}, J=7.6 \mathrm{~Hz}, 1 \mathrm{H}), 7.94\left(\mathrm{dd}, J_{1}=8.8 \mathrm{~Hz}, J_{2}=1.2 \mathrm{~Hz}, 1 \mathrm{H}\right), 7.72(\mathrm{~m}, 17 \mathrm{H}), 4.11(\mathrm{t}, J=7.2 \mathrm{~Hz}, 2 \mathrm{H}), 3.69$ (dd, $J_{1}=16.8 \mathrm{~Hz}, J_{2}=3.2 \mathrm{~Hz}, 2 \mathrm{H}$ ), $3.43(\mathrm{~d}, \mathrm{~J}=4.8 \mathrm{~Hz}, 2 \mathrm{H}), 3.24(\mathrm{~s}, 3 \mathrm{H}), 3.14(\mathrm{q}, 2 \mathrm{H}), 2.34$ (t, J=7.2 Hz, 2H), 2.17 (t, $J=7.2 \mathrm{~Hz}, 2 \mathrm{H}), 1.65(\mathrm{~m}, 8 \mathrm{H}), 1.49(\mathrm{t}, \mathrm{J}=7.2 \mathrm{~Hz}, 2 \mathrm{H}), 1.38(\mathrm{~m}, 2 \mathrm{H}), 1.31(\mathrm{t}, 2 \mathrm{H}) ;{ }^{13} \mathrm{C} \mathrm{NMR}(100 \mathrm{MHz}, \mathrm{CDCl}): \delta$ (ppm) 174.7, 173.2, 163.4, 162.8, 140.8, 135.4, 135.3, 133.6, 133.5, 132.0, 130.7, 130.6, 130.0, 129.8, 129.7, $129.5,129.0,127.8,127.5,123.6,118.6,117.7,53.6,44.9,40.6,38.9,36.5,36.2,29.8,28.6,27.8,26.8,26.2$, 25.6, 25.3, 22.8, 21.6, 21.1; HRMS (ESI) calculated for $[\mathrm{C} 46 \mathrm{H} 51 \mathrm{~N} 3 \mathrm{O} 6 \mathrm{PSH}]^{+} \mathrm{M}^{+}$requires $\mathrm{m} / \mathrm{z}=804.3231$, found 804.3239; mp: $82-84^{\circ} \mathrm{C}$.

Reactions of 1, 8-naphthalimides with ethanethiol (Table S1) The ethanethiol was used as a thiol model. In a typical experimental setting, to a solution of ethanethiol $(5 \mathrm{mmol})$ in $60 \mathrm{ml}$ of $1: 1 \mathrm{EtOH} / \mathrm{PBS}$ was added different 1,8 -naphthalimide $(0.5 \mathrm{mmol})$. Then, the mixture was stirred at $37^{\circ} \mathrm{C}$. The reaction was monitored by 
TLC. The solvent was removed in vacuum and the crude products were purified by silica gel column chromatography to afford the corresponding products.

UV/vis and fluorescence spectroscopy UV-vis absorbance spectra were acquired from UV-vis spectrometer evolution 200 (Thermo Scientific). Fluorescence spectroscopic studies were performed with a LUMINA fluorescence spectrophotometer. The slit width was $5.0 \mathrm{~nm}$ for both excitation and emission. For absorption or fluorescence measurements, compounds were dissolved in DMSO or double distilled water to obtain stock solutions. These stock solutions were diluted with PBS to the desired concentration.

Screening of the probes Cys $(1 \mathrm{M}, 2 \mu \mathrm{l})$, probes $(5 \mathrm{mM}, 2 \mu \mathrm{l})$ and PBS were mixed in a final volume of $2.0 \mathrm{ml}$. After incubating for $60 \mathrm{~min}$ at $37^{\circ} \mathrm{C}$, the fluorescence intensity at $490 \mathrm{~nm}\left(\lambda_{\mathrm{ex}}=390 \mathrm{~nm}\right)$ was measured.

Response of MSBN to thiols and other non-thiol compounds Analytes $(1 \mathrm{M}, 2 \mu \mathrm{l})$, MSBN $(5 \mathrm{mM}, 2 \mu \mathrm{l})$ and PBS were mixed in a final volume of $2.0 \mathrm{ml}$. After incubating for $60 \mathrm{~min}$ at $37^{\circ} \mathrm{C}$, the fluorescence intensity at $490 \mathrm{~nm}\left(\lambda_{\mathrm{ex}}=390 \mathrm{~nm}\right)$ was measured.

Response of MSBN to Cys The time-dependent absorbance spectra and fluorescence spectra $\left(\lambda_{\mathrm{ex}}=390 \mathrm{~nm}\right)$ were acquired as the following procedures. MSBN $(5 \mu \mathrm{M})$ was incubated with Cys $(1 \mathrm{mM})$ at $37^{\circ} \mathrm{C}$ in PBS. The absorbance spectra were scanned every $15 \mathrm{~min}$ for $90 \mathrm{~min}$. The emission spectra were recorded every $10 \mathrm{~min}$ for $80 \mathrm{~min}$. To acquire the emission spectra of MSBN towards different concentrations of Cys, MSBN was incubated with increasing concentrations of Cys at $37{ }^{\circ} \mathrm{C}$ in PBS. The emission spectra were recorded after 60 min. The selectivity of MSBN towards different analytes was measured by determining the fold of fluorescence increase at $490 \mathrm{~nm}$ after mixing MSBN $(5 \mu \mathrm{M})$ with various analytes $(1 \mathrm{mM})$ for $60 \mathrm{~min}$ in PBS.

Image of thiols in live cells MSBN $(10 \mu \mathrm{M})$ was added to the live HeLa cells and incubated for 5,30 and 60 min. To block the sulfhydryl groups in the cells, NEM $(0.1 \mathrm{mM})$ was added 30 min prior to the addition of MSBN. The images were taken under an inverted fluorescence microscope.

Label of BSA thiols by MSBN To a solution of $1.0 \mathrm{mg} \mathrm{ml}^{-1}$ BSA in buffer A $(250 \mu \mathrm{l})$ was added $5 \mathrm{mM}$ TCEP or vehicle. Samples were incubated at $37{ }^{\circ} \mathrm{C}$ for $30 \mathrm{~min}$. The solution was incubated with NEM (1.0 mM) or vehicle for an additional $30 \mathrm{~min}$ at $37^{\circ} \mathrm{C}$. Then the $1.0 \mathrm{ml}$ of $-20{ }^{\circ} \mathrm{C}$ acetone was added, and incubated for 20 $\min$ at $-20{ }^{\circ} \mathrm{C}$. Proteins were isolated by centrifugation at $2000 \mathrm{~g}$ for $10 \mathrm{~min}$ at $4{ }^{\circ} \mathrm{C}$. The supernatant was removed and the protein was washed with cold acetone. Protein samples were resuspended in buffer A (250 
$\mu \mathrm{l})$, to which was added MSBN $(1.0 \mathrm{mM})$ and incubated for $30 \mathrm{~min}$ at $37^{\circ} \mathrm{C}$. All samples were then boiled with $4 \mathrm{x}$ loading buffer without reducing agent and analyzed by SDS-PAGE. After the fluorescent image was taken on ImageQuant LAS 4000 (GE Healthcare), the gel was further stained by CB.

Titration of BSA thiols by DTNB BSA was dissolved in PBS containing $1 \%$ SDS (w/v) to make a stock solution $(5 \mathrm{mg} / \mathrm{ml})$. The reduced BSA was prepared by incubation of the BSA solution with $5 \mathrm{mM}$ TCEP at 37 ${ }^{\circ} \mathrm{C}$ for $30 \mathrm{~min}$. TCEP was removed by acetone precipitation. The non-reduced BSA was treated in the same manner. Then the reduced BSA and non-reduced BSA were re-dissolved in $6 \mathrm{M}$ guanidine hydrochlodide. The reduced BSA sample was further diluted 10 times with $6 \mathrm{M}$ guanidine hydrochlodide. The content of sulfhydryl groups in the reduced BSA and non-reduced BSA was quantified by DTNB.

Label of BSA thiols by different substituted naphthalimides To a solution of $0.5 \mathrm{mg} \mathrm{ml}^{-1} \mathrm{BSA}$ in buffer A $(250 \mu \mathrm{l})$ was added $5 \mathrm{mM}$ DTT or vehicle. Samples were incubated at $37{ }^{\circ} \mathrm{C}$ for $30 \mathrm{~min}$. The solution was incubated with NEM $(10 \mathrm{mM})$ or vehicle for $30 \mathrm{~min}$ at $37{ }^{\circ} \mathrm{C}$. Then the $1.0 \mathrm{ml}$ of $-20^{\circ} \mathrm{C}$ acetone was added to the solution, and incubated for $20 \mathrm{~min}$ at $-20{ }^{\circ} \mathrm{C}$. Proteins were isolated by centrifugation at $2000 \mathrm{~g}$ for $10 \mathrm{~min}$ and were washed with cold acetone. Protein samples were resuspended in buffer $A(250 \mu l)$, to which was added different probe $(0.5 \mathrm{mM})$ and incubated for $30 \mathrm{~min}$ at $37^{\circ} \mathrm{C}$. All samples were then boiled with $4 \mathrm{x}$ loading buffer without reducing agent and analyzed by SDS-PAGE. After the fluorescent image was taken on ImageQuant LAS 4000 (GE Healthcare), the gel was further stained by CB.

Interference of TCEP for the label of BSA thiols by MSBN To a solution of $0.5 \mathrm{mg} \mathrm{ml}^{-1} \mathrm{BSA}$ in buffer A (250 $\mu l)$ was added varying concentrations of TCEP or vehicle. The solution was incubated for 30 min at $37{ }^{\circ} \mathrm{C}$ followed by addition of MSBN $(1 \mathrm{mM})$ and incubation for additional $60 \mathrm{~min}$ at $37^{\circ} \mathrm{C}$. All samples were then boiled with $4 x$ loading buffer without reducing agent and analyzed by SDS-PAGE. After the fluorescent image was taken on ImageQuant LAS 4000 (GE Healthcare), the gel was further stained by CB.

Detection of disulfides in BSA with MSBN To a solution of $1.0 \mathrm{mg} \mathrm{ml}^{-1} \mathrm{BSA}$ in buffer A $(250 \mu \mathrm{l})$ was added varying concentrations of TCEP or vehicle. The solution was incubated for $30 \mathrm{~min}$ at $37^{\circ} \mathrm{C}$. Then $1.0 \mathrm{ml}$ of -20 ${ }^{\circ} \mathrm{C}$ acetone was added to precipitate the protein. After centrifugation the sample was washed with cold acetone and resuspended in buffer $\mathrm{A}(250 \mu \mathrm{l})$, to which was added MSBN $(1.0 \mathrm{mM})$ and incubated for $30 \mathrm{~min}$ at $37{ }^{\circ} \mathrm{C}$. All samples were then boiled with $4 x$ loading buffer without reducing agent and analyzed by SDS-PAGE. After 
the fluorescent image was taken on ImageQuant LAS 4000 (GE Healthcare), the gel was further stained by CB.

Detection of disulfides and s-nitrosylated proteins in cells The HeLa cells were treated with the indicated concentrations of $\mathrm{H}_{2} \mathrm{O}_{2}$ and then stained with MSBN $(10 \mu \mathrm{M})$. For the detection of cellular disulfides, HeLa cells were treated with the indicated concentrations of $\mathrm{H}_{2} \mathrm{O}_{2}$ followed by fixation ( $70 \%$ ethanol $(\mathrm{v} / \mathrm{v})$ with $\left.\mathrm{NEM}\right)$. After incubation with TCEP, MSBN $(10 \mu \mathrm{M})$ was added. For the detection of the s-nitrosylated proteins, the cells were treated with SNOC followed by fixation ( $70 \%$ ethanol $(\mathrm{v} / \mathrm{v})$ with NEM). Then, ascorbate $(5 \mathrm{mM})$ and MSBN $(10 \mu \mathrm{M})$ were added. The control cells were directly stained by MSBN. The images were taken under an inverted fluorescence microscope.

Detection of S-nitrosylated proteins with MSBN To a solution of $2.0 \mathrm{mg} \mathrm{ml}^{-1} \mathrm{BSA}$ in buffer B (250 $\left.\mu \mathrm{l}\right)$ was added $4 \mathrm{mM}$ TCEP or vehicle. The solution was incubated for $30 \mathrm{~min}$ at $37^{\circ} \mathrm{C}$. Then $1.0 \mathrm{ml}$ of $-20{ }^{\circ} \mathrm{C}$ acetone was added to precipitate the protein. After centrifugation, the sample was washed with cold acetone and resuspended in buffer B $(250 \mu \mathrm{l})$. A solution of buffer B with SNOC, old SNOC (2 mM) or vehicle was added. After incubation of the samples in the dark for $20 \mathrm{~min}$ at room temperature, NEM (5.0 mM) was added and the samples were incubated at $37{ }^{\circ} \mathrm{C}$ for $30 \mathrm{~min}$. Then $1.0 \mathrm{ml}$ of $-20{ }^{\circ} \mathrm{C}$ acetone was added to precipitate the protein. After centrifugation the sample was washed with cold acetone and resuspended in buffer B $(250 \mu l)$. Ascorbic acid $(10 \mathrm{mM})$ and MSBN $(1 \mathrm{mM})$ were added, and the solution was incubated for $30 \mathrm{~min}$ at $37{ }^{\circ} \mathrm{C}$. All samples were then boiled with $4 x$ loading buffer without reducing agent and analyzed by SDS-PAGE. After the fluorescent image was taken, the gel was further stained by CB.

Assay of redox states of Trx by MSBN-TPP To a solution of $1.0 \mathrm{mg} \mathrm{ml}^{-1} \operatorname{Trx}$ in buffer A ( $\left.250 \mu \mathrm{l}\right)$ was added 5 $\mathrm{mM}$ diamide or $5 \mathrm{mM}$ TCEP. The solution was incubated for $30 \mathrm{~min}$ at $37{ }^{\circ} \mathrm{C}$. Then $1.0 \mathrm{ml}$ of $-20{ }^{\circ} \mathrm{C}$ acetone was added to precipitate the protein. After centrifugation the sample was washed with cold acetone and resuspended in buffer $\mathrm{C}(250 \mu \mathrm{l})$. MSBN-TPP $(2 \mathrm{mM})$ was added to the solution and the solution was incubated for $60 \mathrm{~min}$ at $37^{\circ} \mathrm{C}$. All samples were then boiled with $4 \mathrm{x}$ loading buffer without reducing agent and analyzed by SDS-PAGE. The gel was stained by CB.

Mass spectrometry characterization of labelling Trx by MSBN-TPP The stock E.coli Trx solution was diluted with PBS containing $1 \%$ SDS to $1 \mathrm{mg} \mathrm{ml}^{-1}$. Then the protein was treated with $5 \mathrm{mM}$ TCEP to generate the reduced Trx. After removing the excess TCEP by acetone precipitation, the sample was further incubated 
with $2 \mathrm{mM}$ MSBN-TPP or vehicle solvent for $1 \mathrm{~h}$ at $37^{\circ} \mathrm{C}$. The samples were analysed by Orbitrap Elite mass spectrometer.

Western blotting detection of Trx redox states in HeLa cell lysate HeLa cell lysate (8 $\mathrm{mg}$ total protein $\left.\mathrm{ml}^{-1}\right)$ was prepared by lysing the cells with PBS containing $1 \%$ SDS. The lysate was treated with TCEP ( $1 \mathrm{mM})$, diamide $(1 \mathrm{mM})$ or vehicle solvent for $30 \mathrm{~min}$ followed by acetone precipitation to remove the reducing or oxidizine reagents. All samples were resuspended in the buffer B $(250 \mu \mathrm{L})$. MSBN-TPP $(2 \mathrm{mM})$ or IAM (1 mM) was added to the solution and the solution was incubated for $60 \mathrm{~min}$ at $37^{\circ} \mathrm{C}$. The samples were then boiled with $4 x$ loading buffer with reducing agent (DTT, $1 \mathrm{mM}$ ) and separated by SDS-PAGE (15\%; $120 \mathrm{~V} ; 180 \mathrm{~min})$. Proteins were transferred to PVDF membranes, blocked with $5 \%$ nonfat milk at room temperature for $1 \mathrm{~h}$, and incubated with the anti-huamn $\operatorname{Trx} 1$ antibody overnight at $4^{\circ} \mathrm{C}$. The membranes were washed three times with Tris-buffered saline-5\% Tween 20 (TBST) solution and incubated with a horseradish peroxidase-conjugated secondary antibody at room temperature for $1 \mathrm{~h}$. The target protein bands were detected by the enhanced chemiluminescence (GE healthcare).

Cell cultures and cytotoxicity assay HeLa cells and HepG2 cells, from the Shanghai Institute of Biochemistry and Cell Biology, were cultured in DMEM supplemented with 10\% FBS (v/v), 2 mM glutamine, and 100 units $\mathrm{ml}^{-1}$ penicillin/streptomycin and maintained in an atmosphere of $5 \% \mathrm{CO}_{2}$ at $37{ }^{\circ} \mathrm{C}$. The cytotoxicity of MSBN was detected by the MTT assay. Briefly, the cells were seeded into 96-well plates and treated with varying concentrations of MSBN for $24 \mathrm{~h}$. The cell viability was determined by the MTT assay.

Imaging cellular thiols in live cells HeLa cells were plated in a 12-well plate. MSBN (10 $\mu \mathrm{M})$ was added, and continued incubation for $5 \mathrm{~min}, 30 \mathrm{~min}$ or $60 \mathrm{~min}$ at $37^{\circ} \mathrm{C}$. To block the cellular thiols, the cells were pretreated with NEM $(0.1 \mathrm{mM})$ for $30 \mathrm{~min}$ followed by MSBN staining for $60 \mathrm{~min}$. The cells were visualized and photographed under Floid cell imaging station (Life Technologies, USA).

Imaging cellular disulfides HeLa cells were plated in 12-well plates and were treated with $\mathrm{H}_{2} \mathrm{O}_{2}$ or vehicle for 30 min. After removal of the medium, HeLa cells were washed with PBS. MSBN (10 $\mu \mathrm{M})$ was added, and continued incubation for $30 \mathrm{~min}$ at $37^{\circ} \mathrm{C}$. To determine the cellular disulfides, the $\mathrm{H}_{2} \mathrm{O}_{2}$-treated cells were fixed with $1.0 \mathrm{ml}$ of fixation solution $\mathrm{A}$ for $30 \mathrm{~min}$ at $37^{\circ} \mathrm{C}$. After removal of the solution, the cells were washed with PBS. Then TCEP ( $1 \mathrm{mM}$ in $1.0 \mathrm{ml}$ of PBS) was added, and continued incubation for $30 \mathrm{~min}$ at $37^{\circ} \mathrm{C}$. After removal of the solution, the cells were washed with PBS. Finally, MSBN $(10 \mu \mathrm{M})$ in PBS was added, and S14 
continued incubation for $30 \mathrm{~min}$ at $37^{\circ} \mathrm{C}$. The cells were visualized and photographed under Floid cell imaging station (Life Technologies, USA).

Detection of PSNO in HeLa cells HeLa cells were plated in 12-well plates and treated with SNOC, old SNOC or vehicle for $30 \mathrm{~min}$. After removal of the medium, the cells were washed with buffer $\mathrm{B}$. The cell fixation solution $\mathrm{B}(1.0 \mathrm{ml})$ was added to each well, and continued incubation for $30 \mathrm{~min}$ at $37^{\circ} \mathrm{C}$ in the dark. After removal of the fixation solution, HeLa cells were washed with PBS followed by addition of ascorbic acid (5 mM) and MSBN $(10 \mu \mathrm{M})$ in PBS $(1.0 \mathrm{ml})$ was added, and continued incubation for $30 \mathrm{~min}$ at $37^{\circ} \mathrm{C}$. The cells were visualized and photographed under Floid cell imaging station (Life Technologies, USA). 
Table S1. Reaction of the substituted naphthalimides with ethyl mercaptan (EtSH) ${ }^{\text {a }}$.

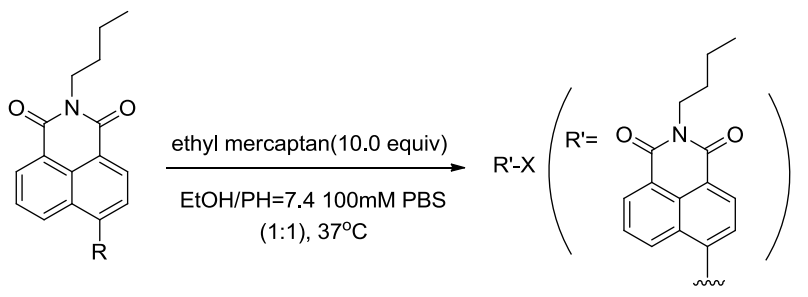

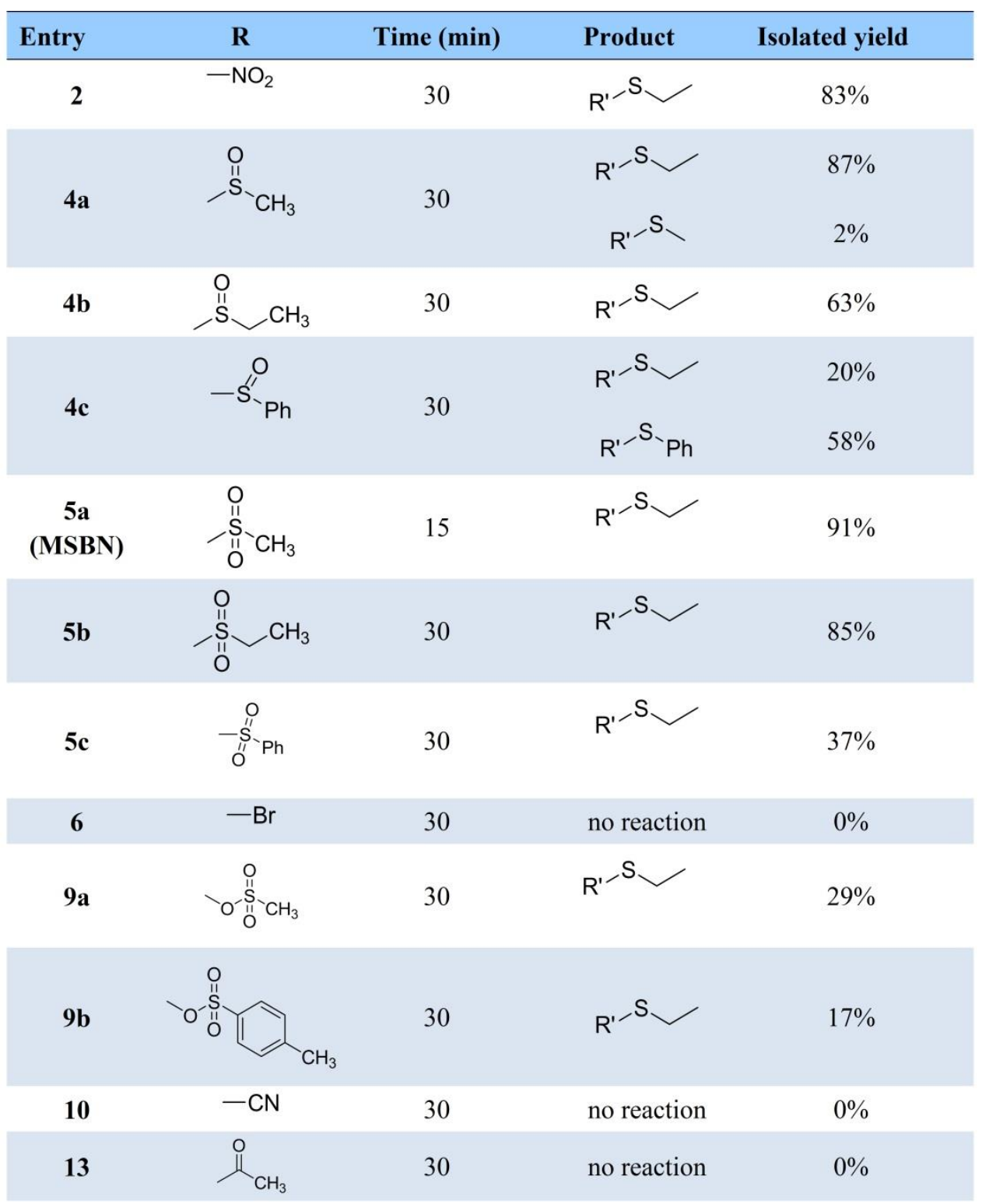

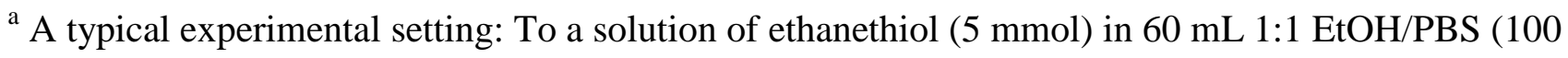
$\mathrm{mM}, \mathrm{pH}=7.4)$ were added 1,8 -naphthalimides $(0.5 \mathrm{mmol})$. Then, the mixture was stirred at $37^{\circ} \mathrm{C}$.

The reaction was monitored by TLC. The solvent was removed in vacuo and the crude products was purified by silica gel column chromatography to afford the corresponding products. 


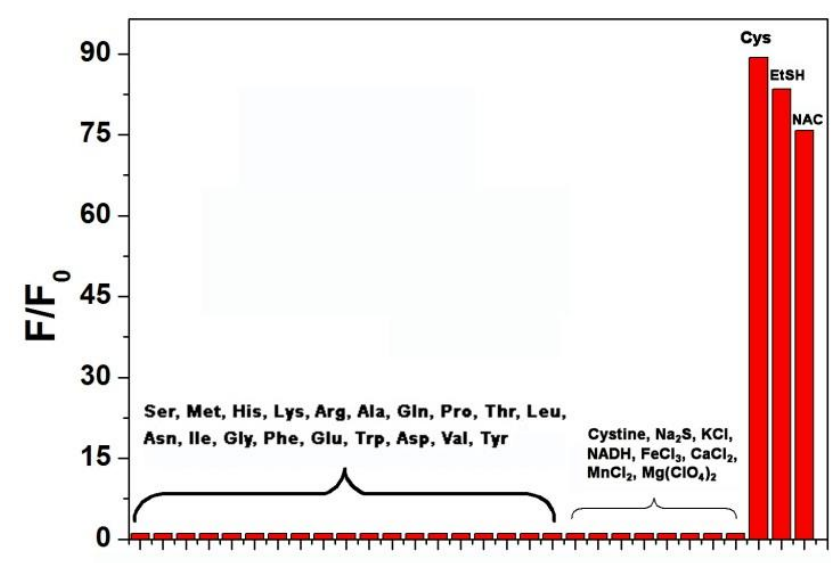

Figure S1. Selective recognition of thiols by MSBN. MSBN $(5 \mu \mathrm{M})$ was incubated with different analytes $\left(1 \mathrm{mM}\right.$ each) for $60 \mathrm{~min}$ at $37^{\circ} \mathrm{C}$ in PBS, $\mathrm{pH} 7.4$, and the fluorescence intensity at $490 \mathrm{~nm}$ was determined with the excitation at $390 \mathrm{~nm}$. 


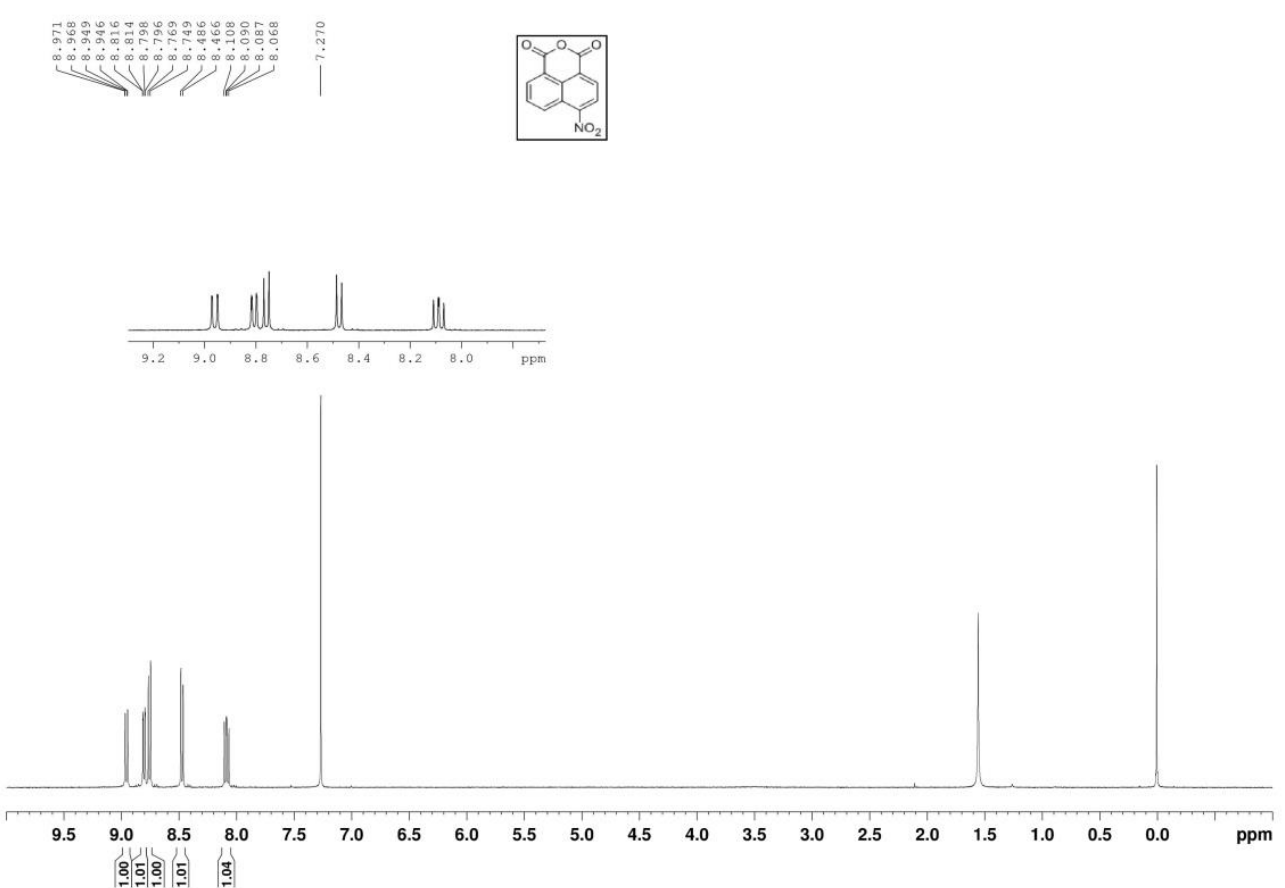

Figure S2 ${ }^{1} \mathrm{H}$ NMR of compound $\mathbf{1}$
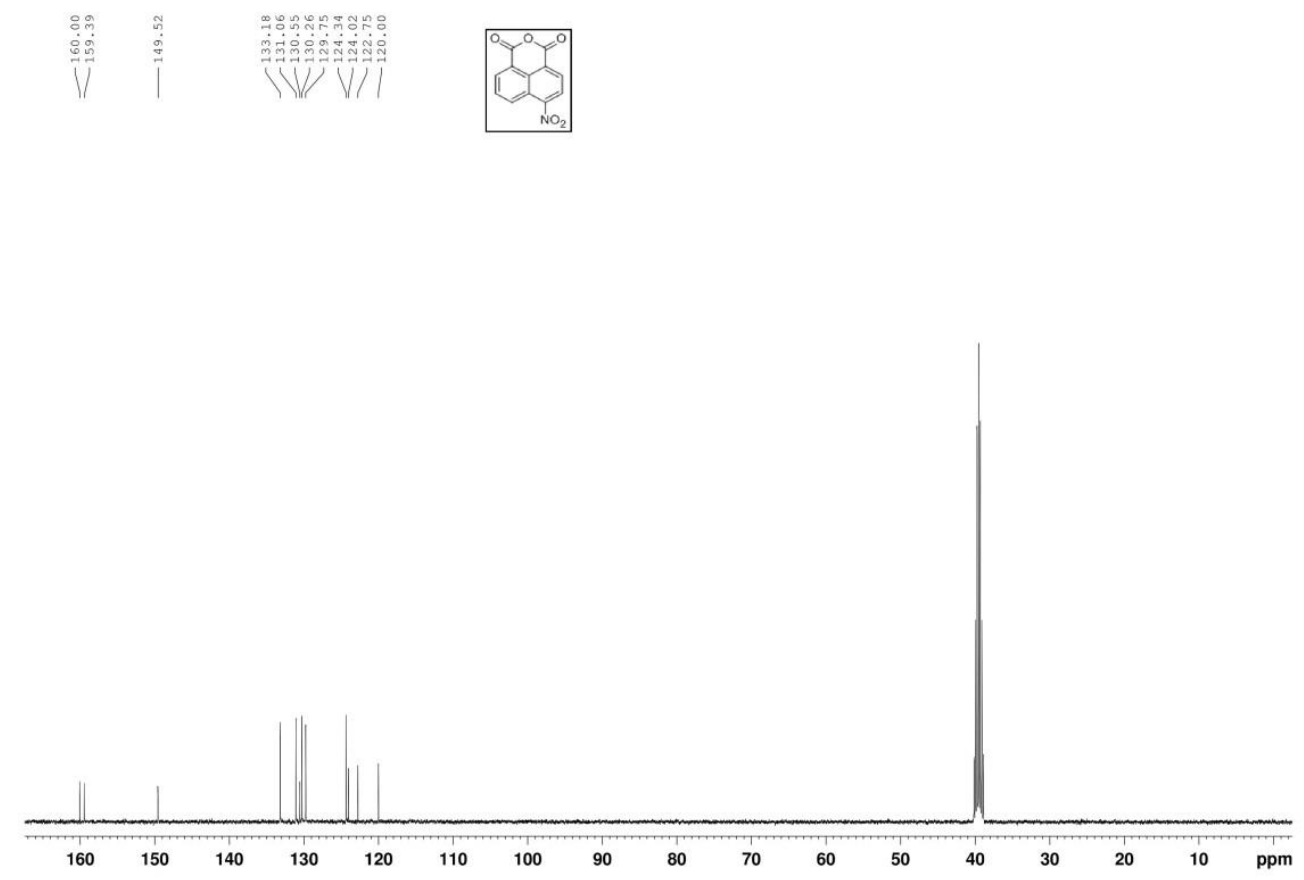

Figure S3 ${ }^{13} \mathrm{C}$ NMR of compound $\mathbf{1}$ 


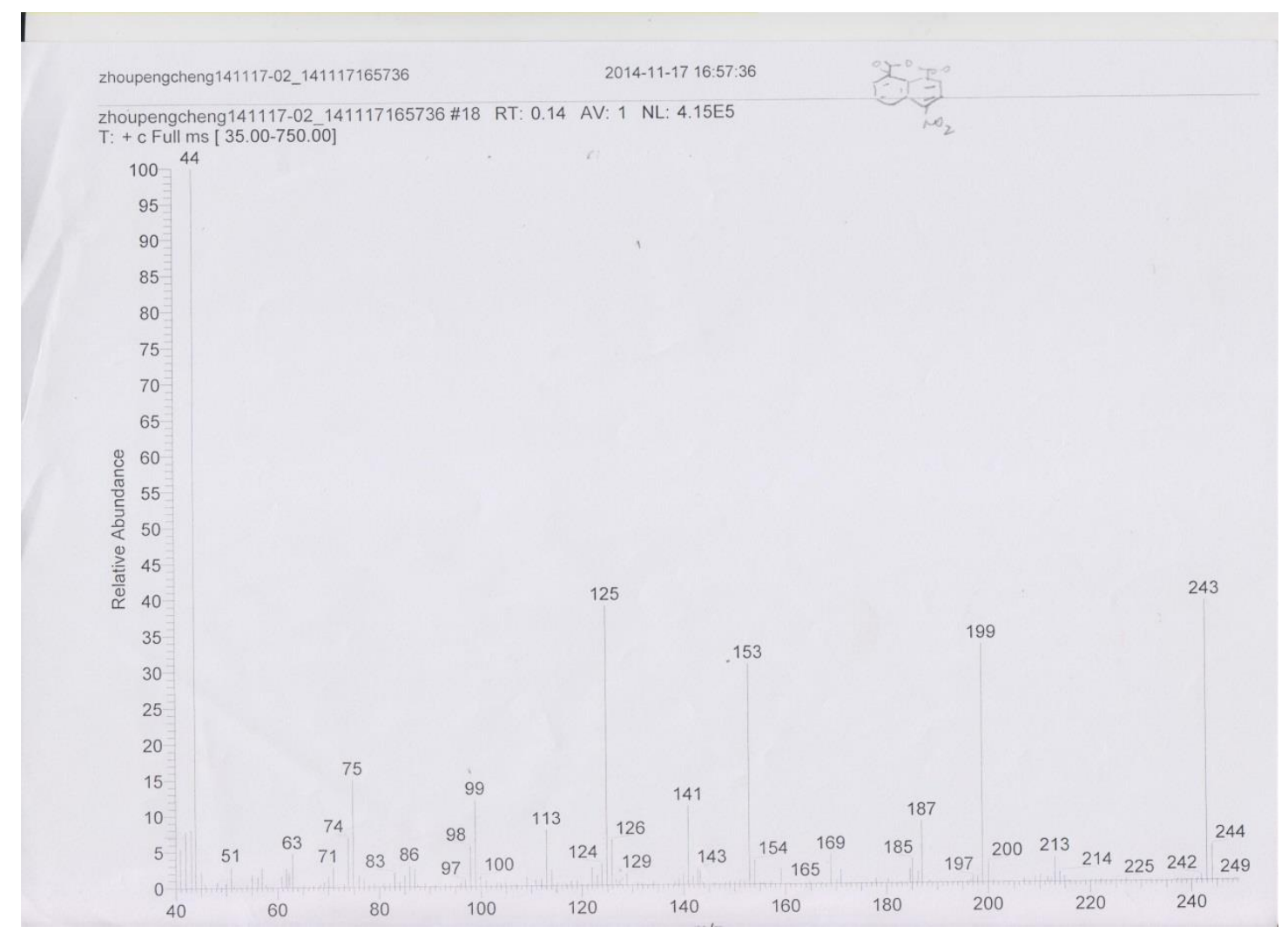

Figure S4 EI-MS of compound 1

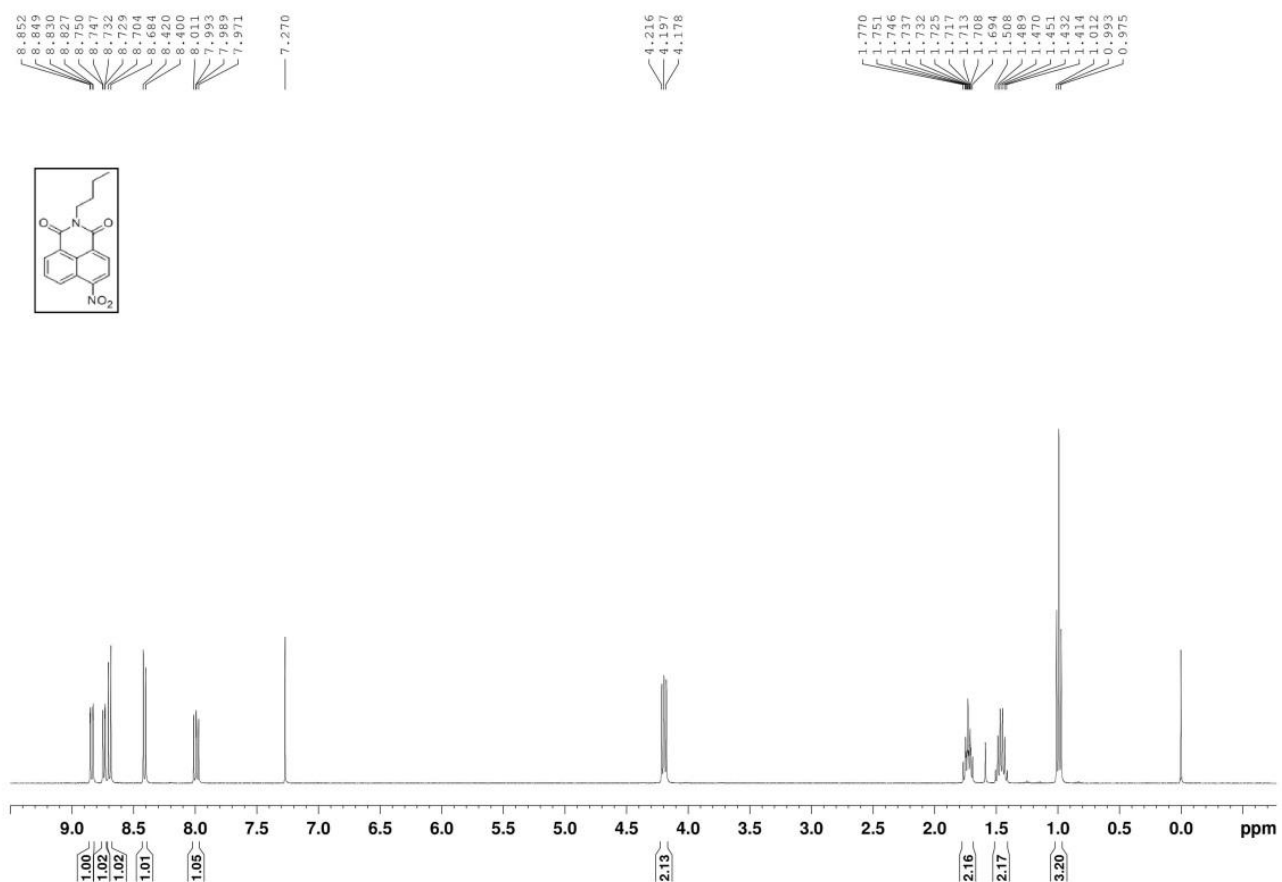

Figure S5 ${ }^{1} \mathrm{H}$ NMR of compound 2 . 


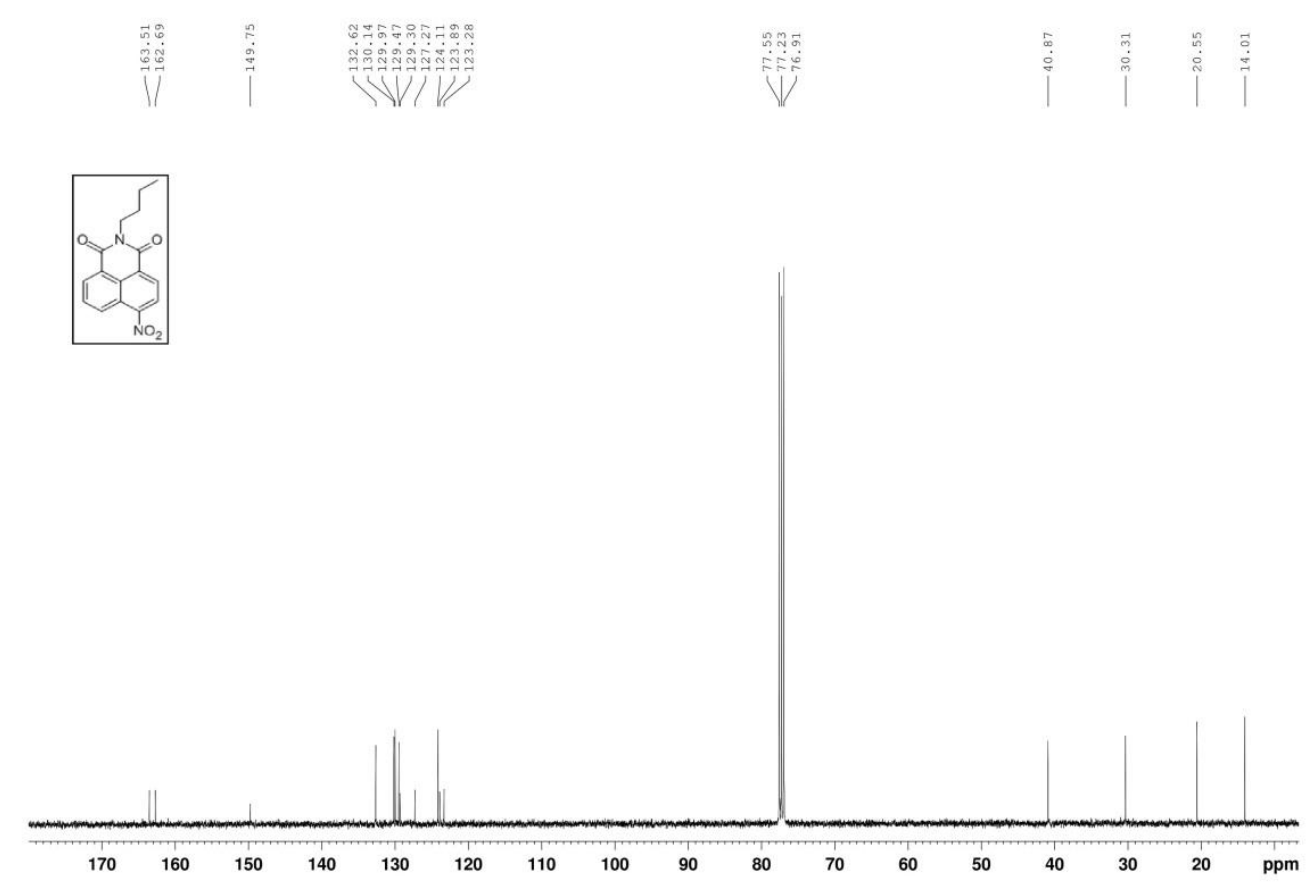

Figure S6 ${ }^{13} \mathrm{C}$ NMR of compound 2 .

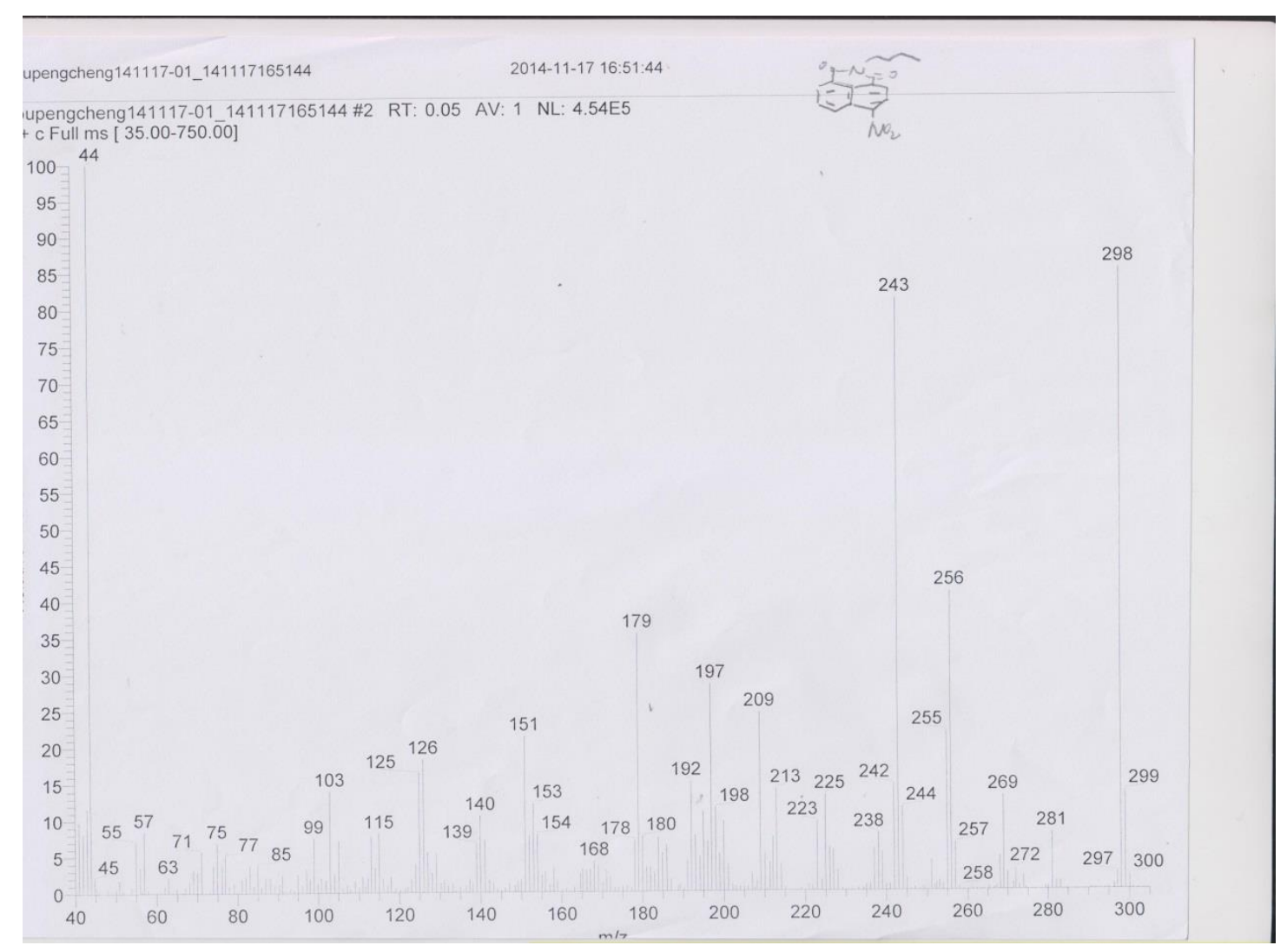

Figure S7 EI-MS of compound 2. 

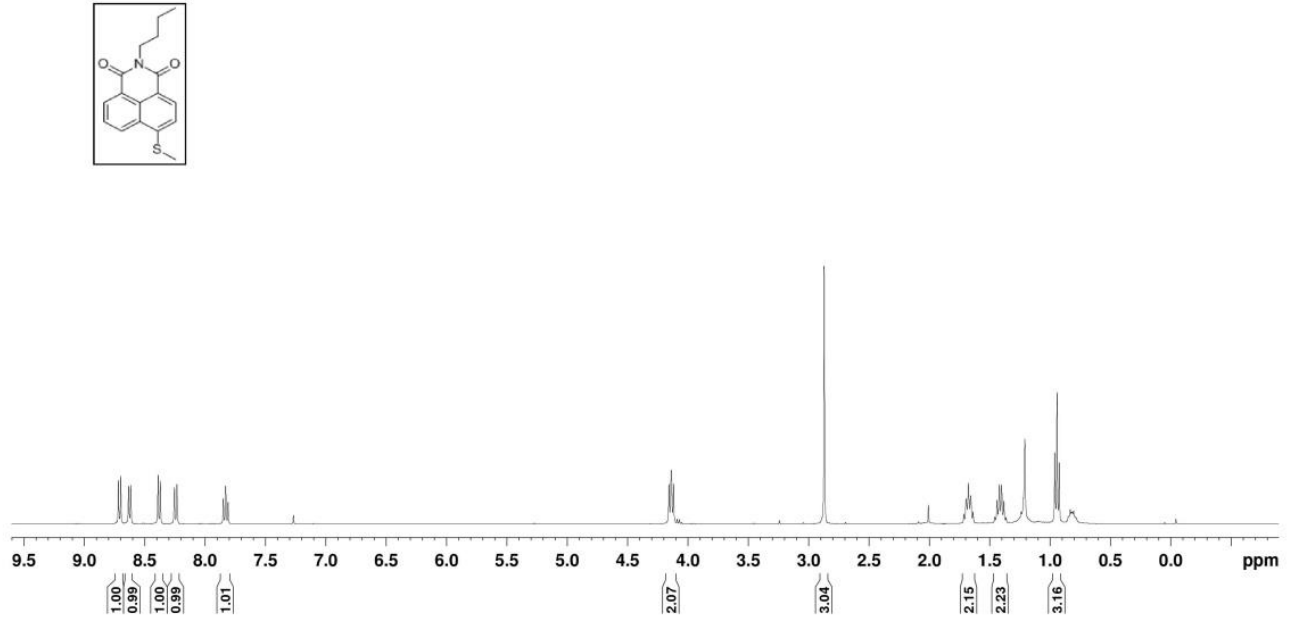

Figure S8 ${ }^{1} \mathrm{H}$ NMR of compound $\mathbf{3 a}$.
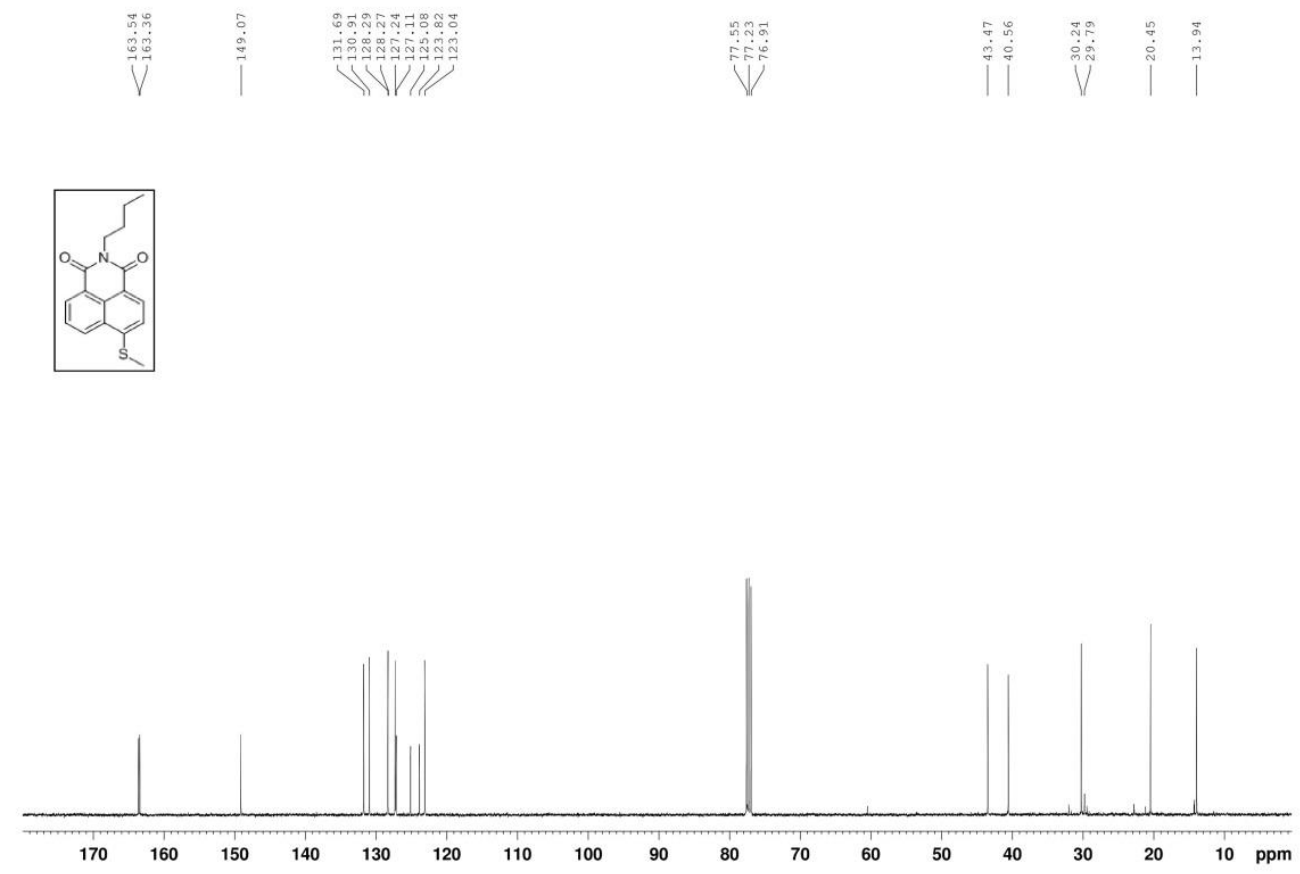

Figure S9 ${ }^{13} \mathrm{C}$ NMR of compound 3a. 


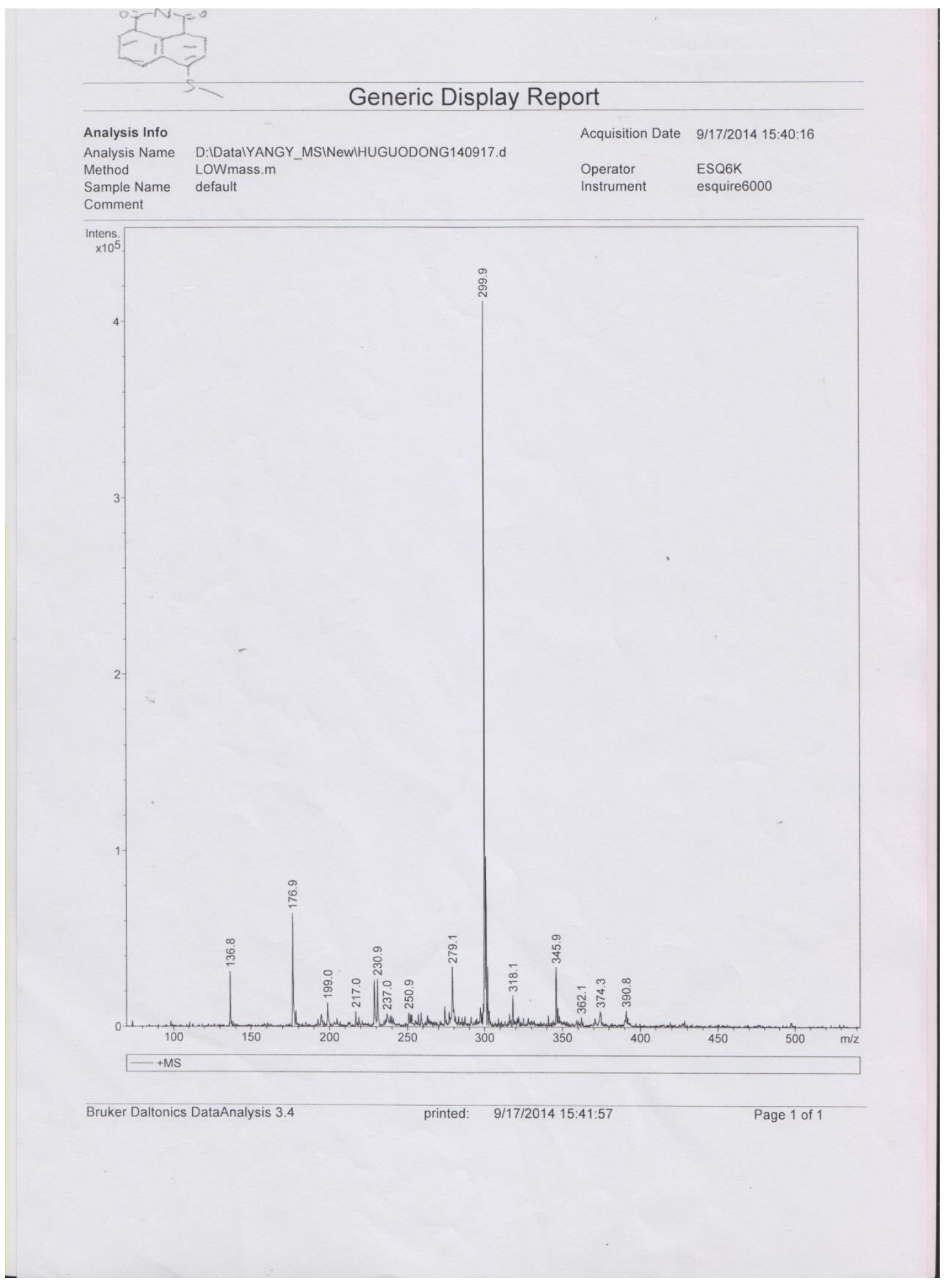

Figure S10 ESI-MS of compound 3a. 

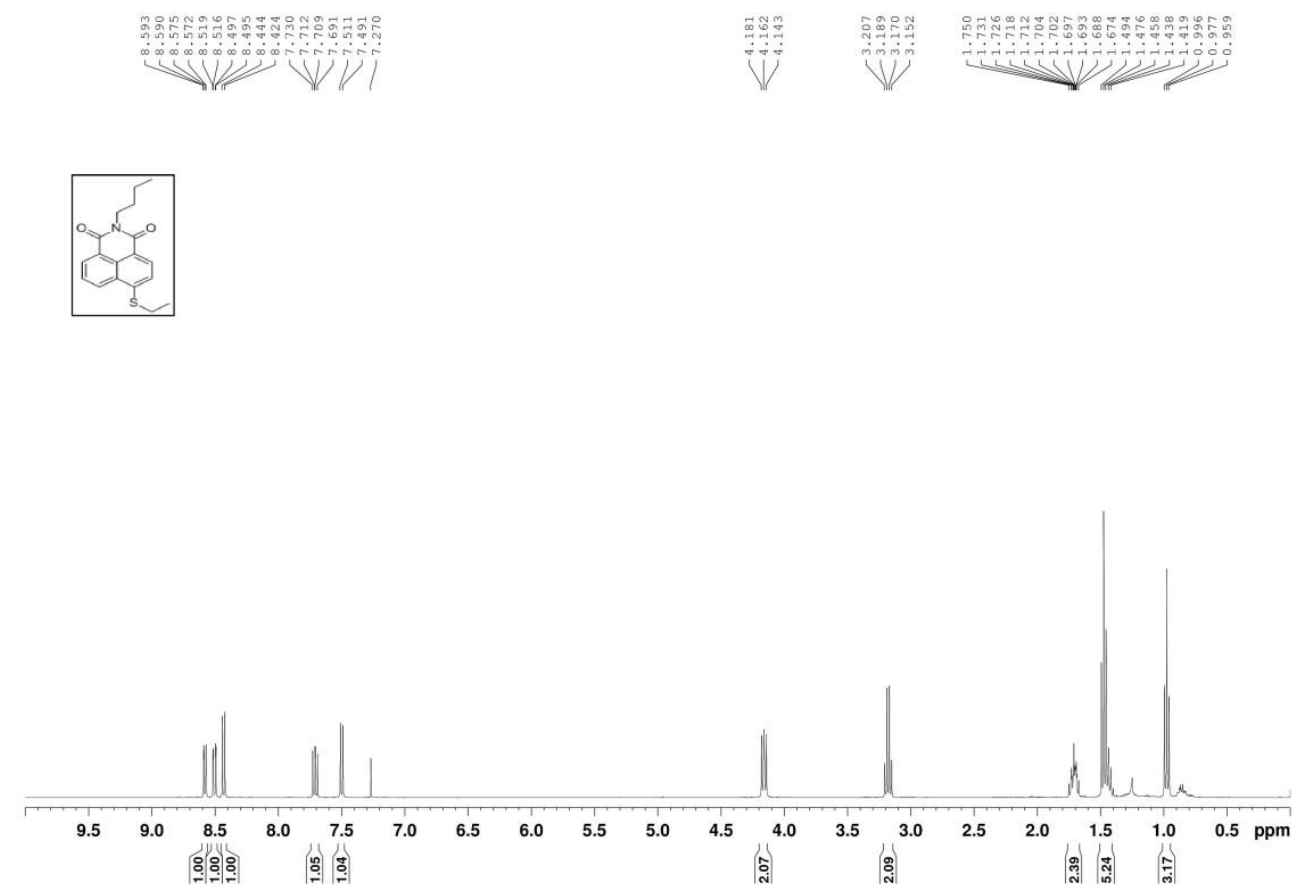

Figure S11 ${ }^{1} \mathrm{H}$ NMR of compound $\mathbf{3 b}$.
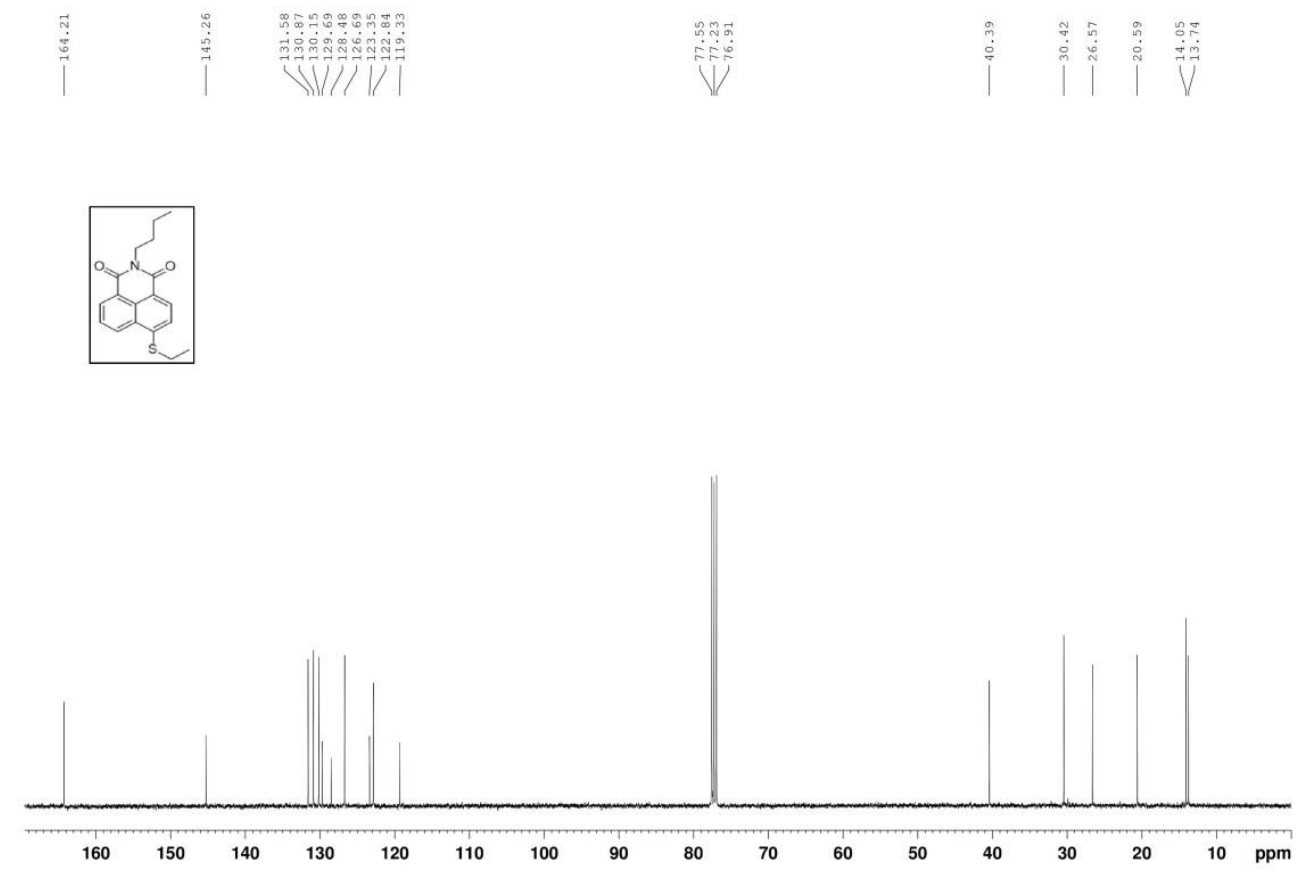

Figure S12 ${ }^{13} \mathrm{C}$ NMR of compound $\mathbf{3 b}$. 


\section{Generic Display Report}

Analysis Info

Analysis Name D:IDatalYANGY MSINewIZHOUPENGCHENG140917.d

Method LOWmass.m

Acquisition Date 9/17/2014 15:42:11

Sample Name OWmass.m

Operator

ESOGK

Comment

nstrument esquire6000

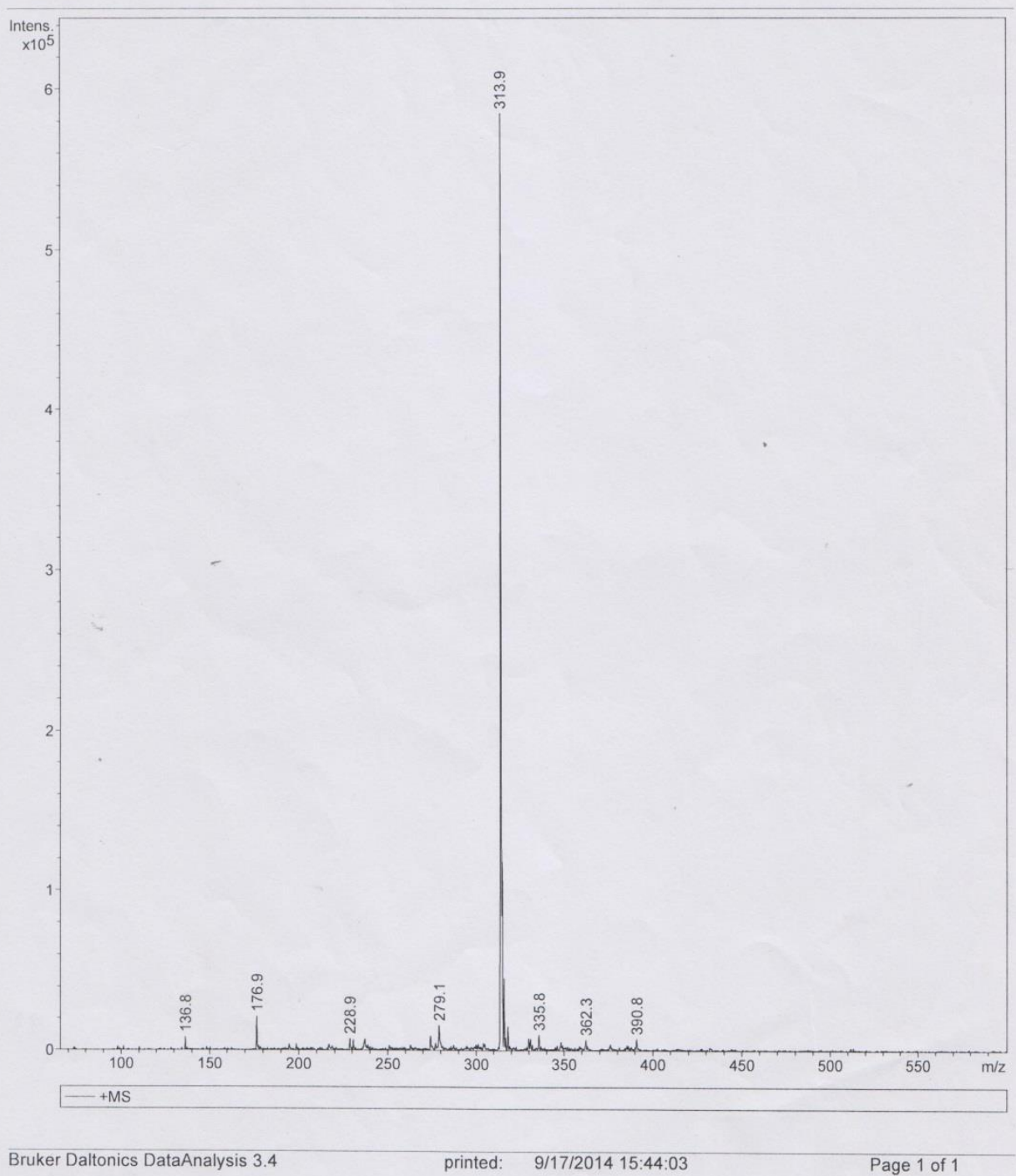

Figure S13 ESI-MS of compound 3b. 


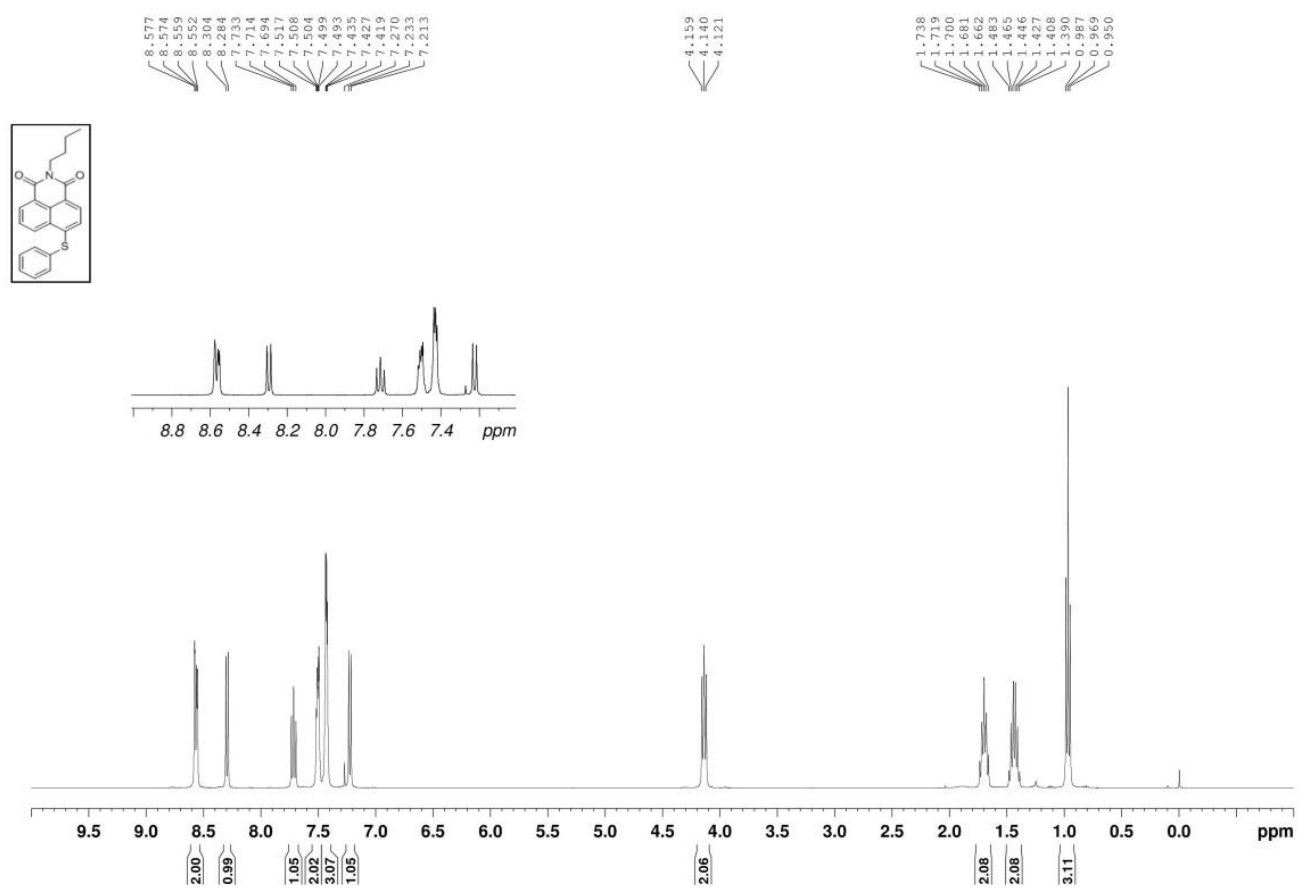

Figure S14 ${ }^{1} \mathrm{H}$ NMR of compound $\mathbf{3 c}$.

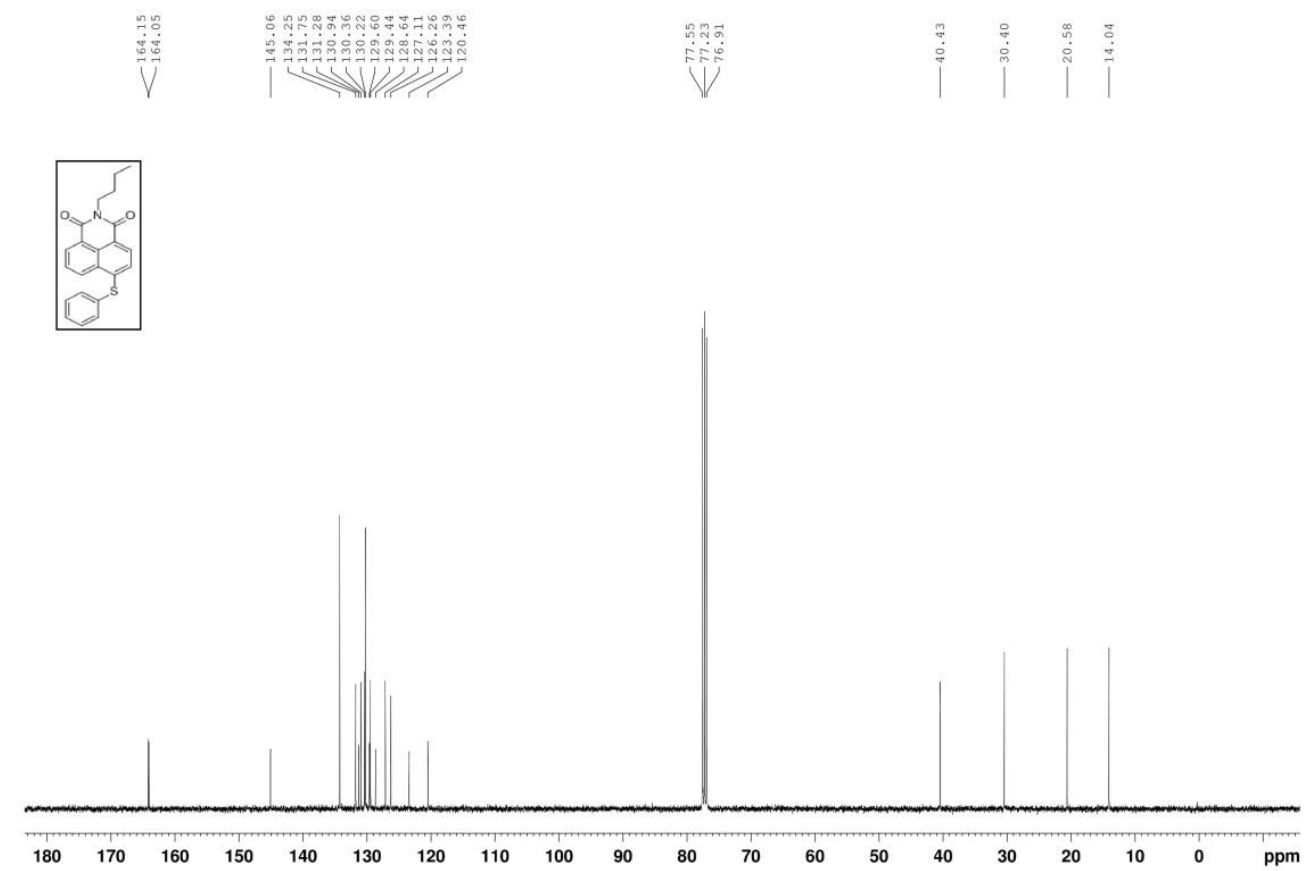

Figure S15 ${ }^{13} \mathrm{C}$ NMR of compound $\mathbf{3 c}$. 


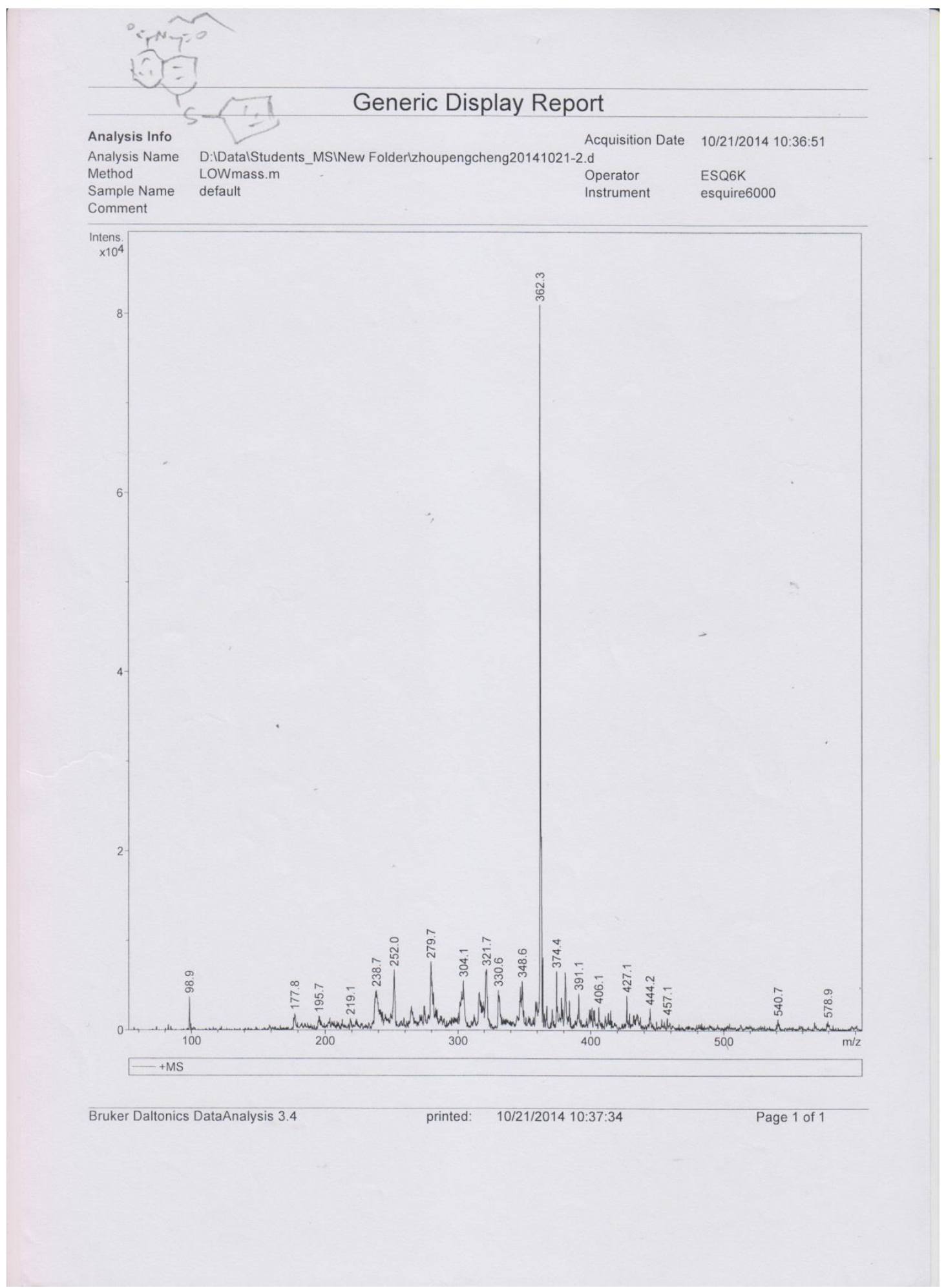

Figure S16 ESI-MS of compound 3c. 


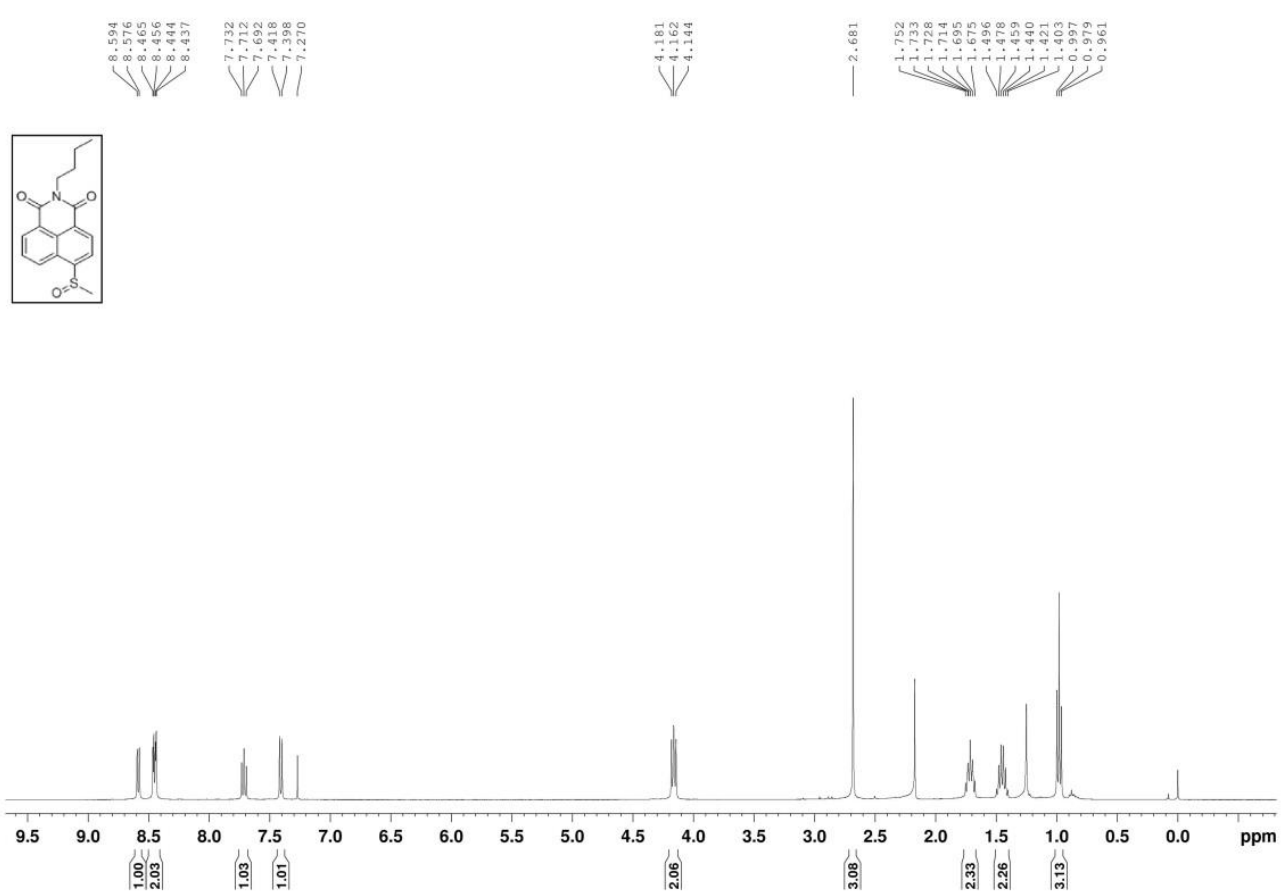

Figure S17 ${ }^{1} \mathrm{H}$ NMR of compound 4 a.
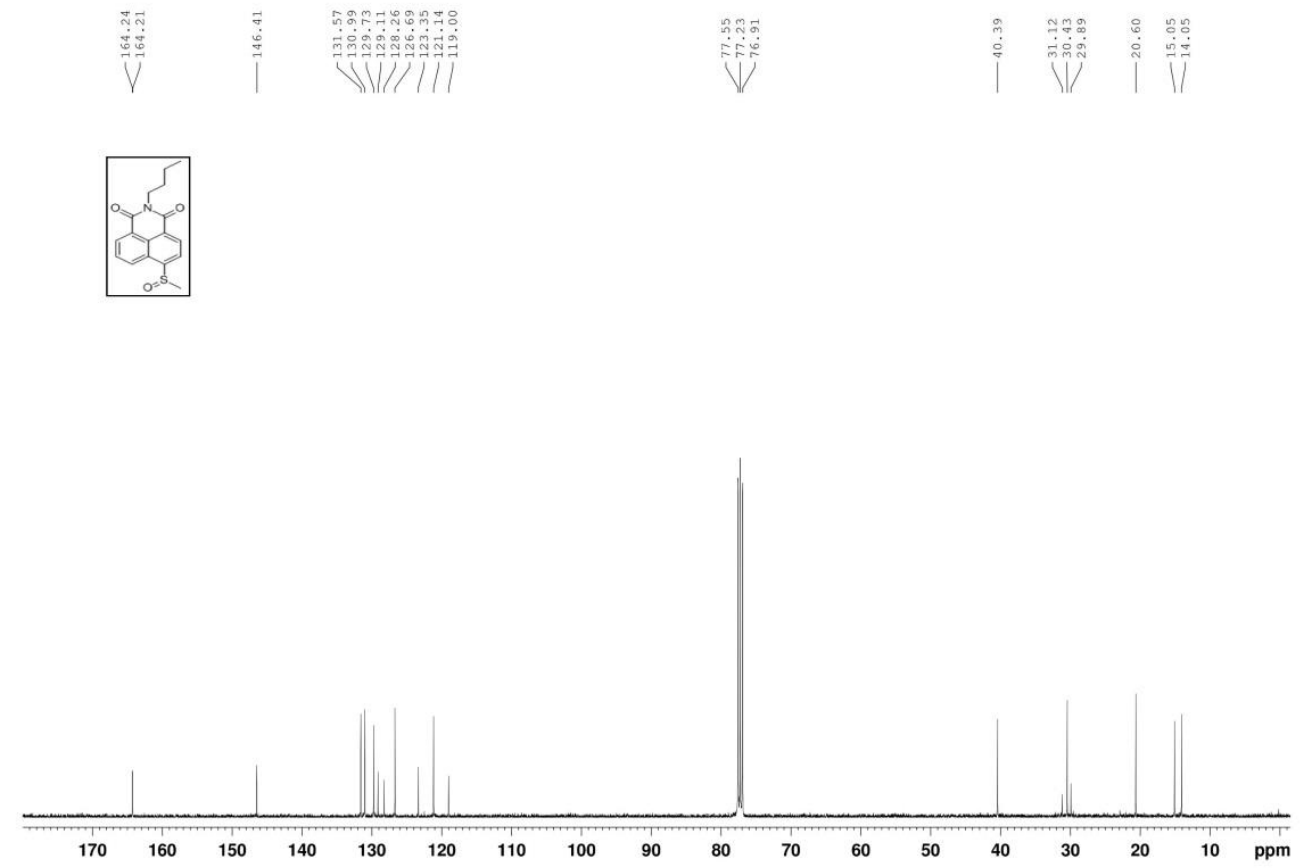

Figure S18 ${ }^{13} \mathrm{C}$ NMR of compound $4 \mathrm{a}$. 


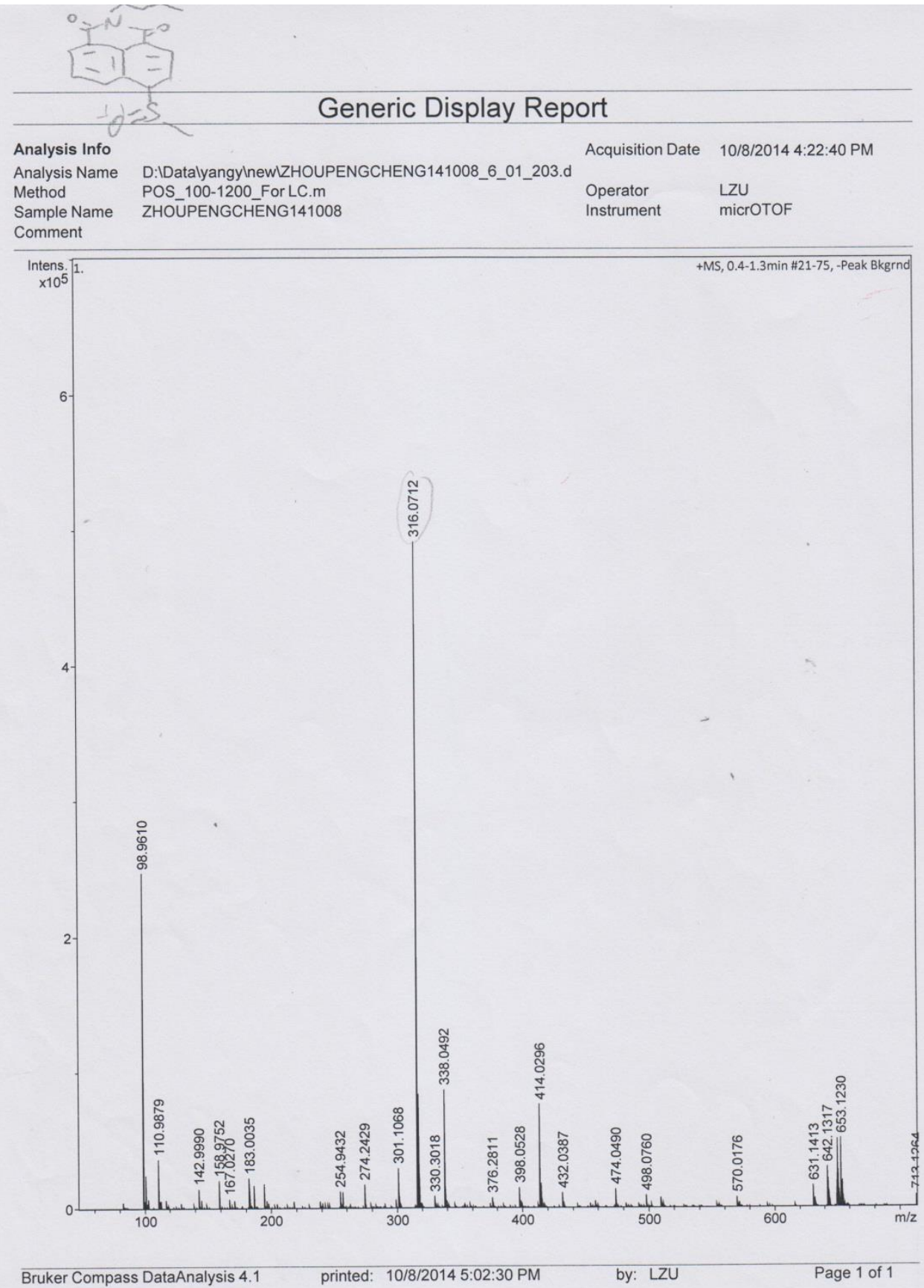

Figure S19 ESI-MS of compound $4 a$ 

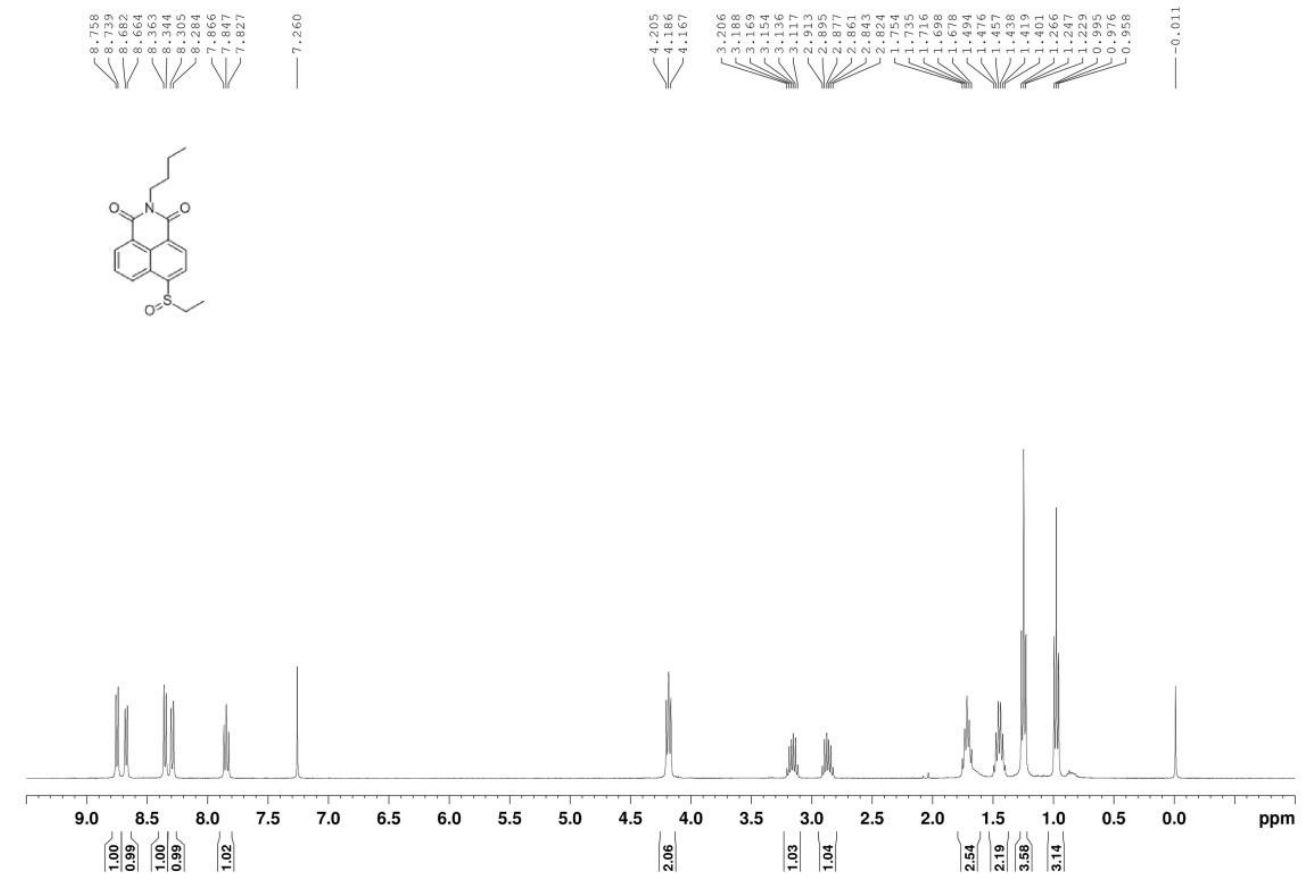

Figure S20 ${ }^{1} \mathrm{H}$ NMR of compound $\mathbf{4 b}$.

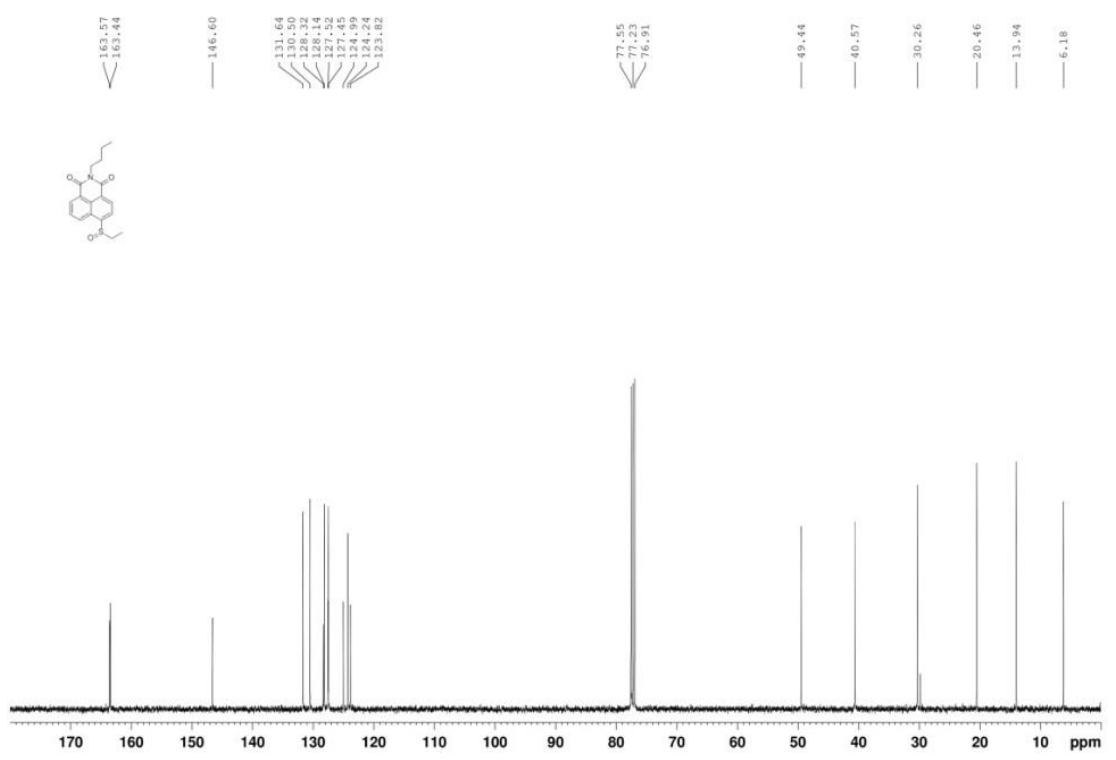

Figure S21 ${ }^{13} \mathrm{C}$ NMR of compound $\mathbf{4 b}$. 


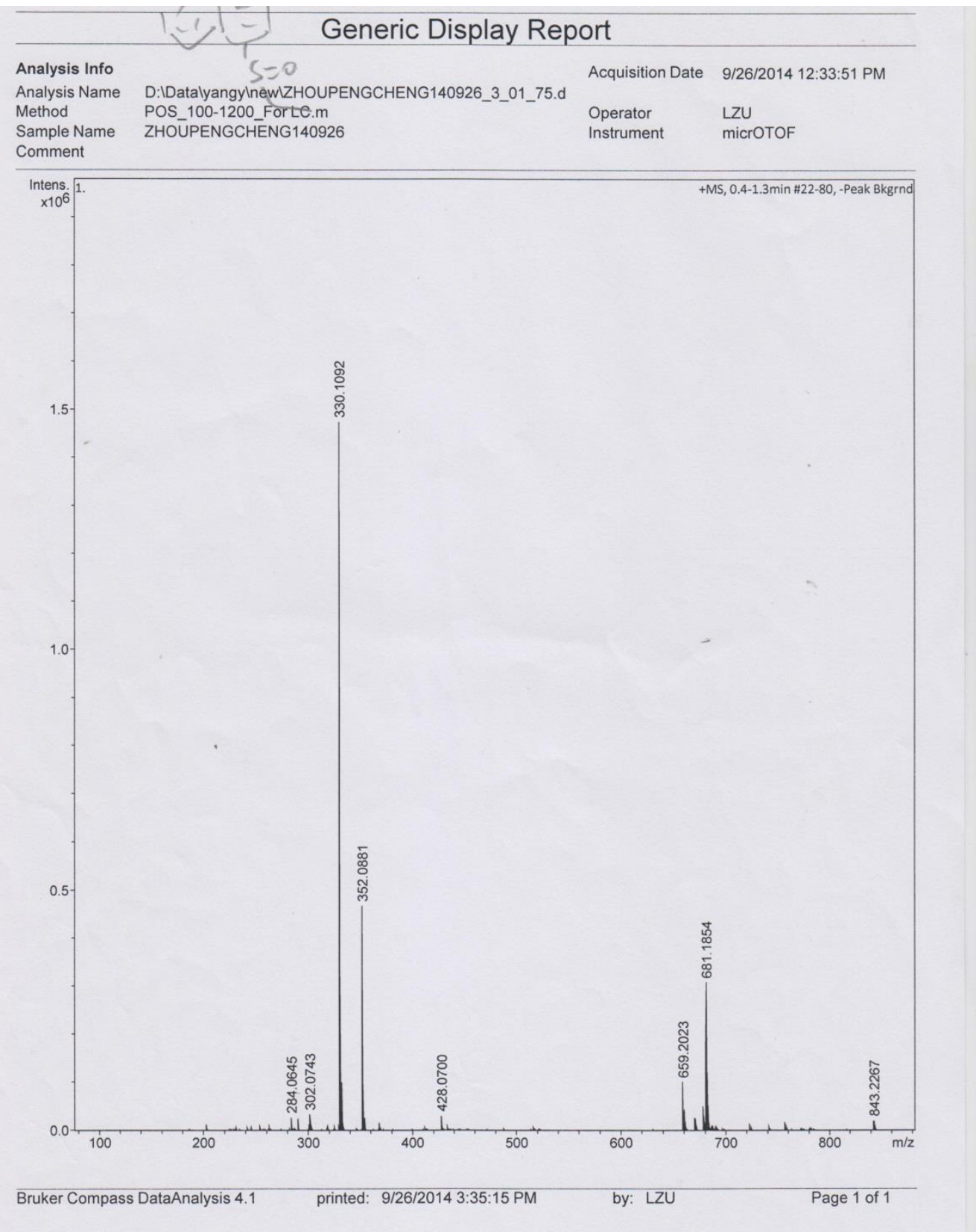

Figure S22 ESI-MS of compound $\mathbf{4 b .}$ 


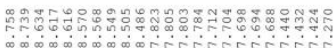

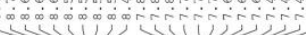

ソำ

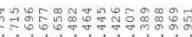
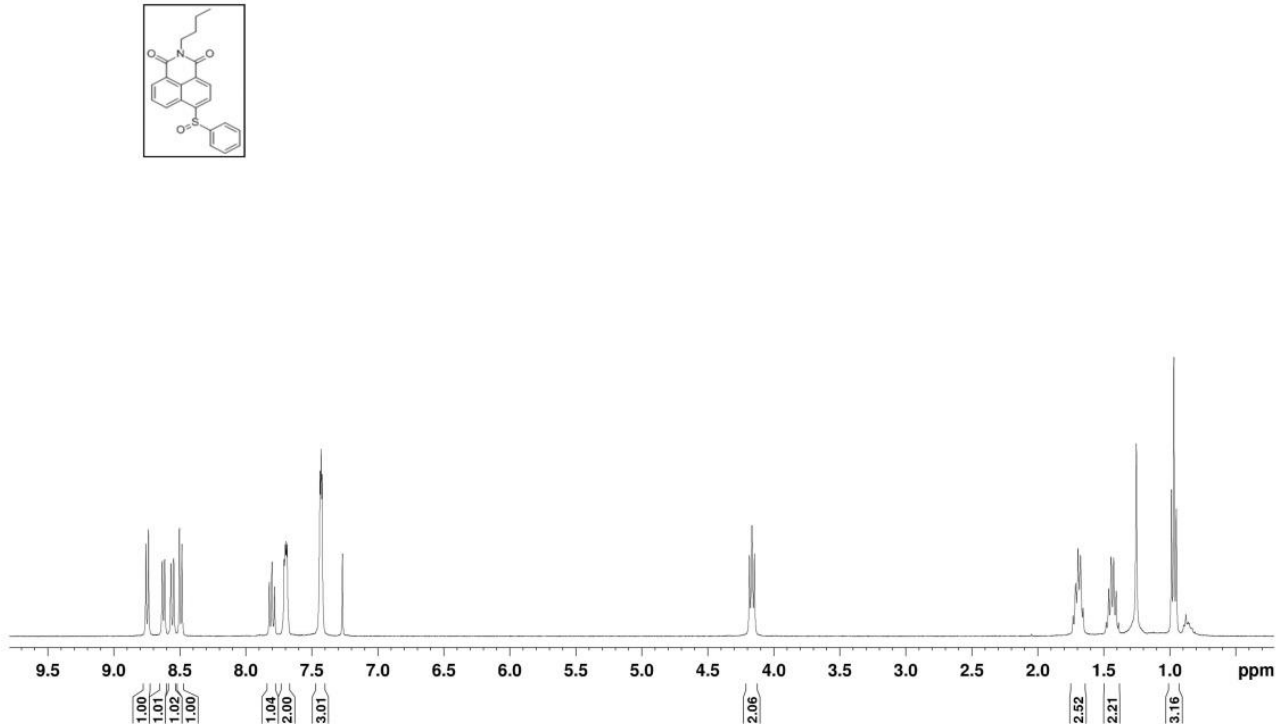

Figure $\mathbf{S 2 3}{ }^{1} \mathrm{H}$ NMR of compound $4 \mathrm{c}$.
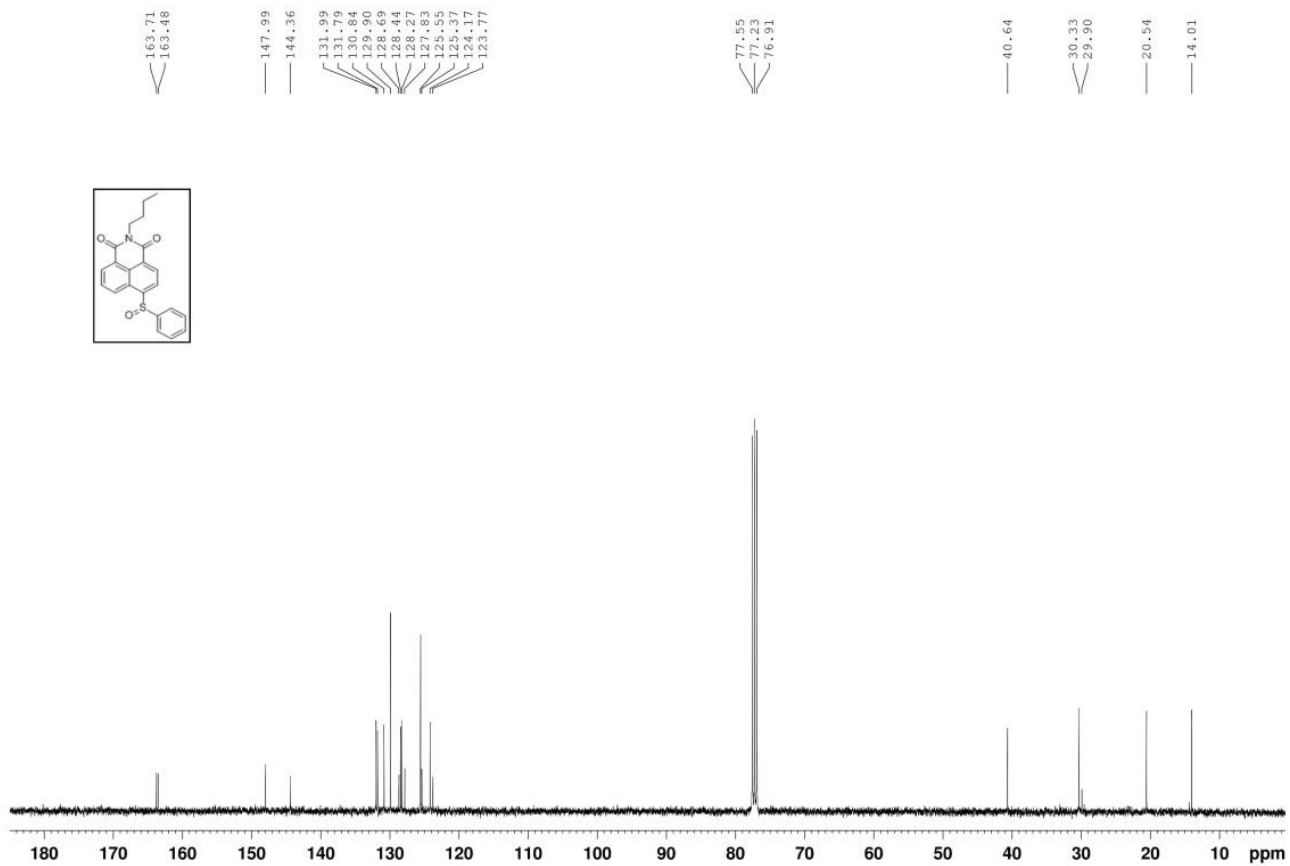

Figure S24 ${ }^{13} \mathrm{C}$ NMR of compound $4 \mathrm{c}$. 


\section{Generic Display Report}

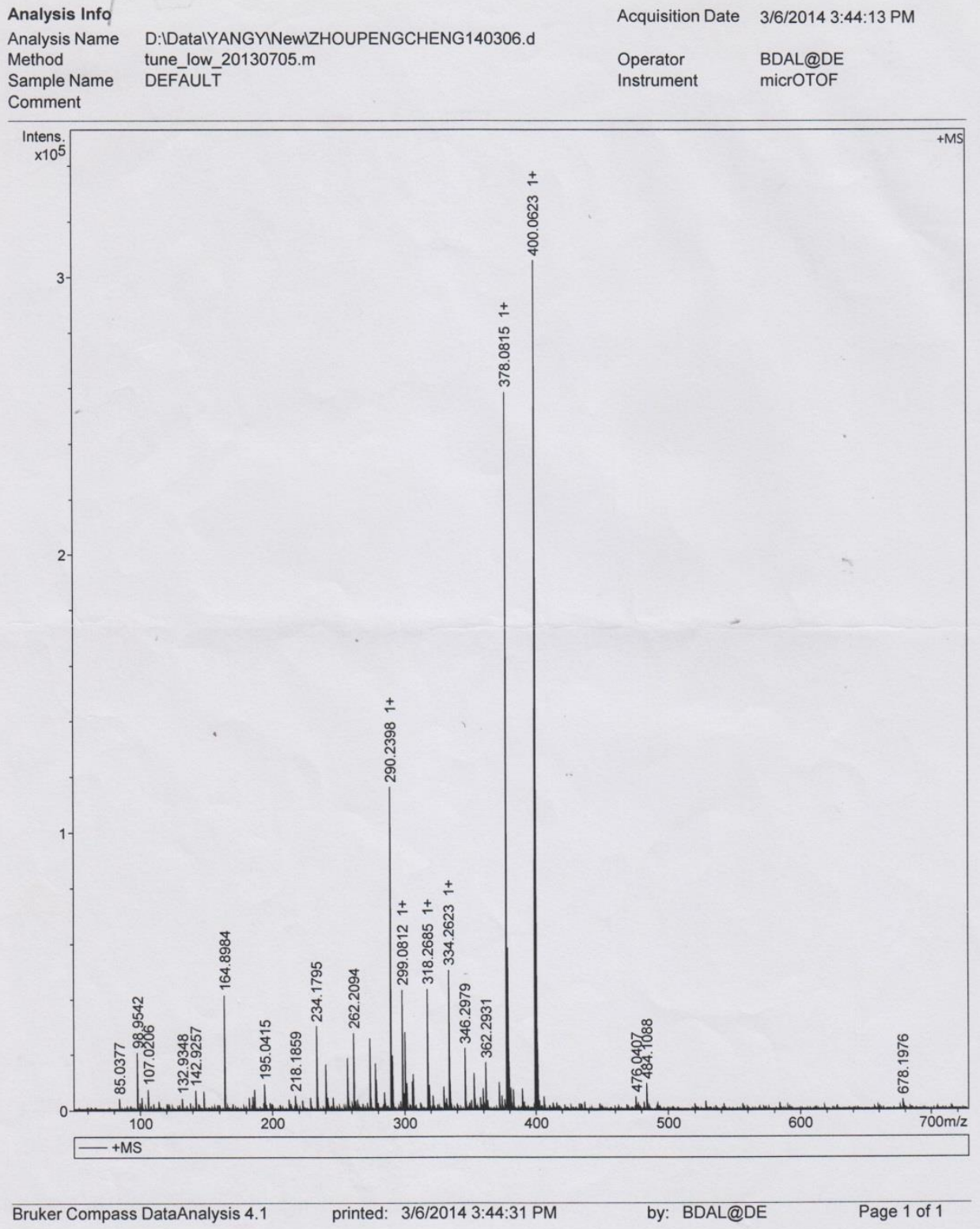

Figure S25 ESI-MS of compound 4c. 


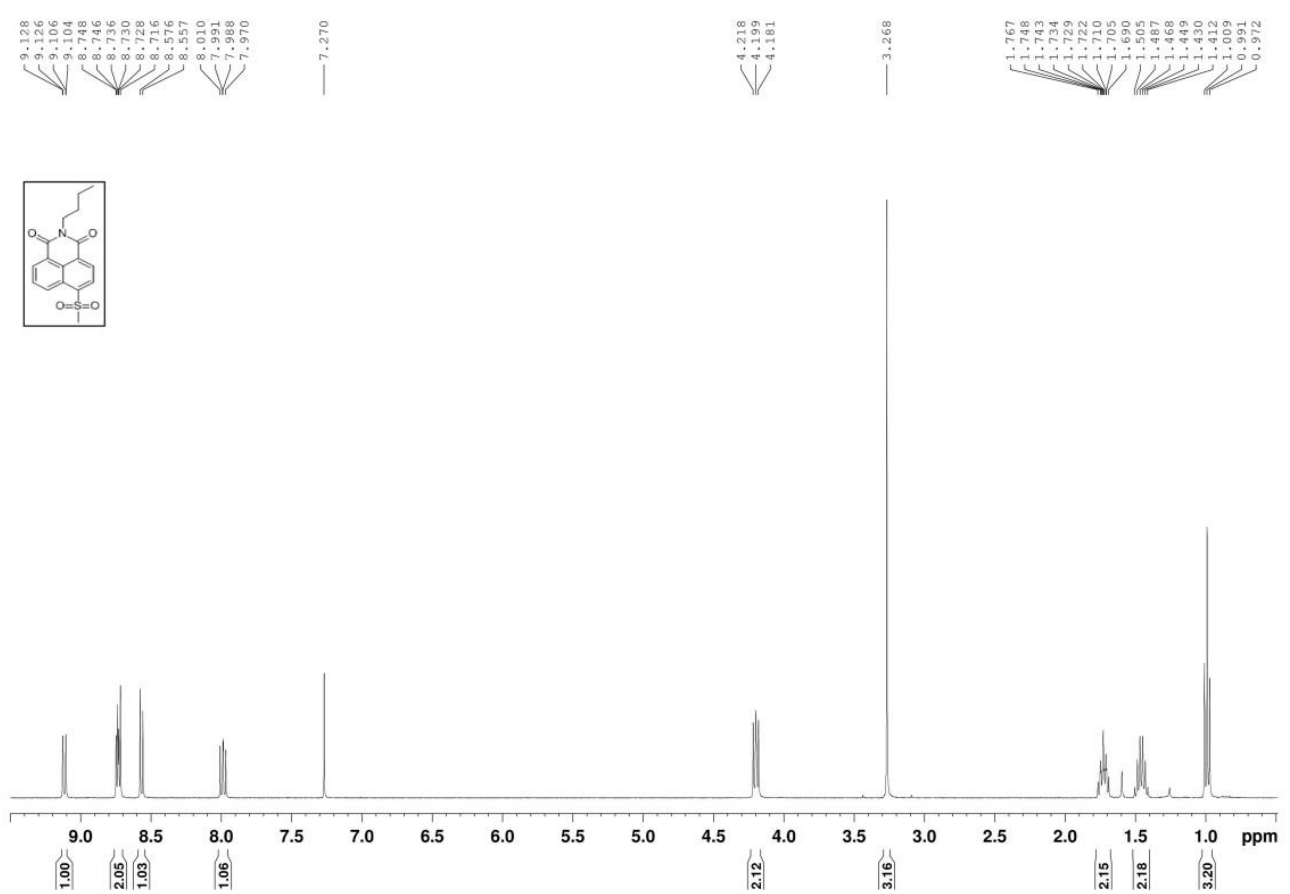

Figure S26 ${ }^{1} \mathrm{H}$ NMR of coupound $\mathbf{5 a}$.

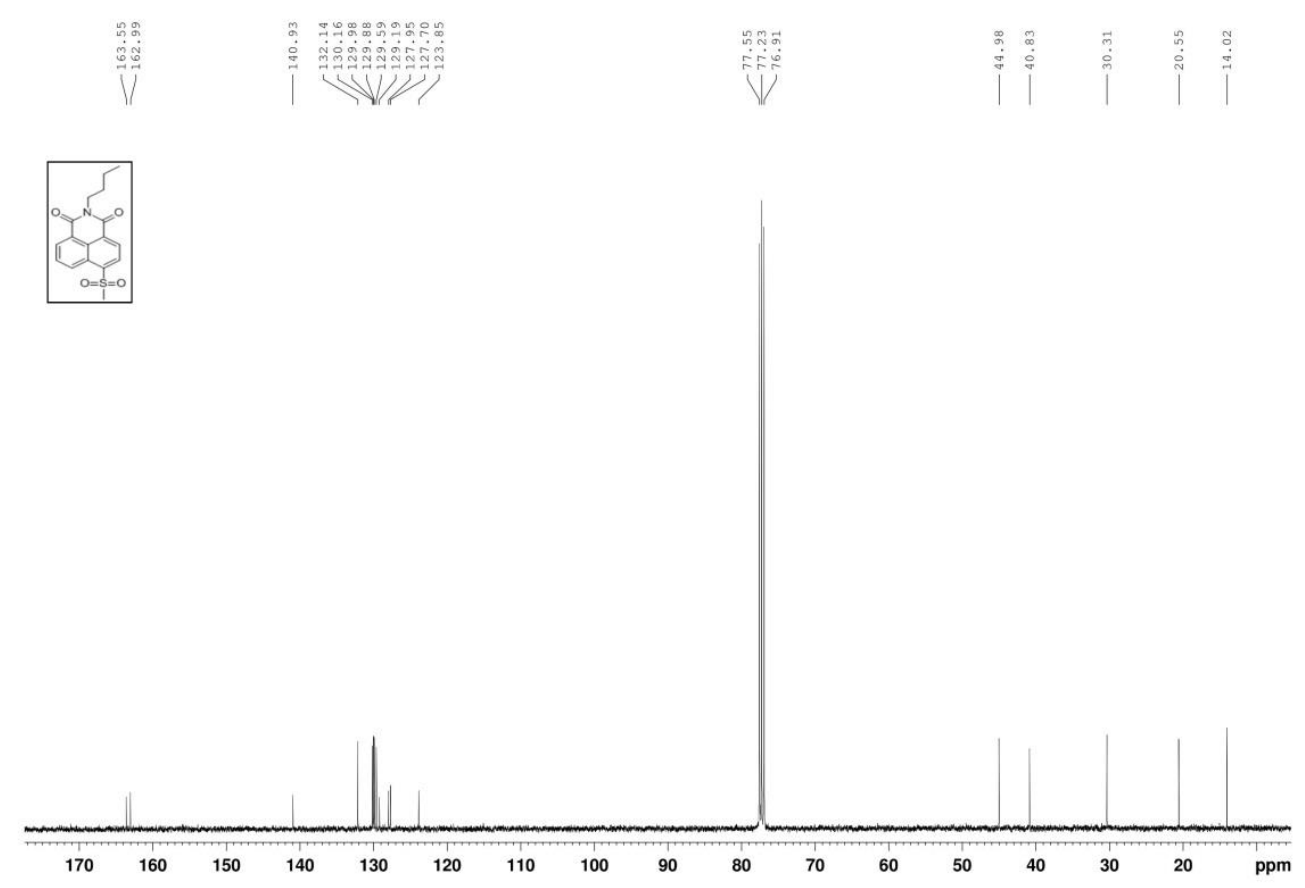

Figure S27 ${ }^{13} \mathrm{C}$ NMR of compound $\mathbf{5 a}$. 


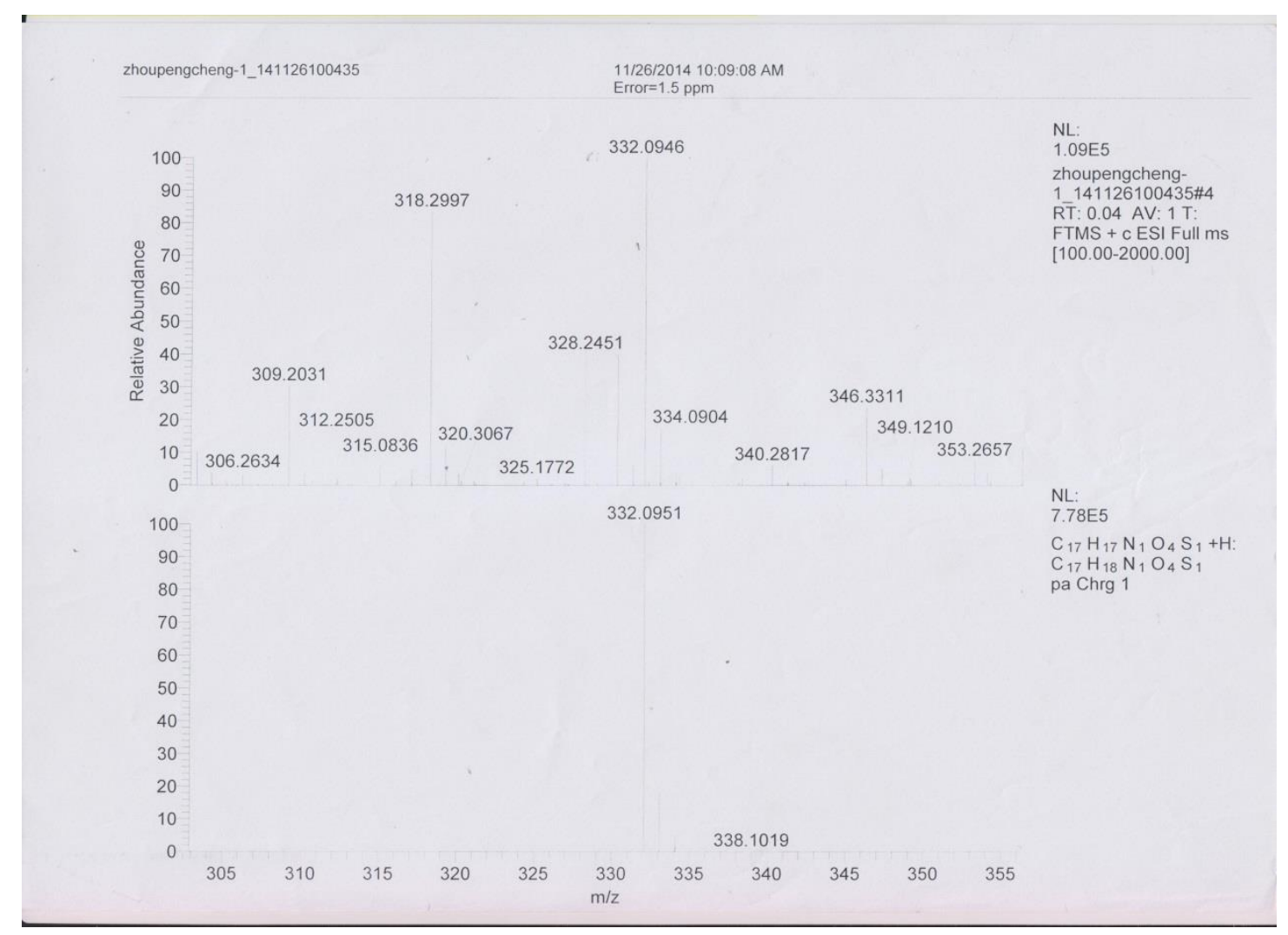

Figure S28 HRMS of compound 5a.

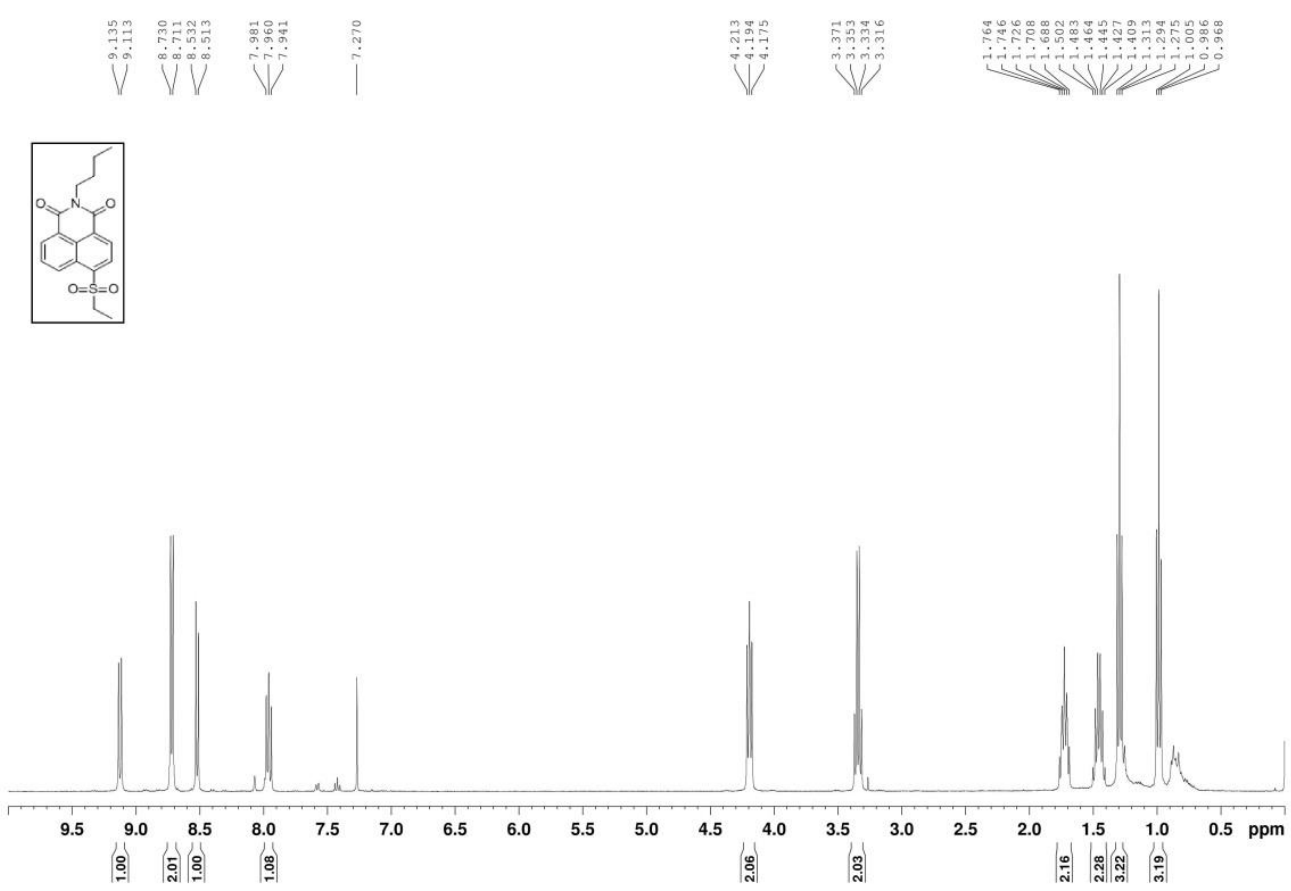

Figure S29 ${ }^{1} \mathrm{H}$ NMR of compound $\mathbf{5 b}$. 


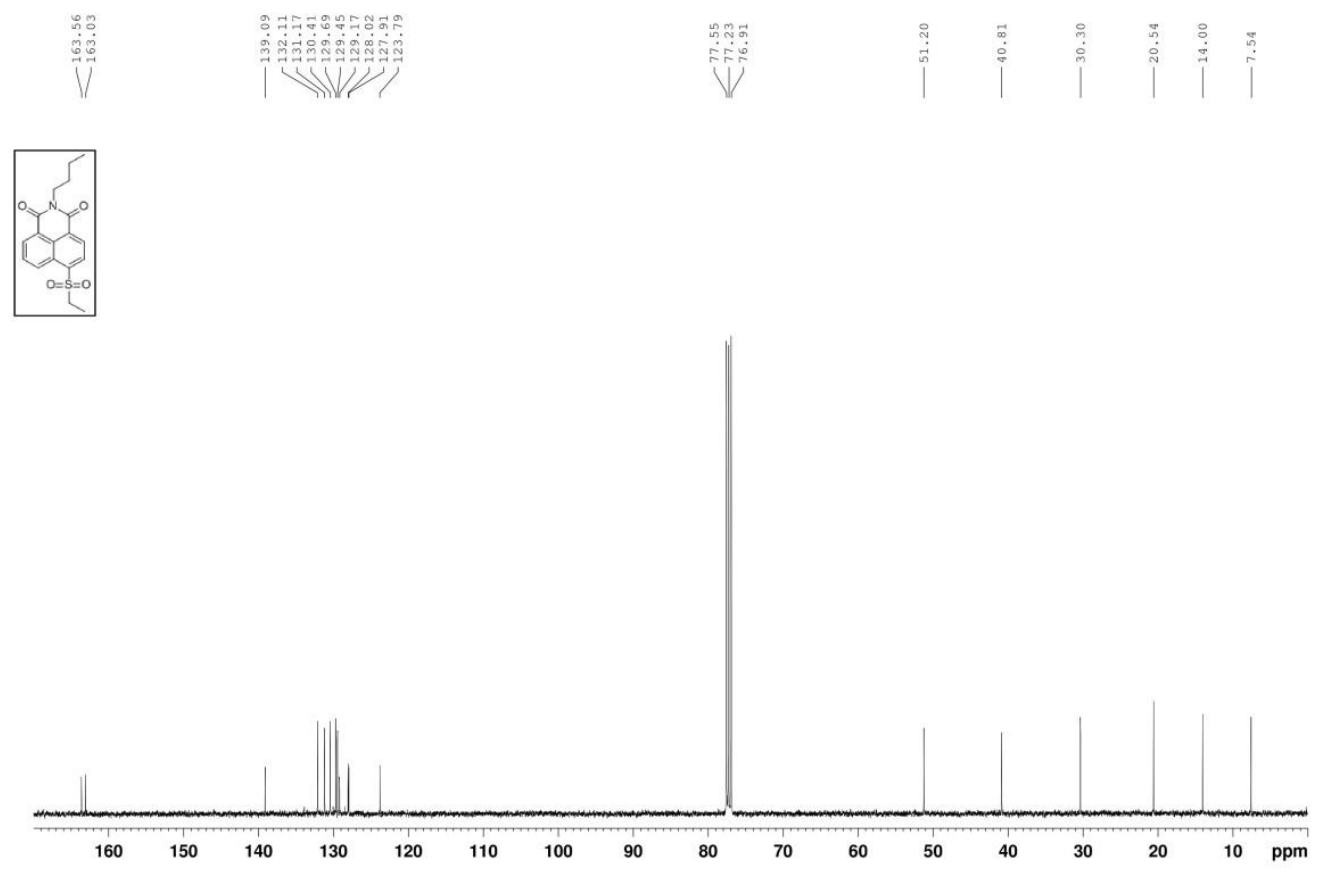

Figure S30 ${ }^{13} \mathrm{C}$ NMR of compound $\mathbf{5 b}$. 


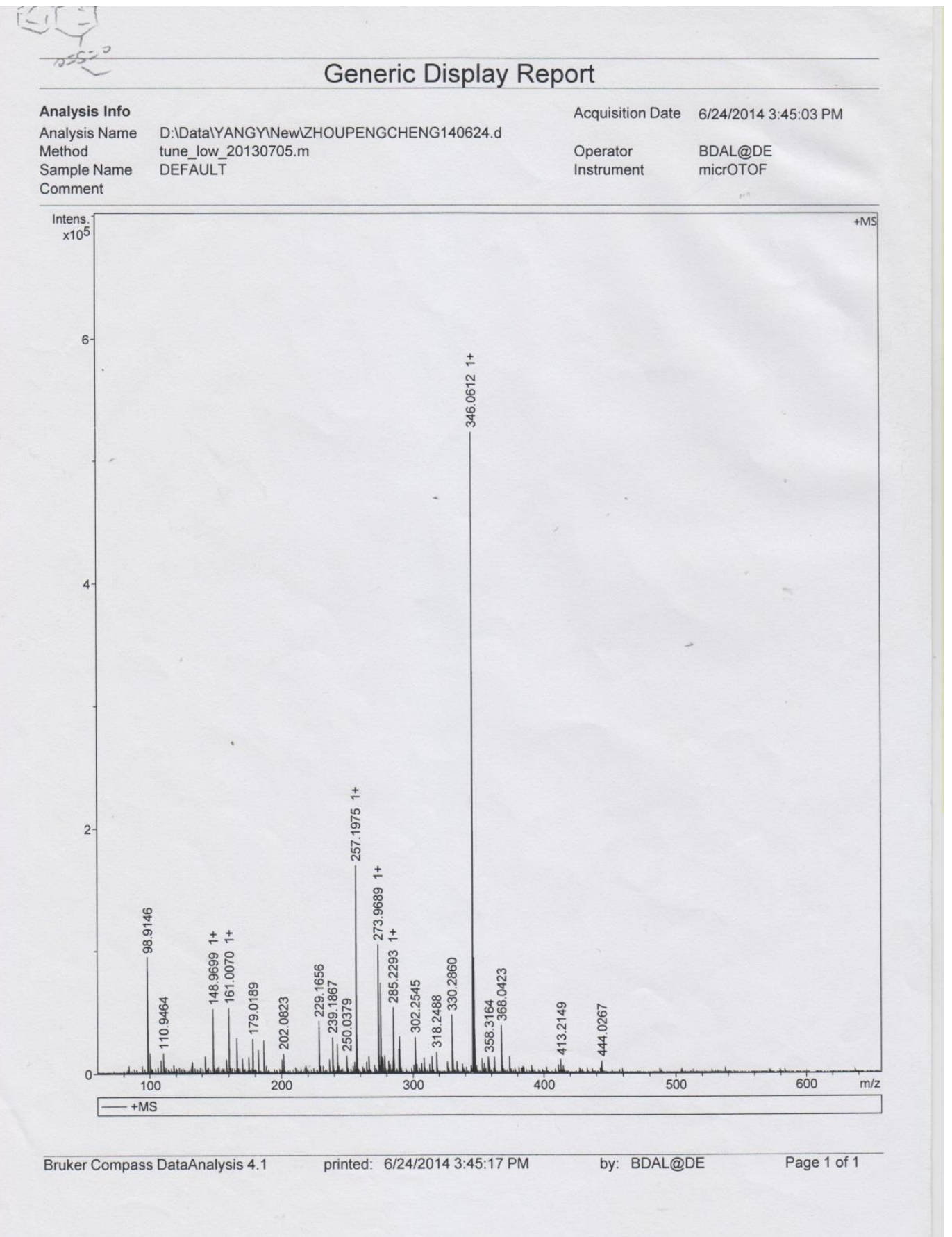

Figure S31 ESI-MS of compound $\mathbf{5 b}$. 


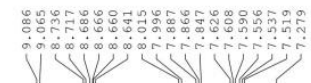

Vं
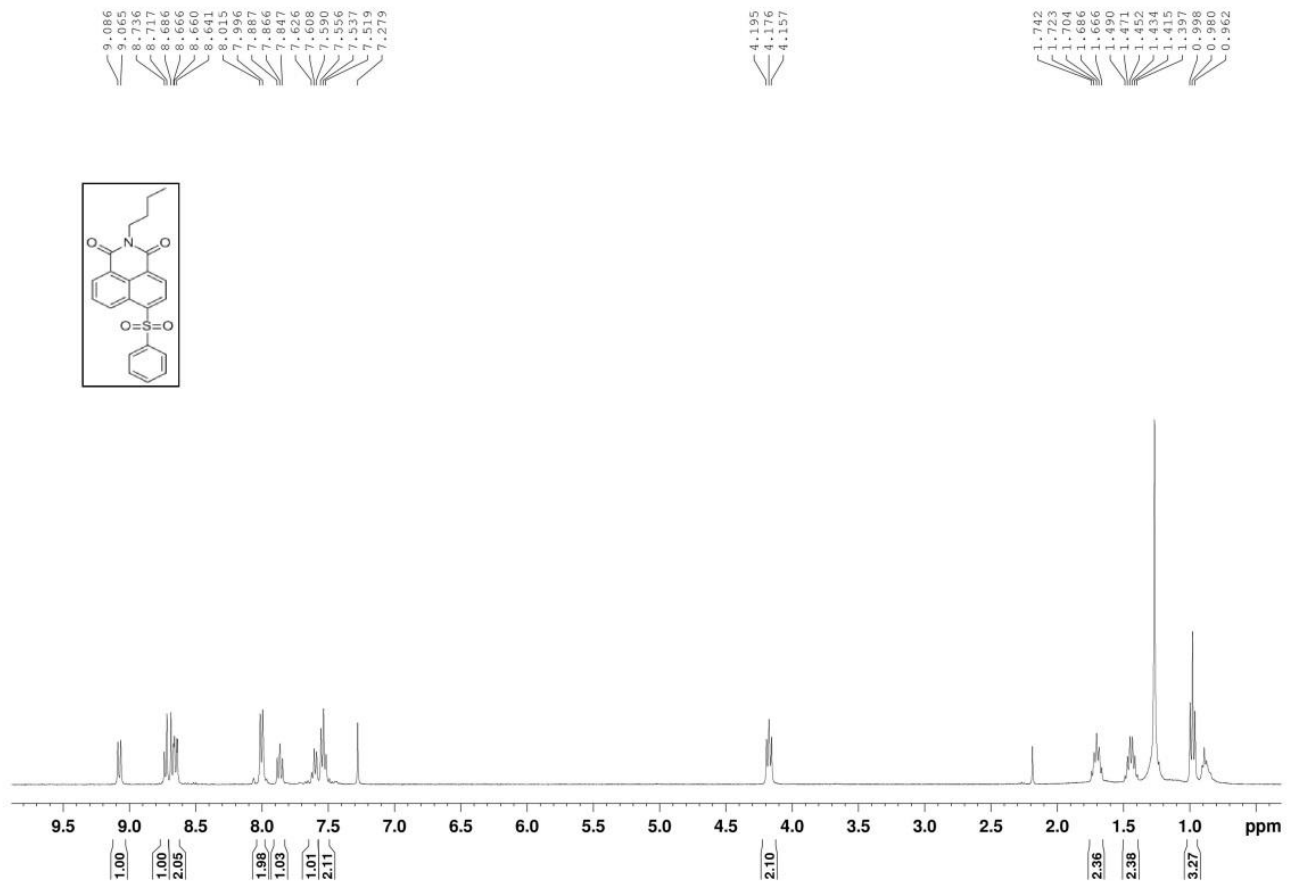

Figure S32 ${ }^{1} \mathrm{H}$ NMR of compound $\mathbf{5 c}$.

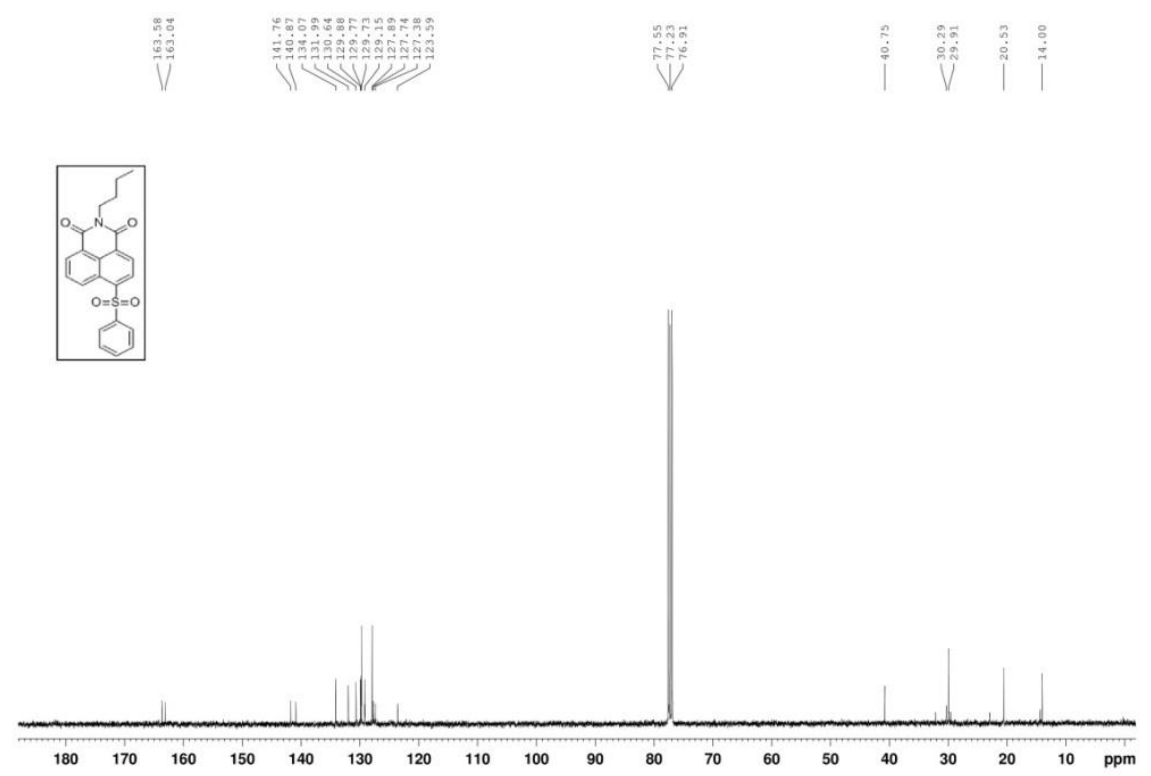

Figure S33 ${ }^{13} \mathrm{C}$ NMR of compound $\mathbf{5 c}$. 


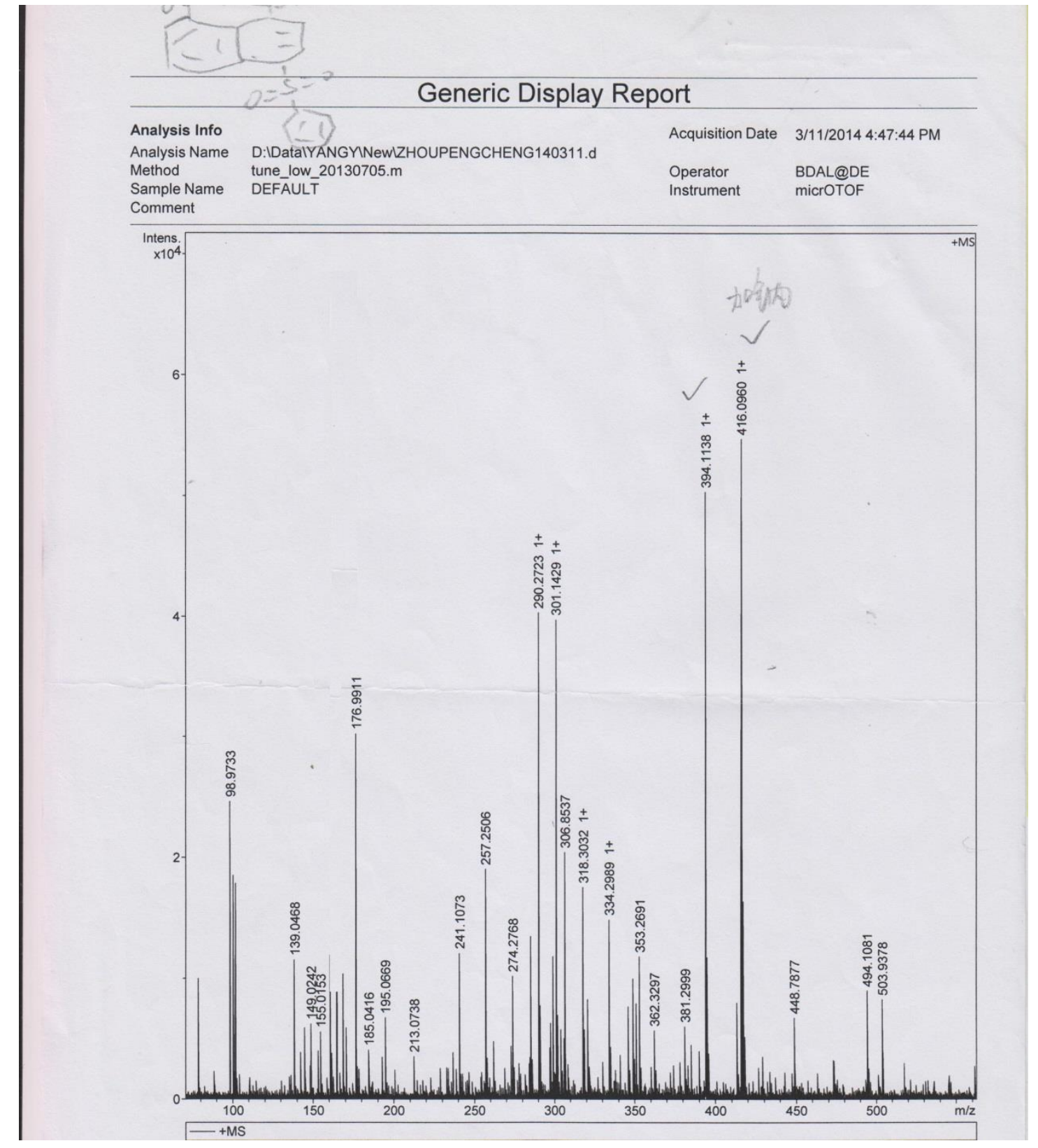

Figure S34 ESI-MS of compound 5c. 


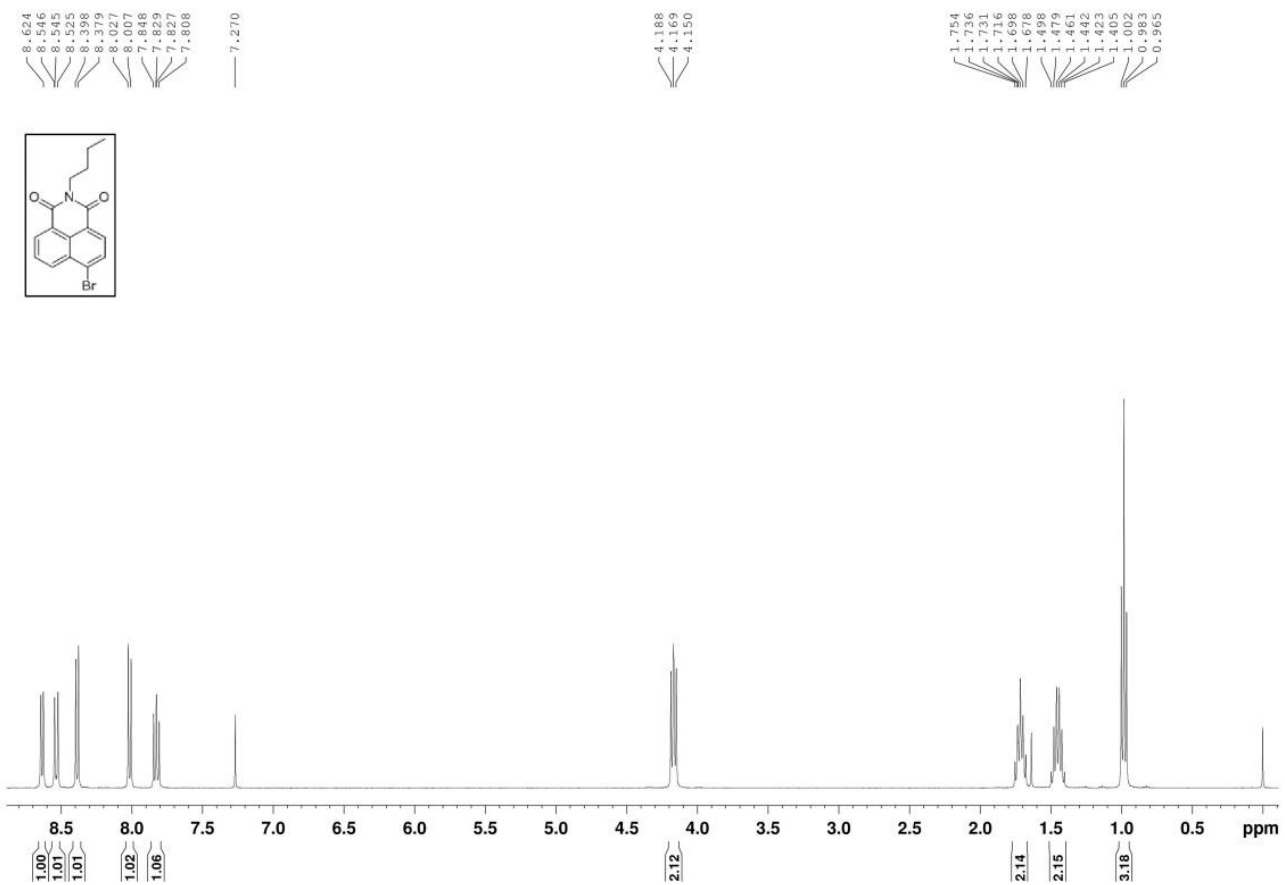

Figure S35 ${ }^{1} \mathrm{H}$ NMR of compound 6 .
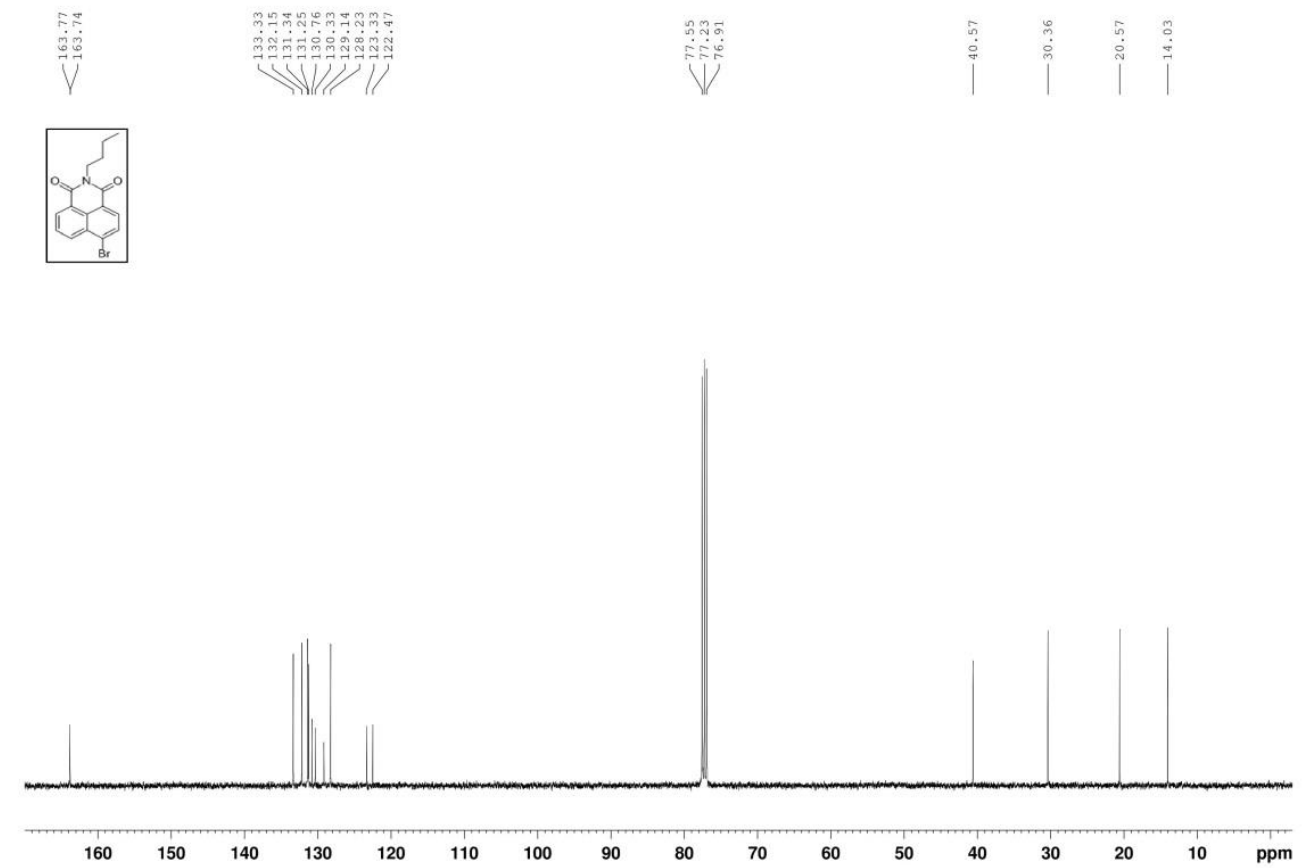

Figure S36 ${ }^{13} \mathrm{C}$ NMR of compound 6 . 


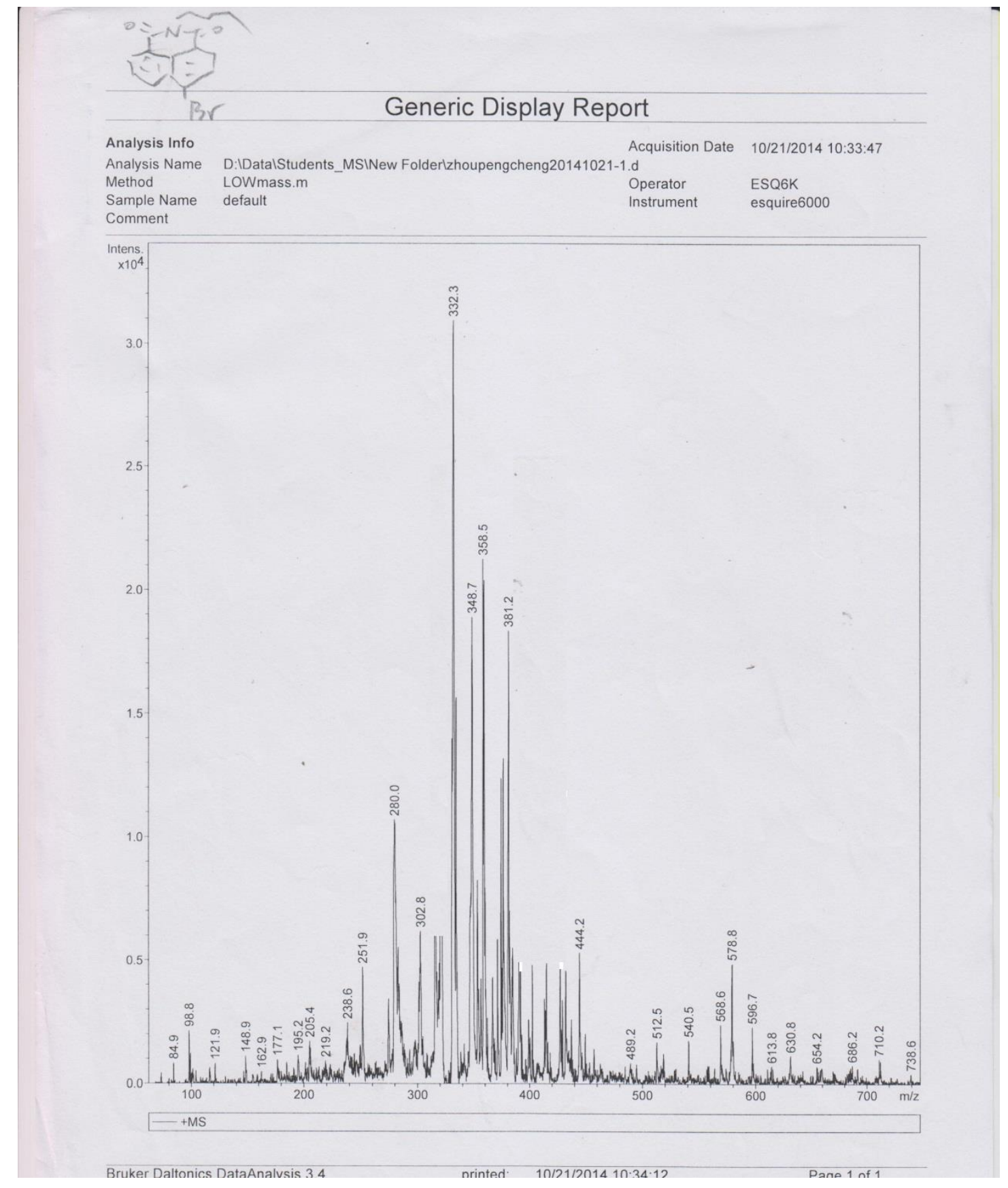

Figure S37 ESI-MS of compound 6. 


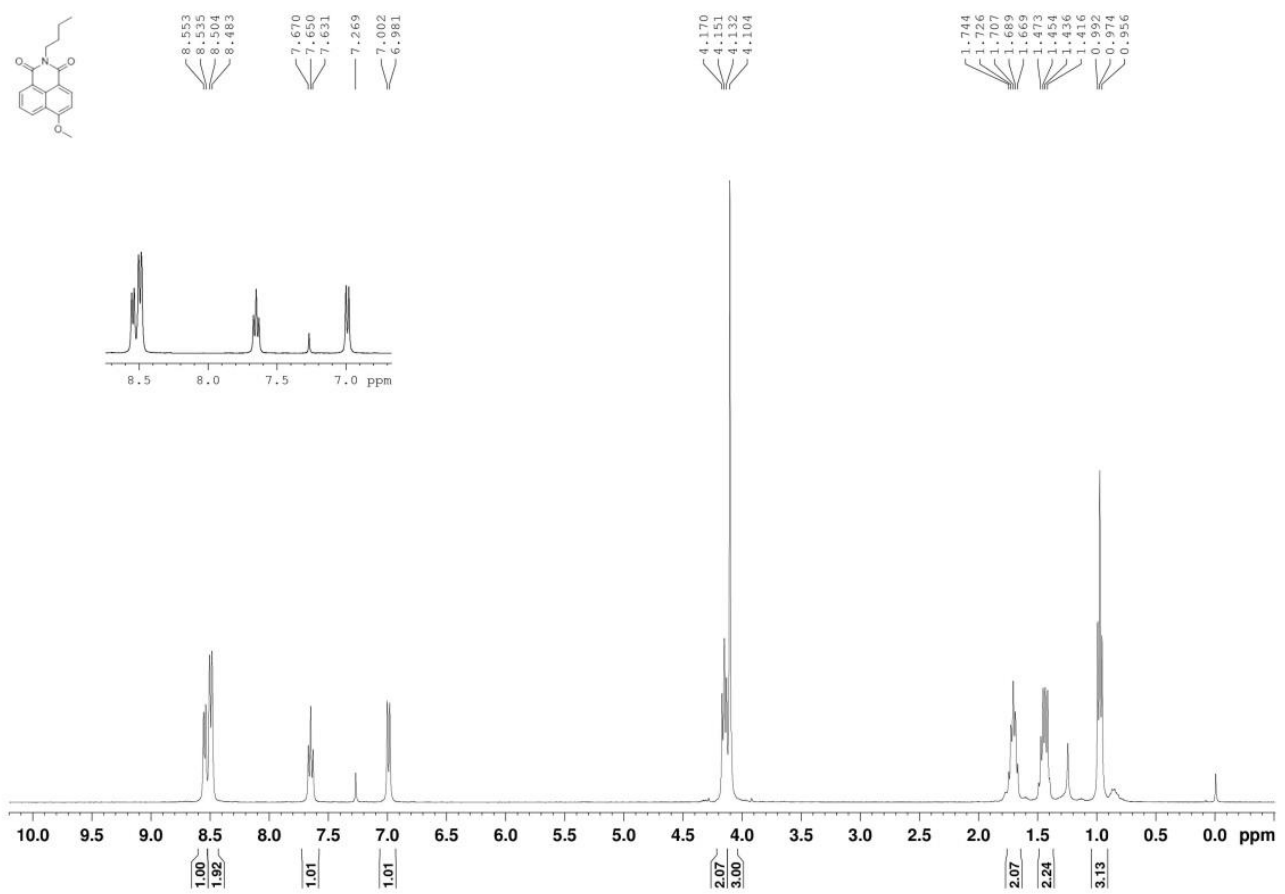

Figure S38 ${ }^{1} \mathrm{H}$ NMR of compound $\mathbf{7}$.
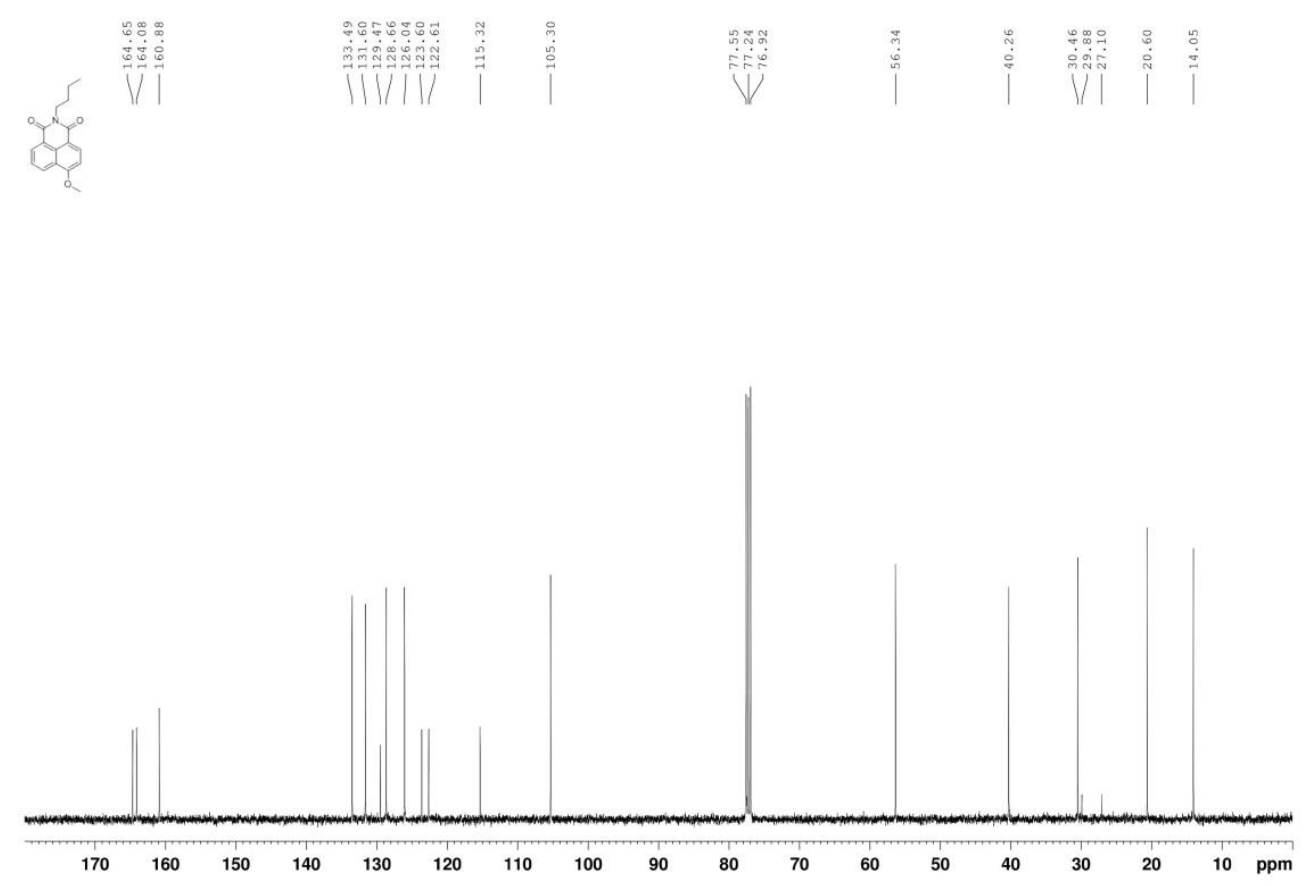

Figure S39 ${ }^{13} \mathrm{C}$ NMR of compound 7. 


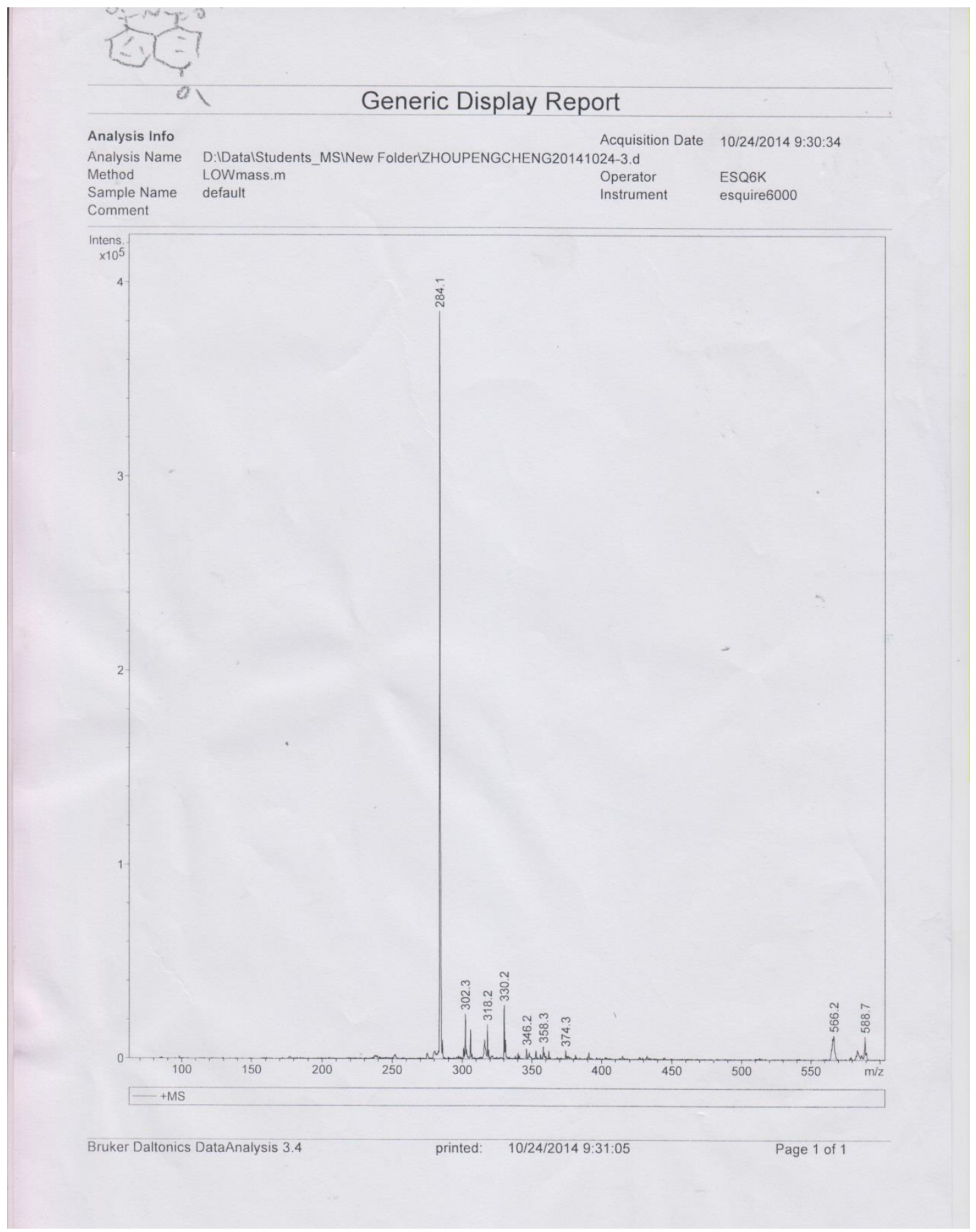

Figure S40 ESI-MS of compound 7. 


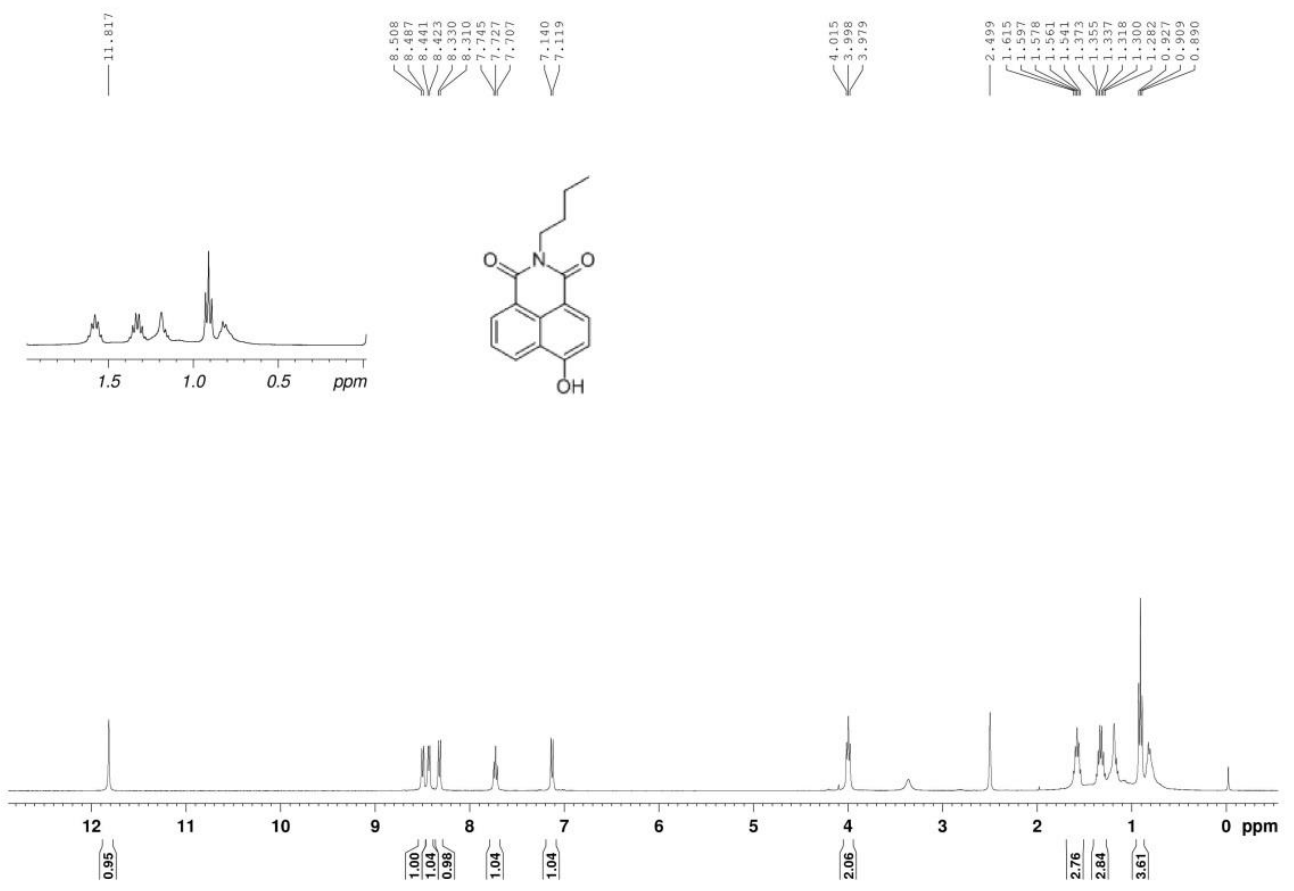

Figure $\mathbf{S 4 1}{ }^{1} \mathrm{H}$ NMR of compound 8 .
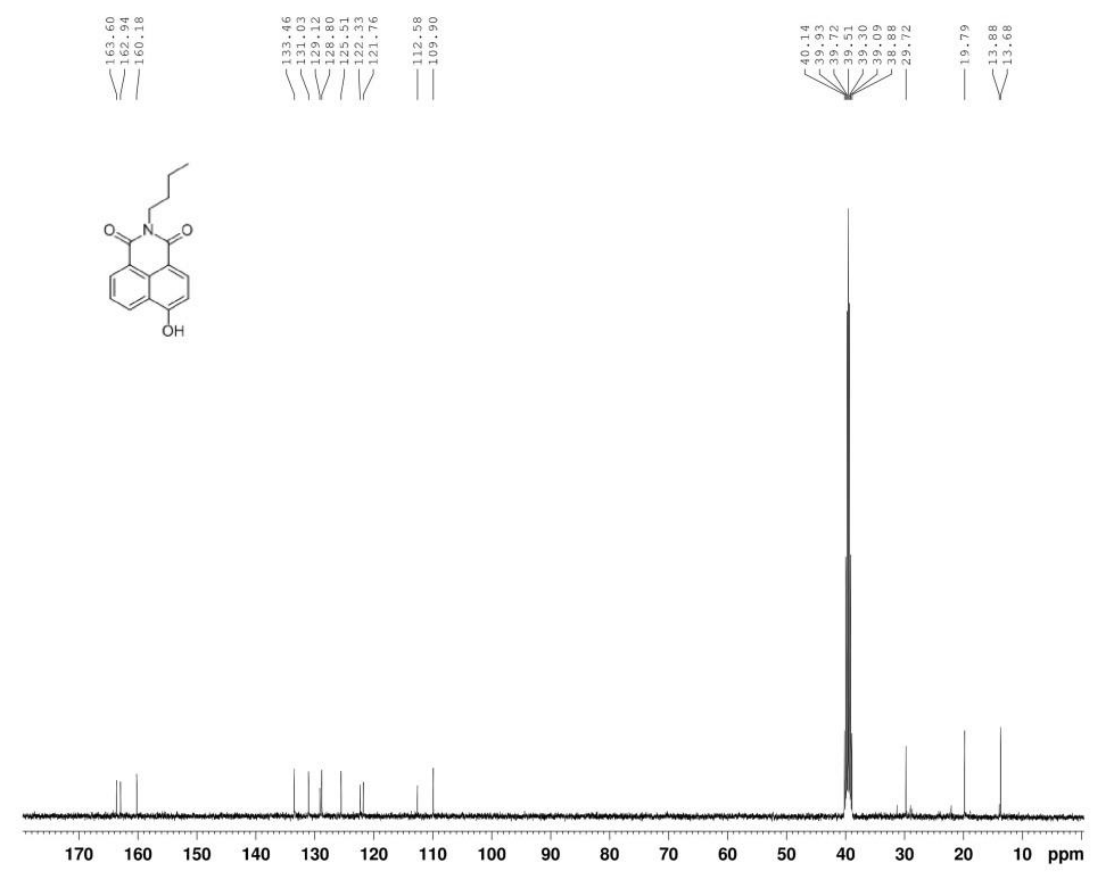

Figure $\mathbf{S 4 2}{ }^{13} \mathrm{C}$ NMR of compound 8 . 


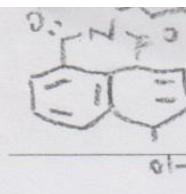

Generic Display Report

Analysis Info

Analysis Name

Method

Sample Name

Comment

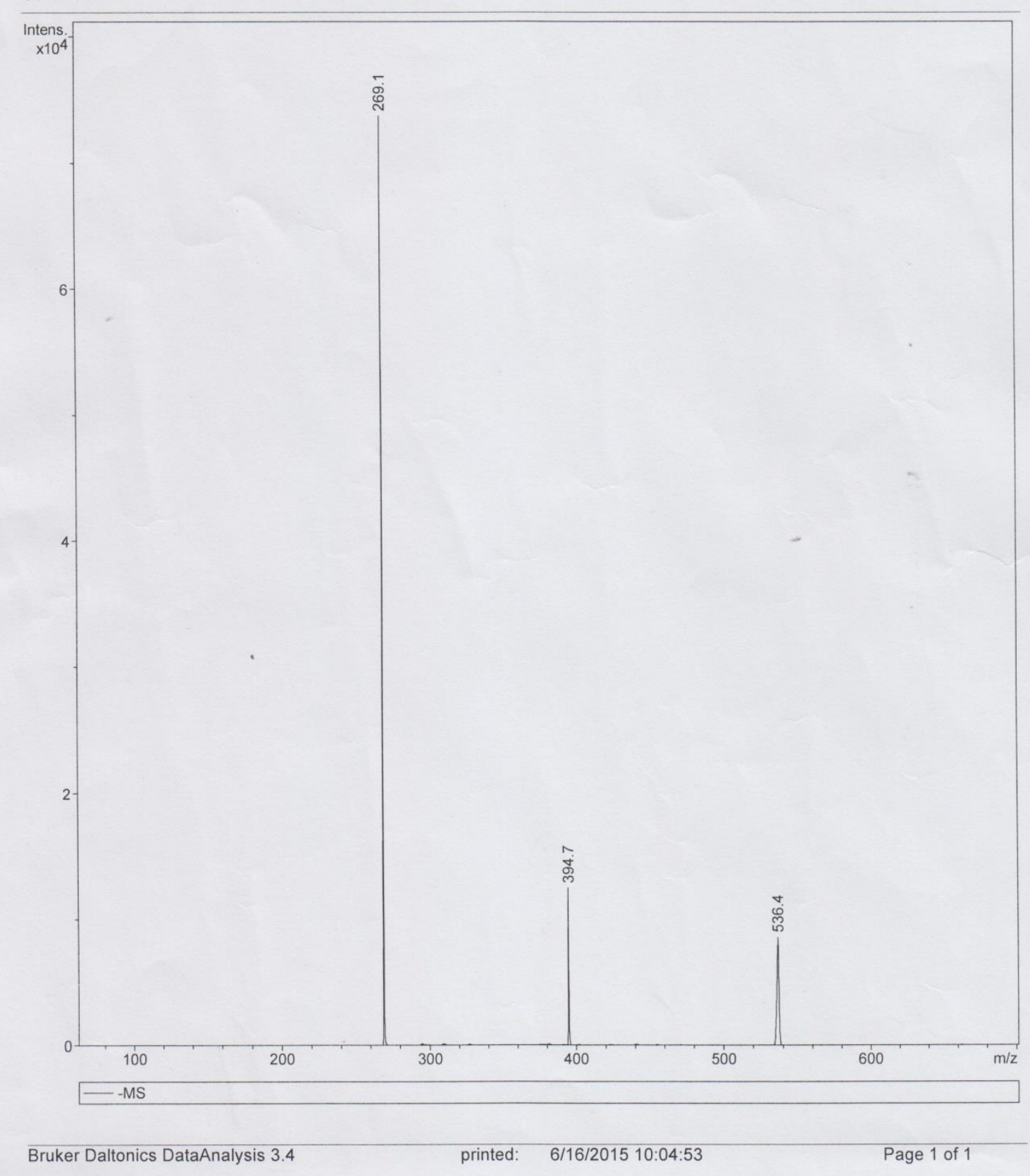

Acquisition Date $\quad 6 / 16 / 2015$ 10:04:26

Operator ESQ6K

Instrument esquire 6000
Thew Folderlzhoupc-20150616-269.d

STUDENTS.m

default

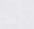

Figure S43 ESI-MS of compound 8. 


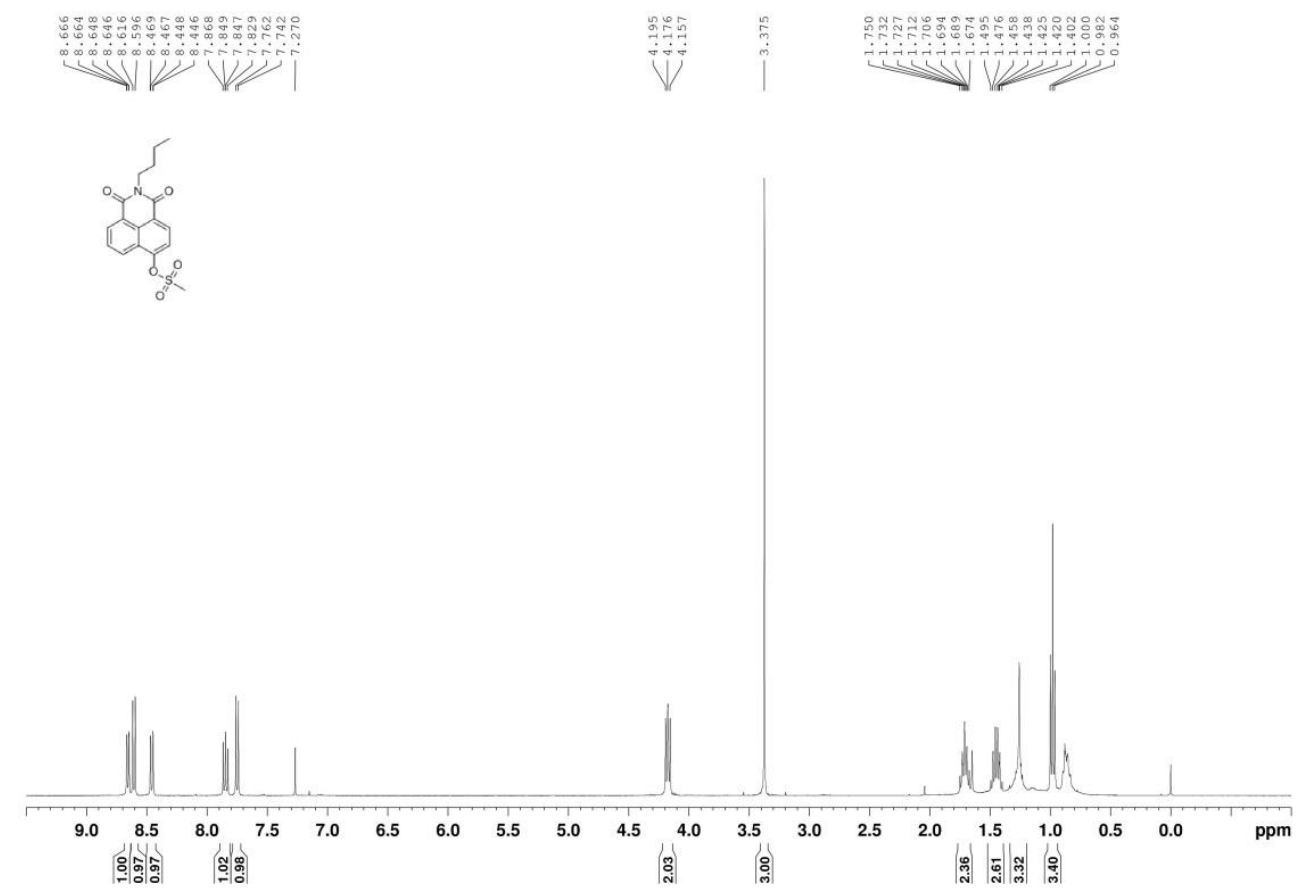

Figure S44 ${ }^{1} \mathrm{H}$ NMR of compound 9a.
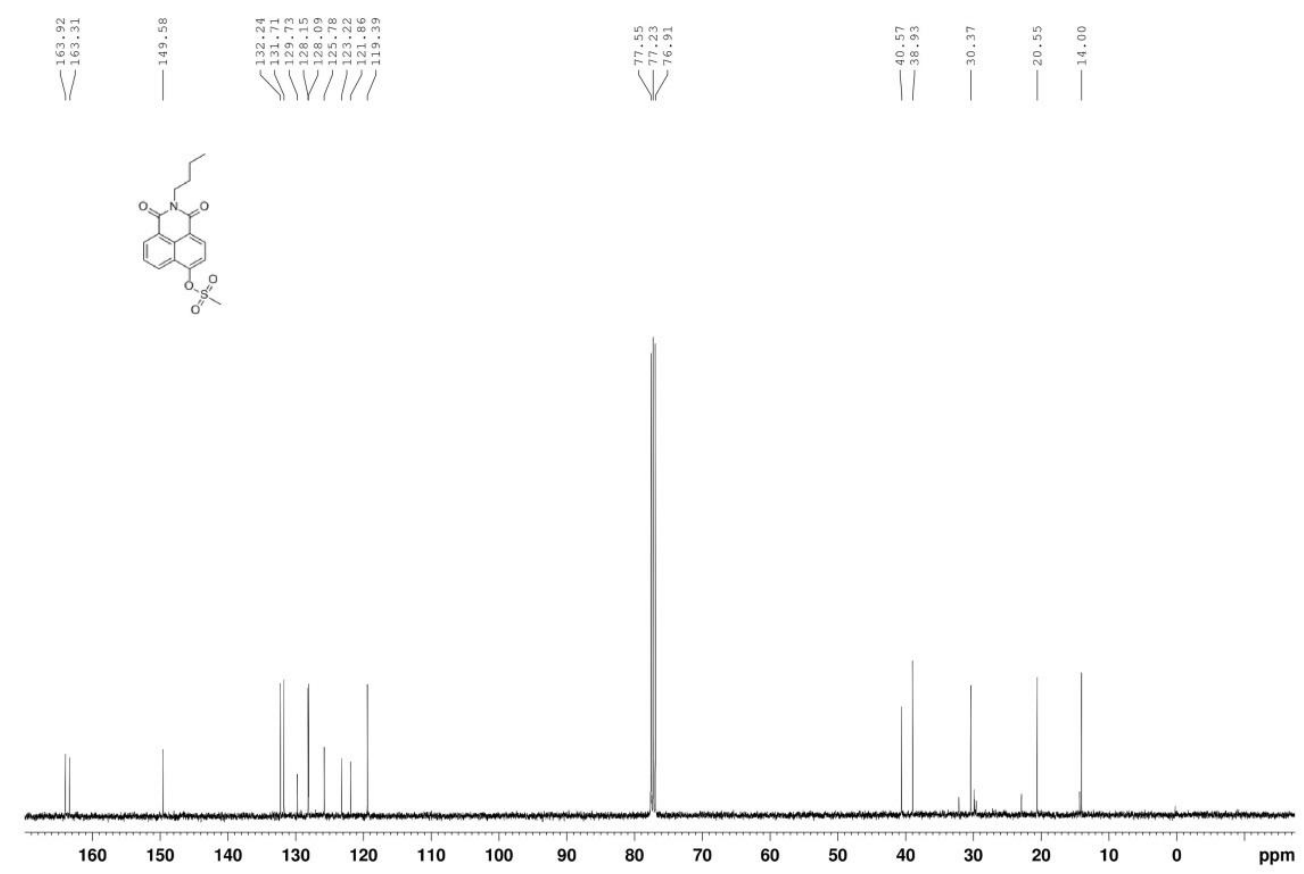

Figure S45 ${ }^{13} \mathrm{C}$ NMR of compound 9a. 


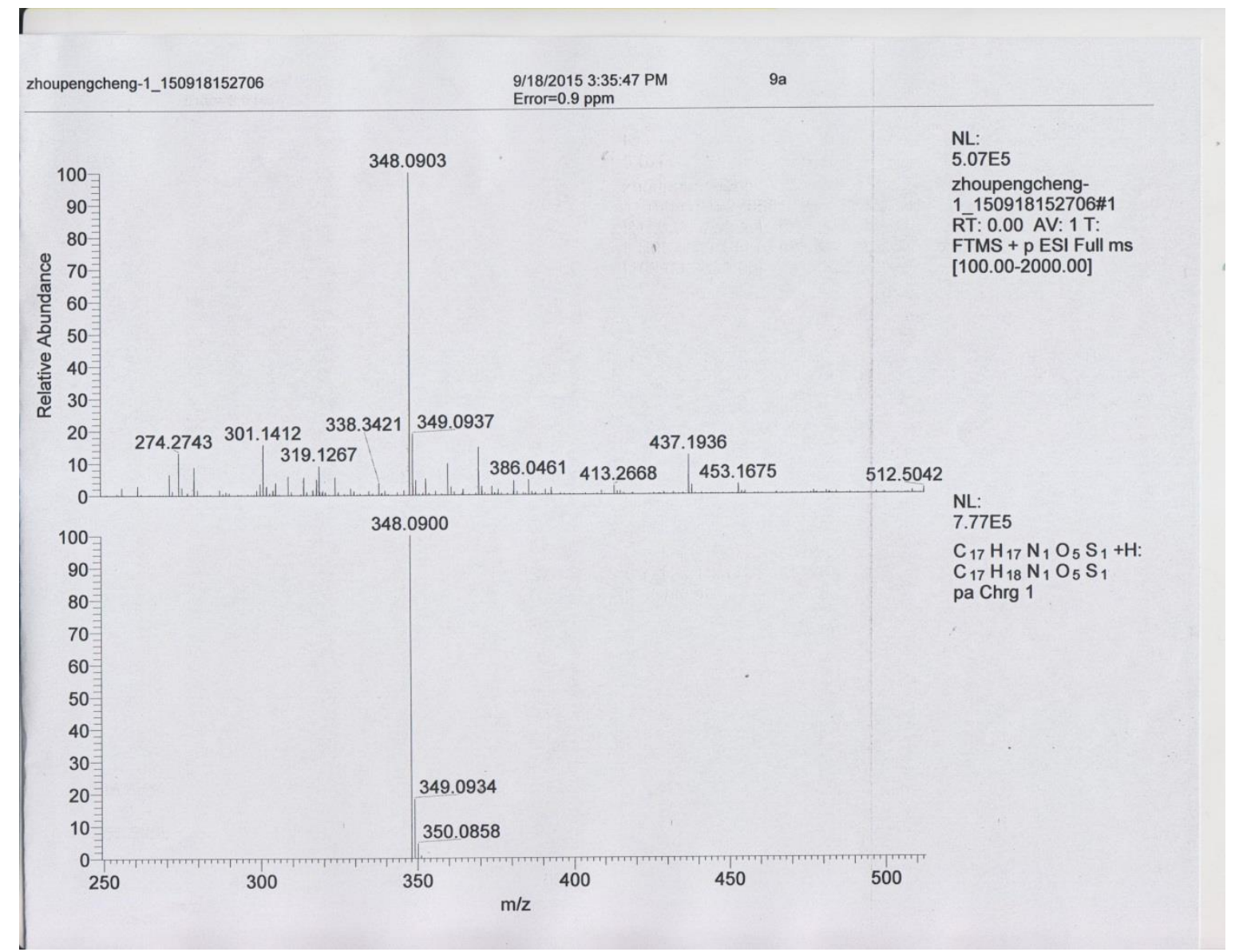

Figure S46 HRMS of compound 9a.

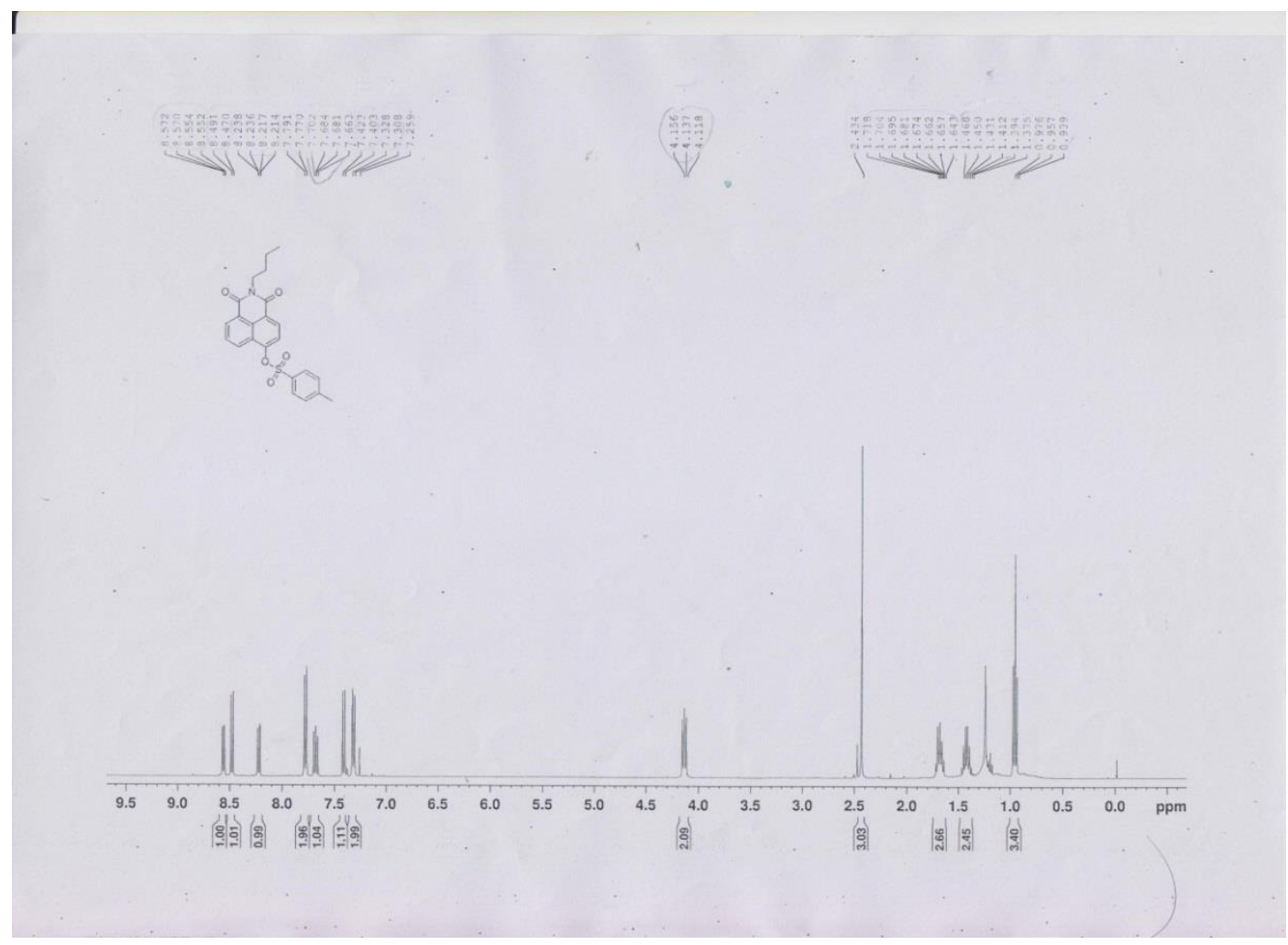

Figure $\mathbf{5 4 7}{ }^{1} \mathrm{H}$ NMR of compound $\mathbf{9 b}$. 


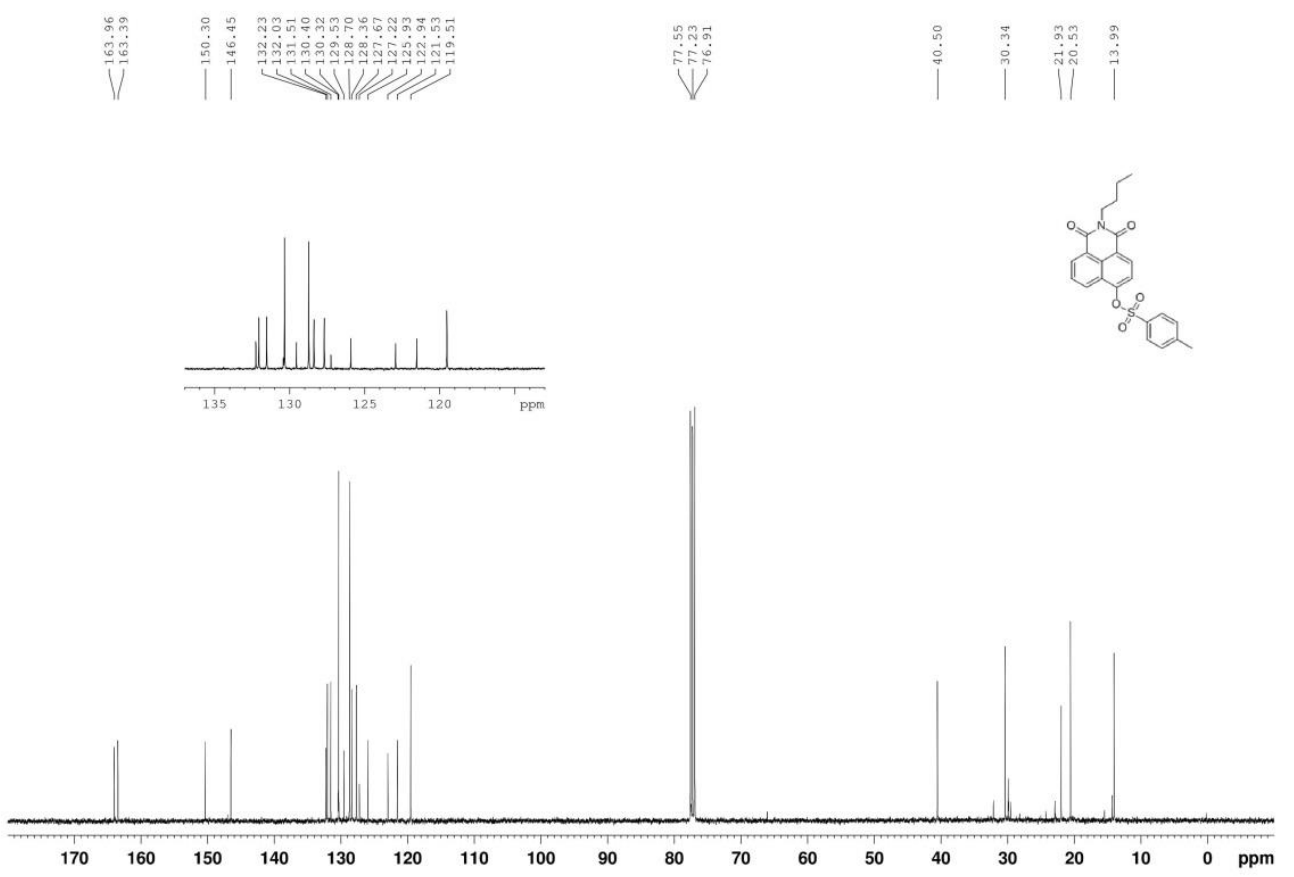

Figure $\mathbf{S 4 8}{ }^{13} \mathrm{C}$ NMR of compound $\mathbf{9 b}$.

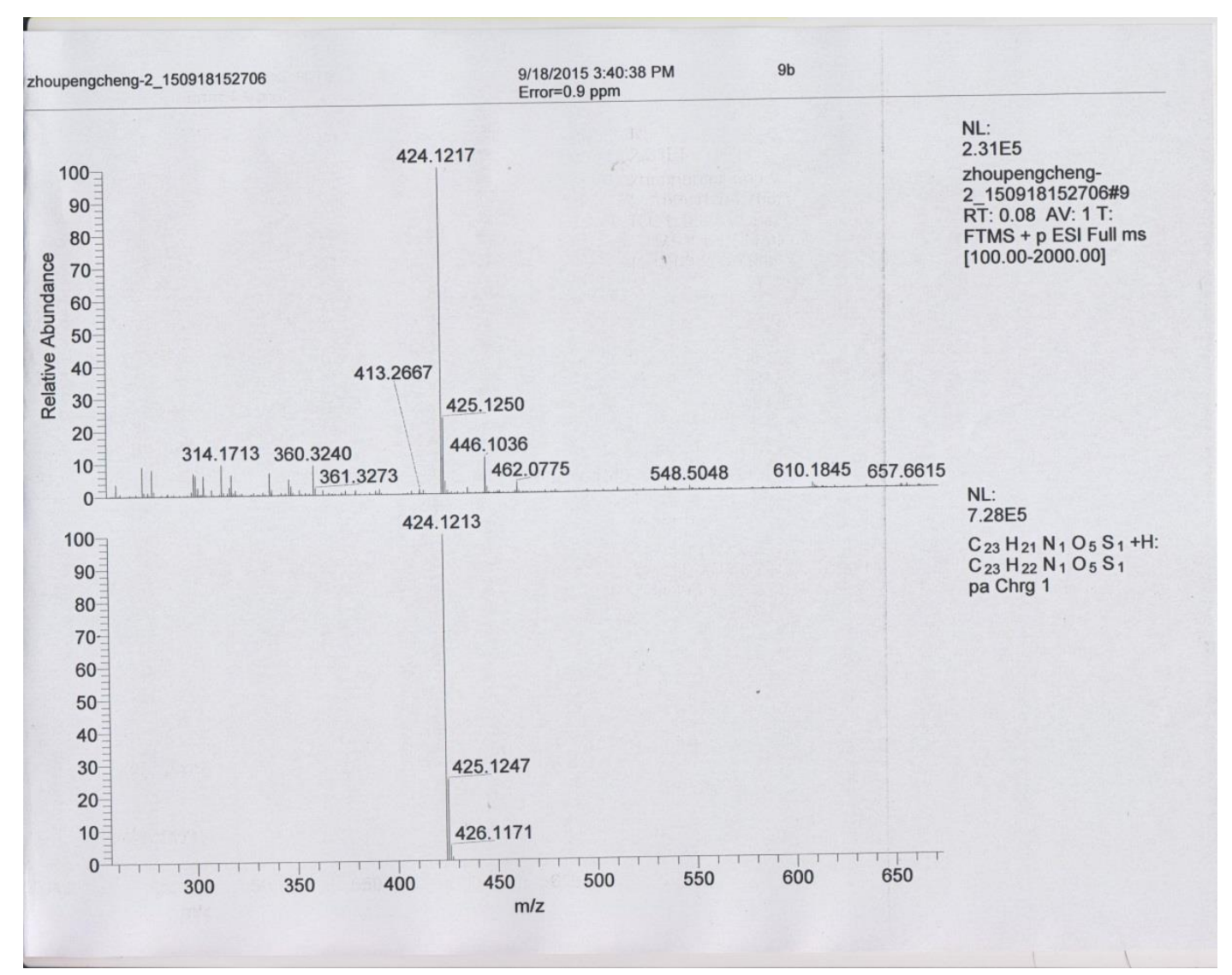

Figure S49 HRMS of compound 9b. 


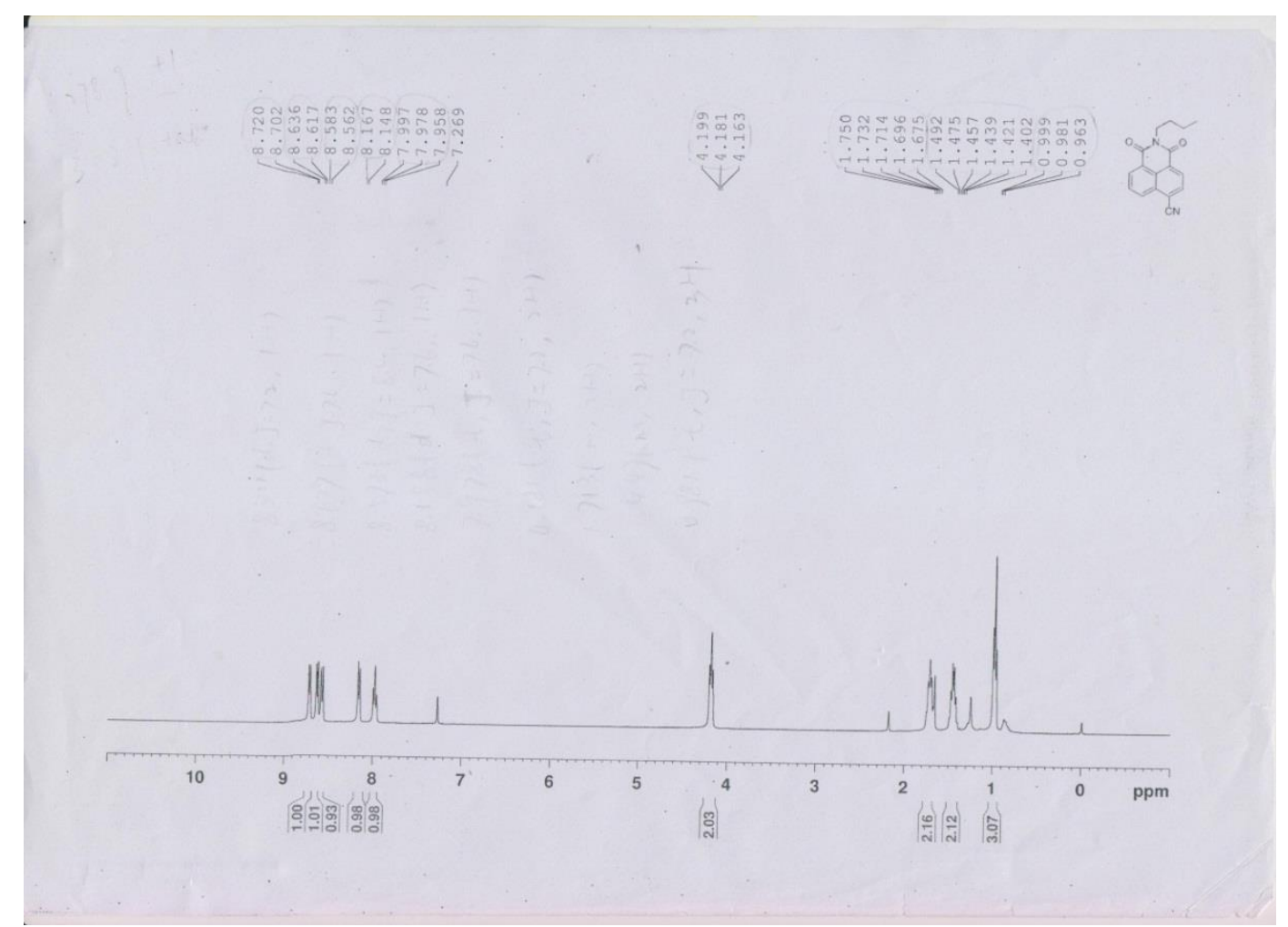

Figure S50 ${ }^{1} \mathrm{H}$ NMR of compound 10.

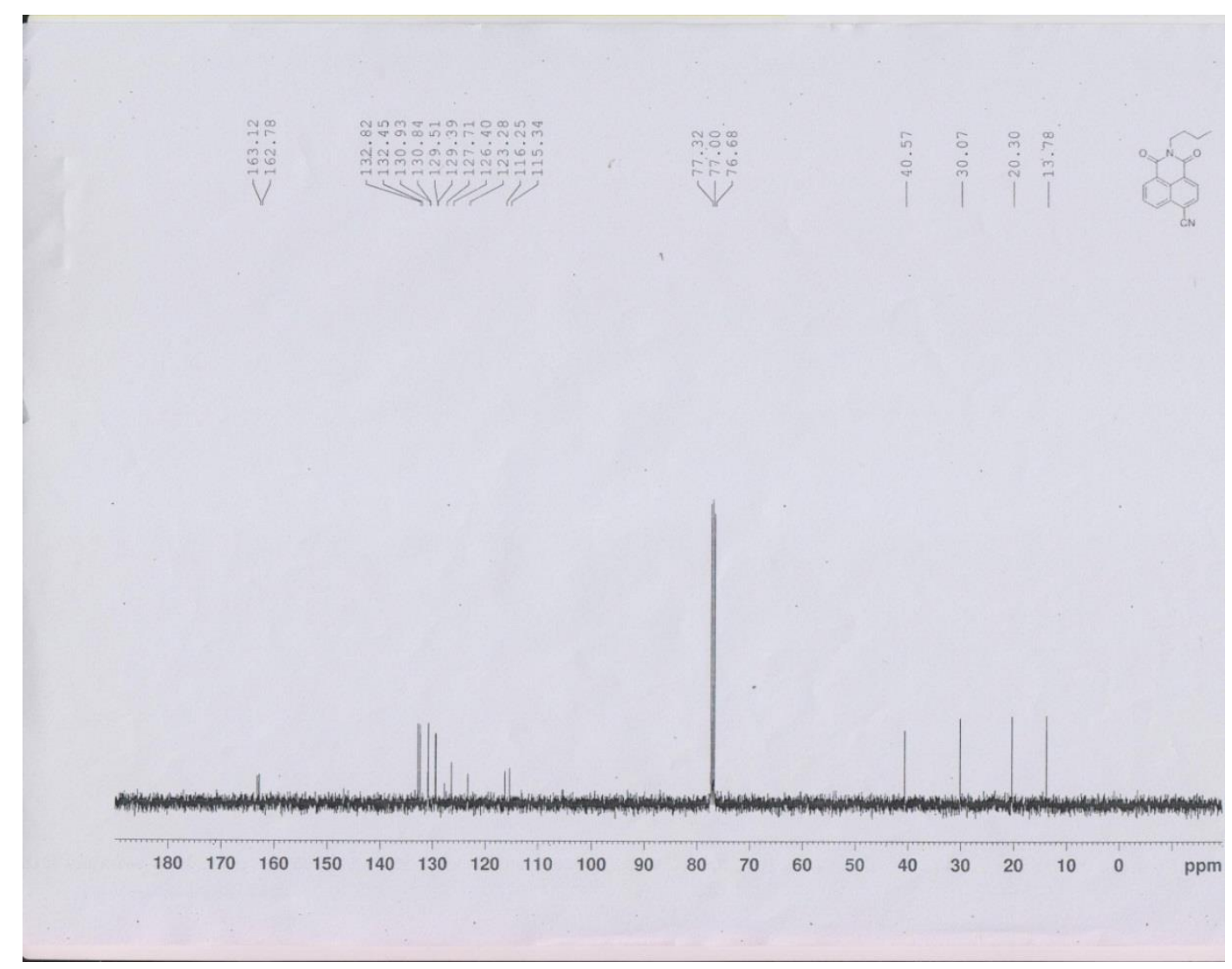

Figure S51 ${ }^{13} \mathrm{C}$ NMR of compound $\mathbf{1 0}$. 


\section{Generic Display Report}

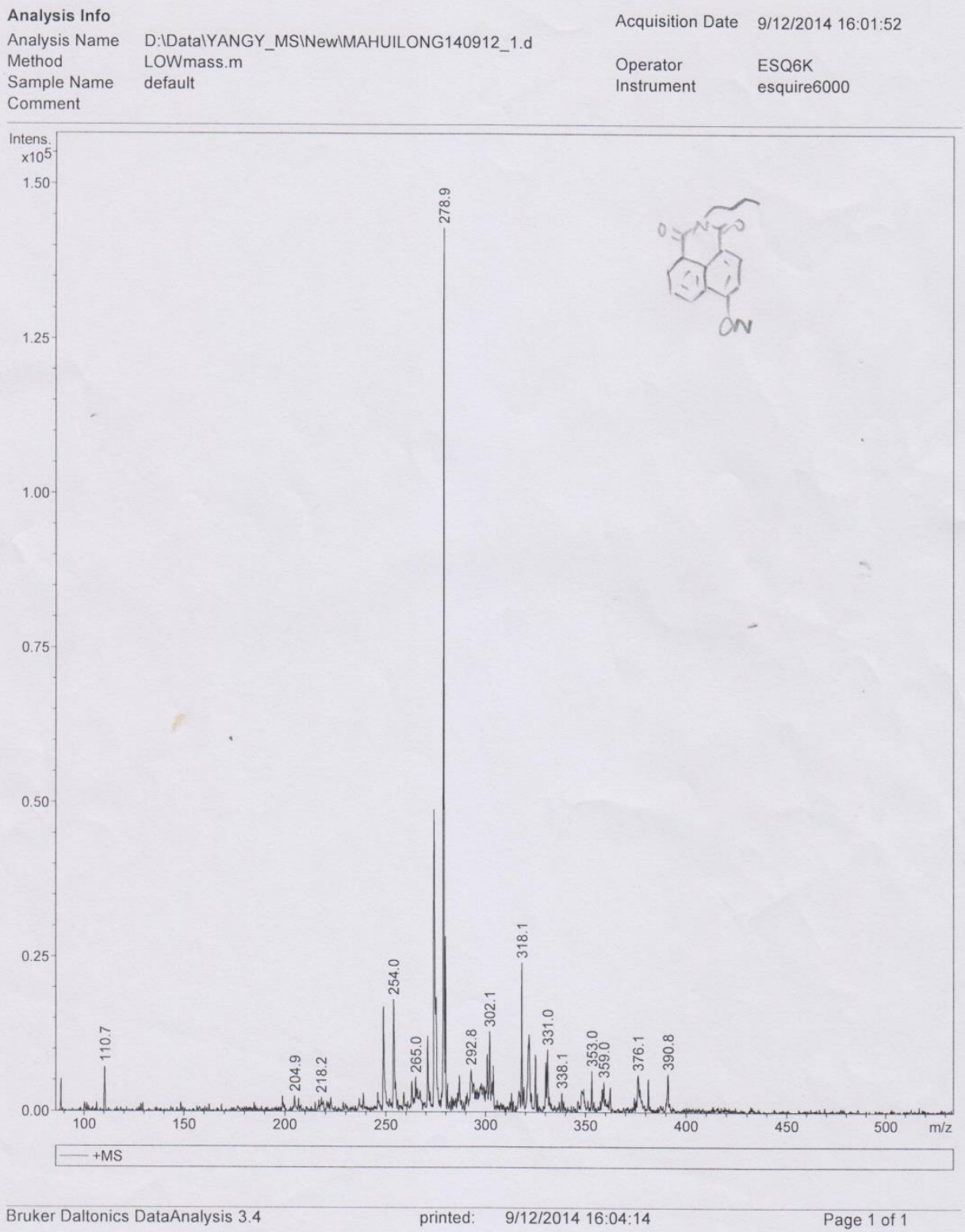

Figure S52 ESI-MS of compound 10. 


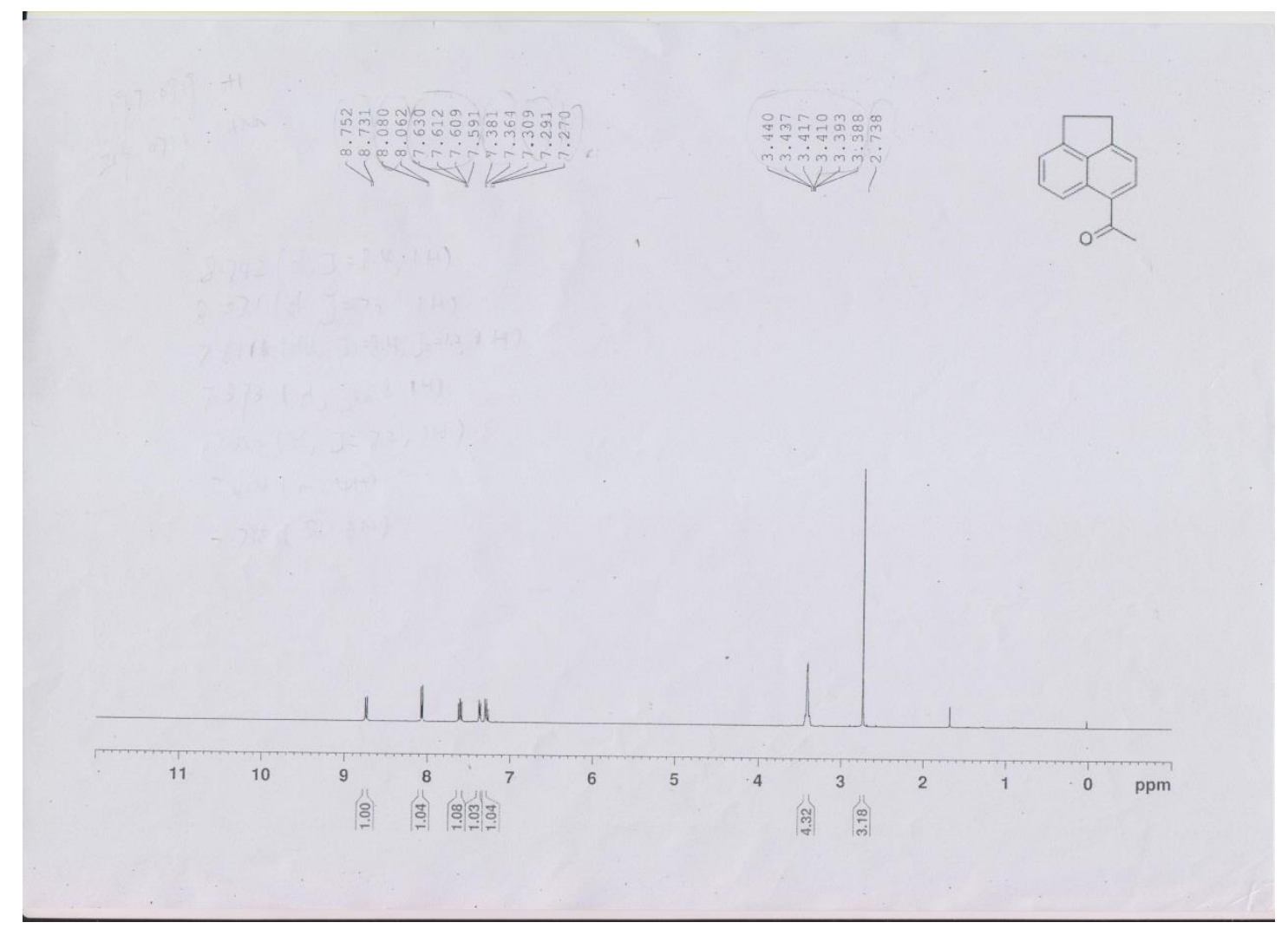

Figure S53 ${ }^{1} \mathrm{H}$ NMR of compound 11.

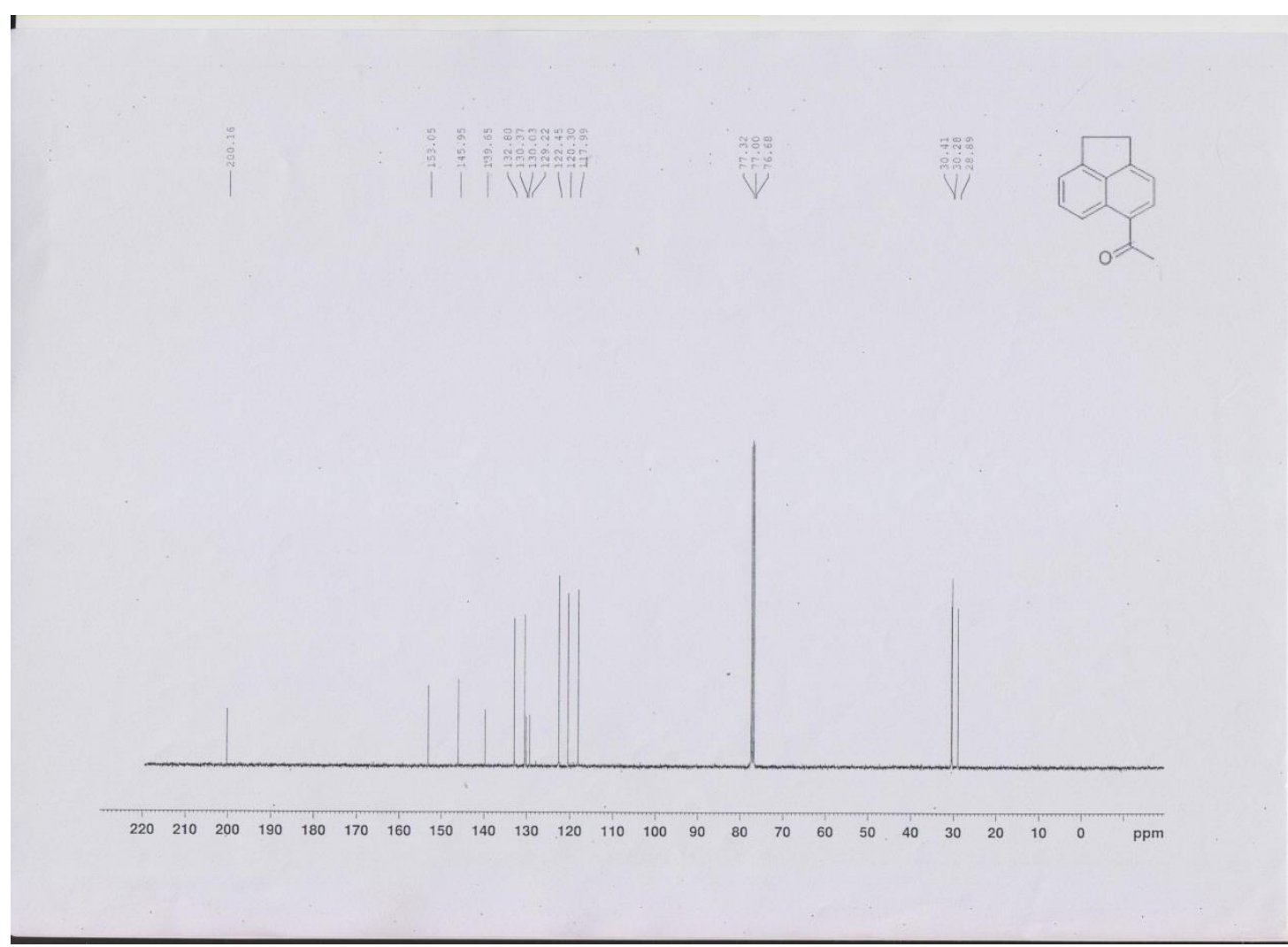

Figure S54 ${ }^{13} \mathrm{C}$ NMR of compound 11 


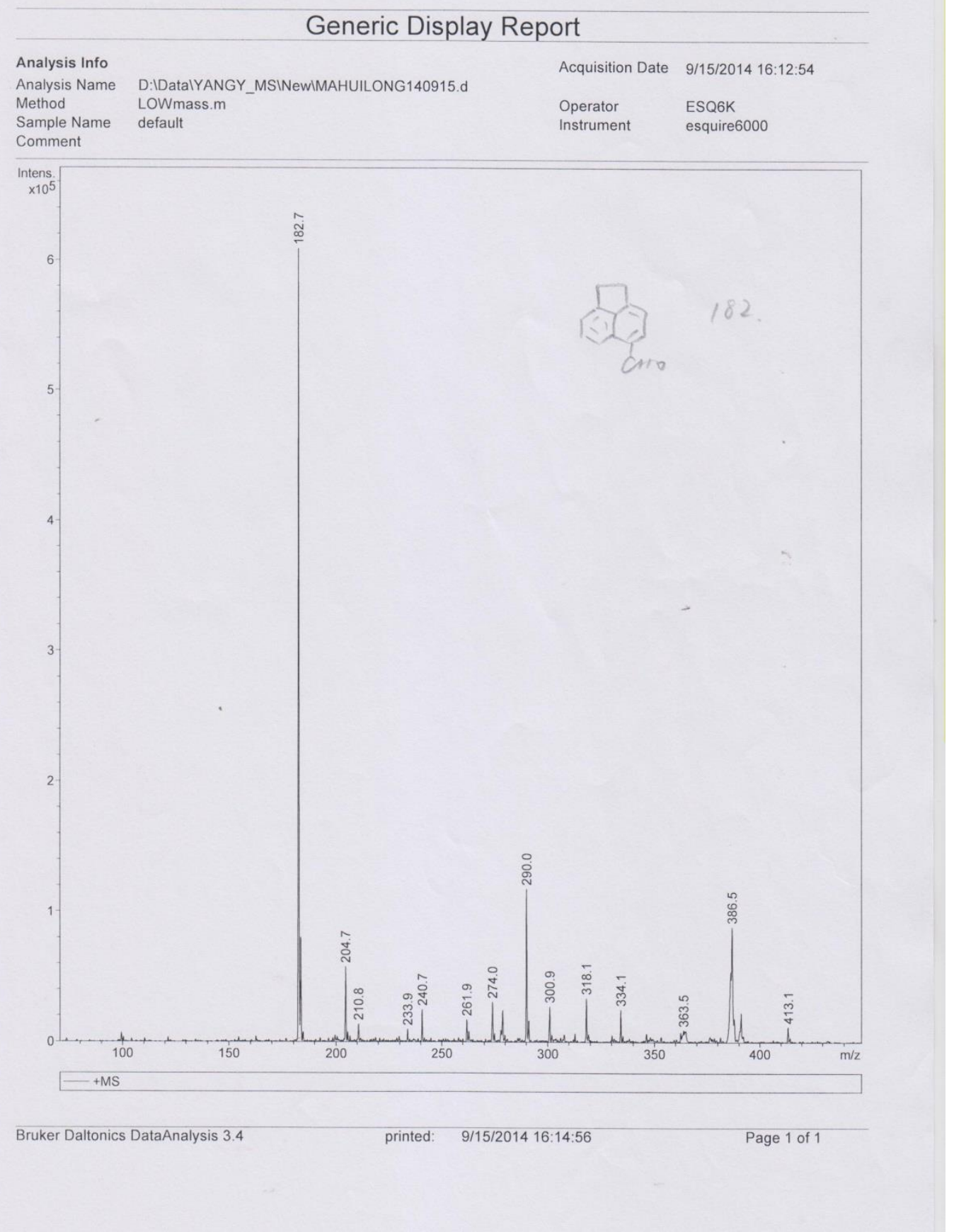

Figure S55 ESI-MS of compound 11. 


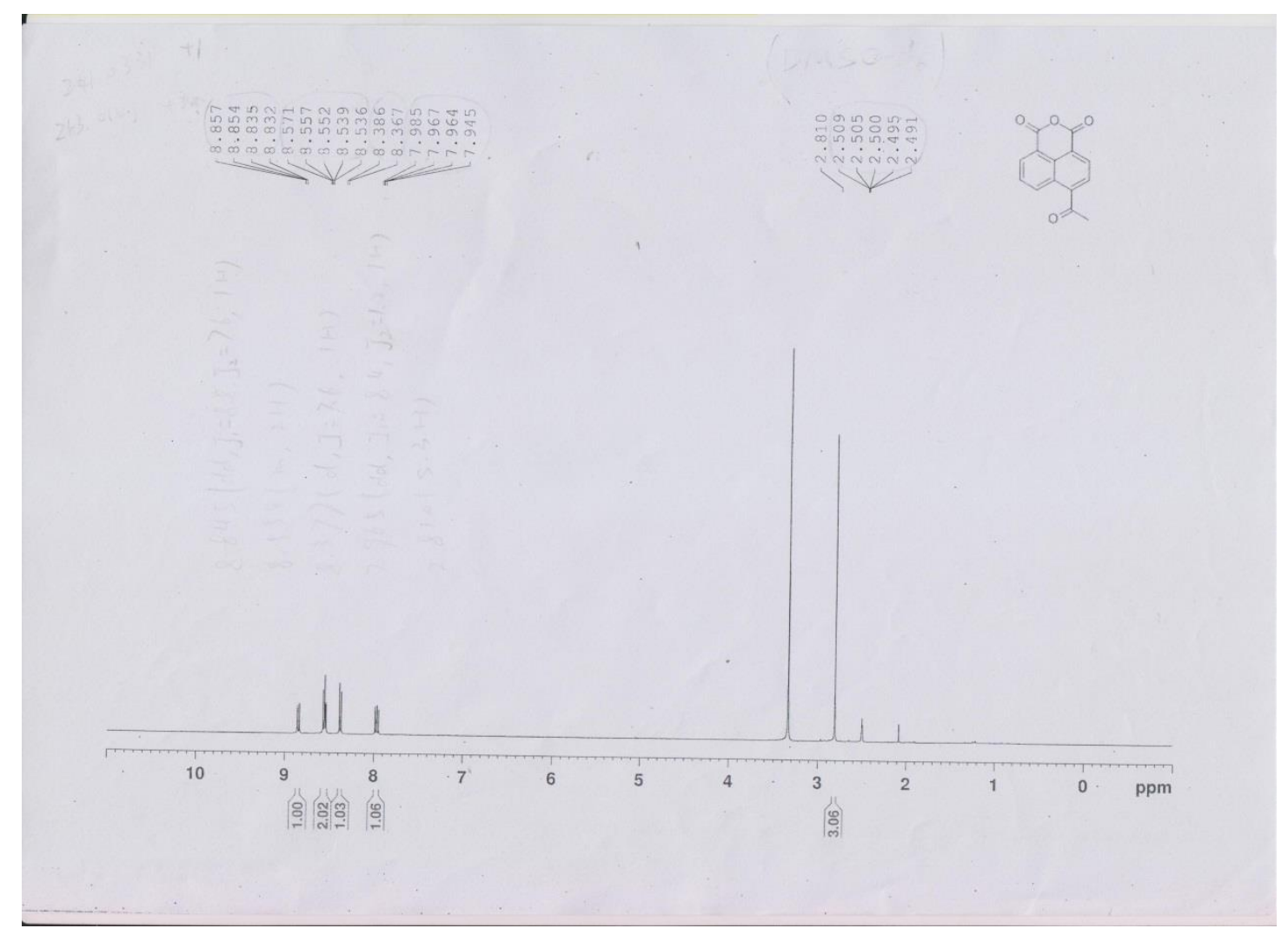

Figure S56 ${ }^{1} \mathrm{H}$ NMR of compound $\mathbf{1 2}$.

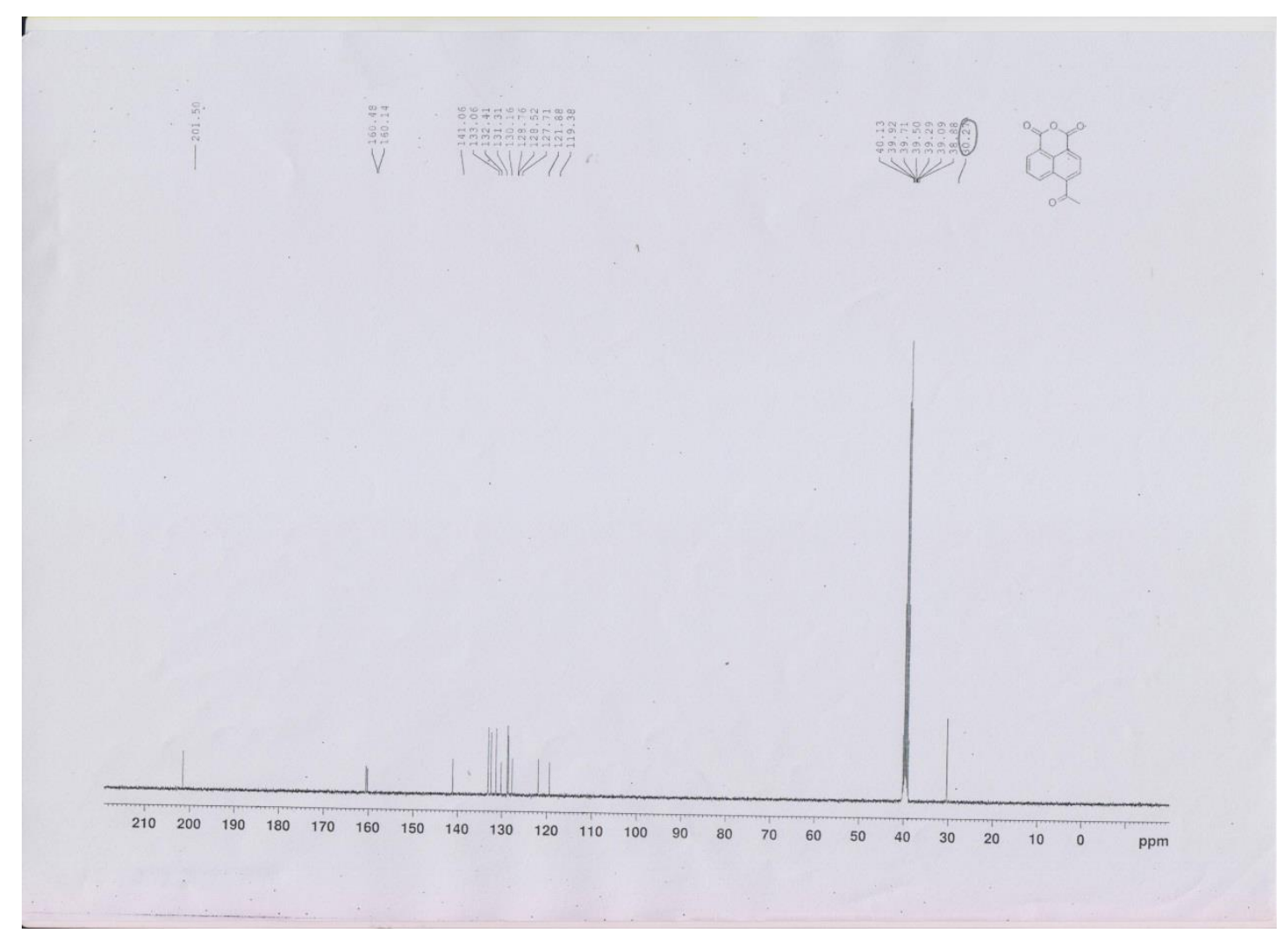

Figure S57 ${ }^{13} \mathrm{C}$ NMR of compound $\mathbf{1 2}$. 


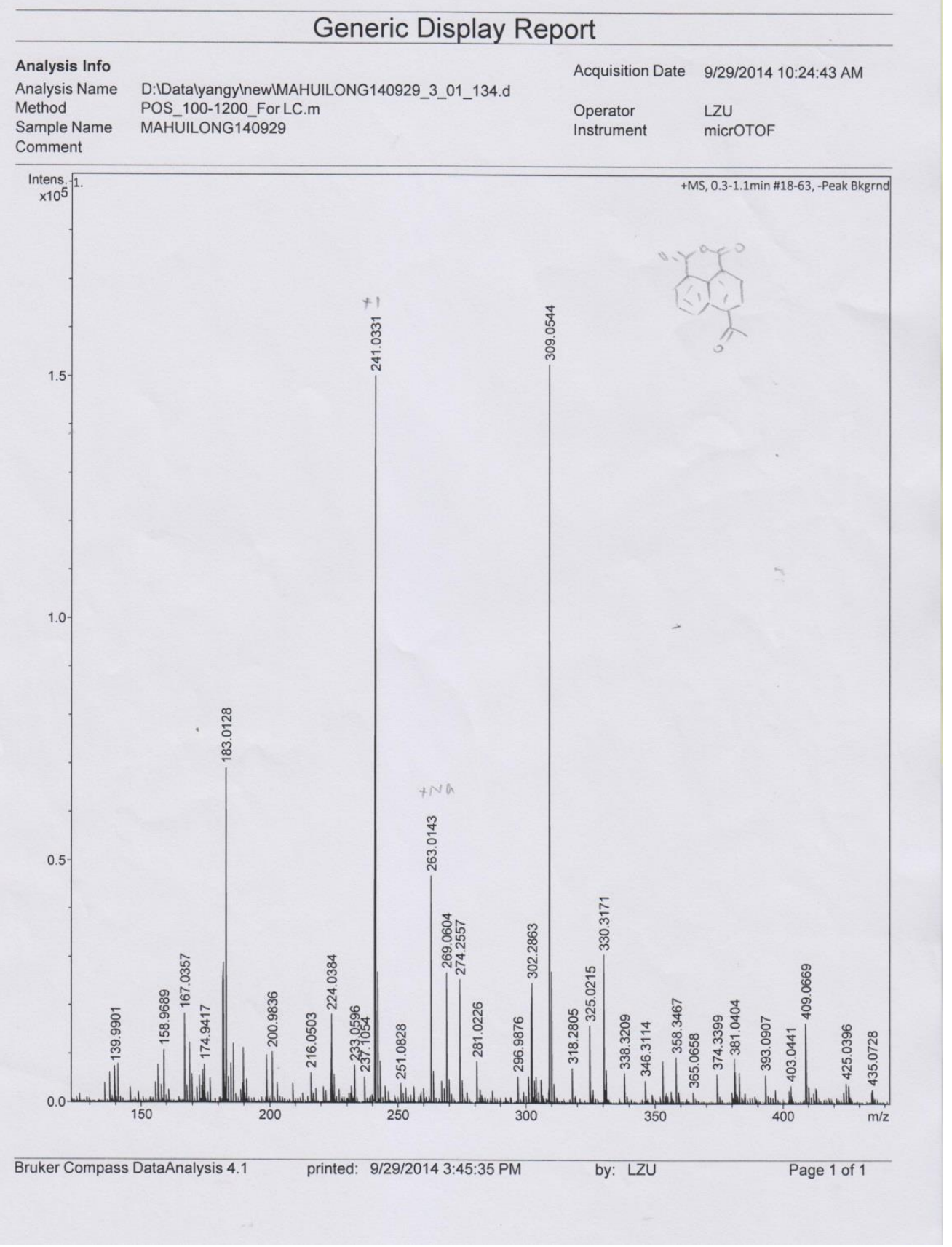

Figure S58 ESI-MS of compound 12. 


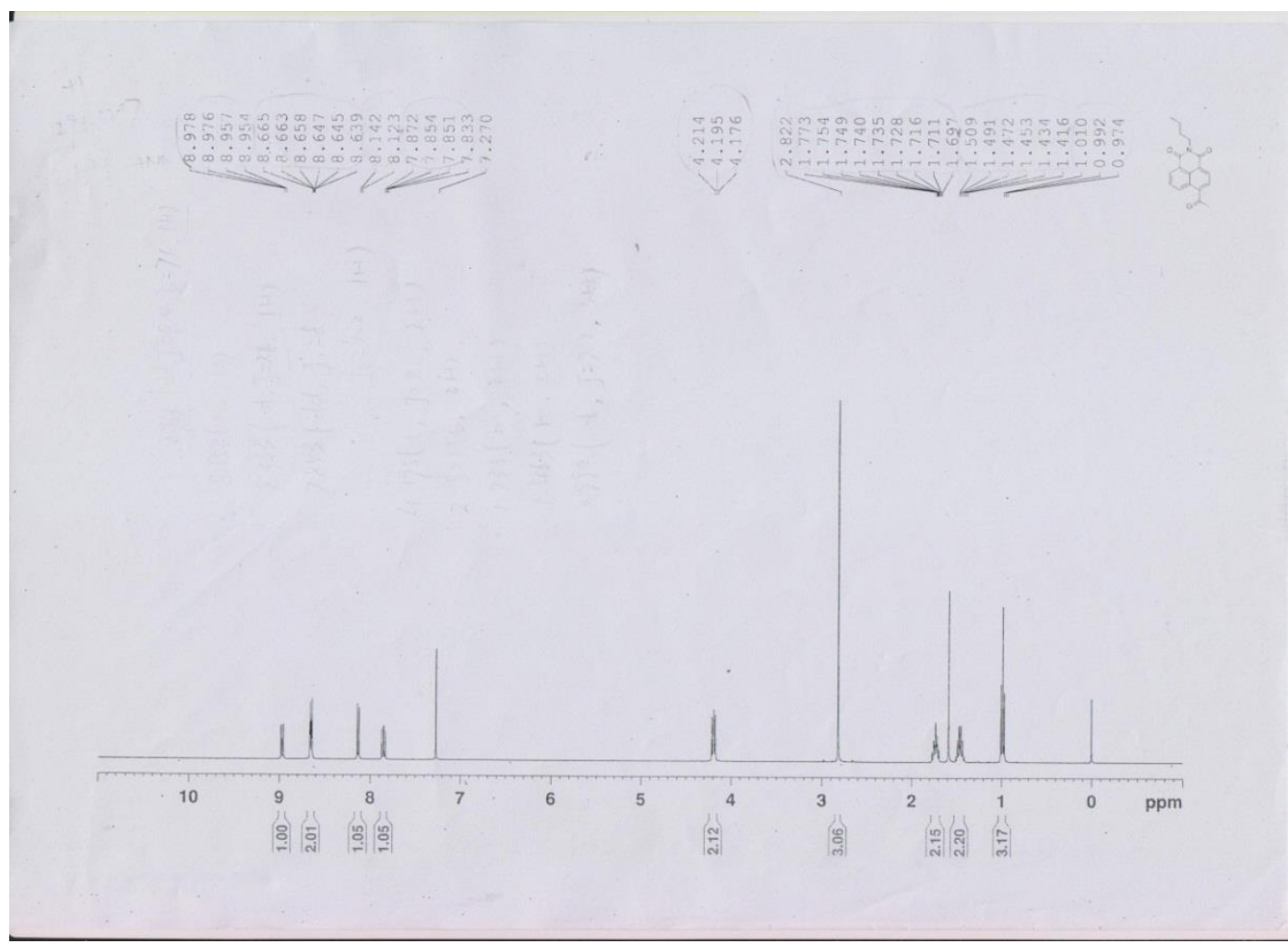

Figure S59 ${ }^{1} \mathrm{H}$ NMR of compound 13.

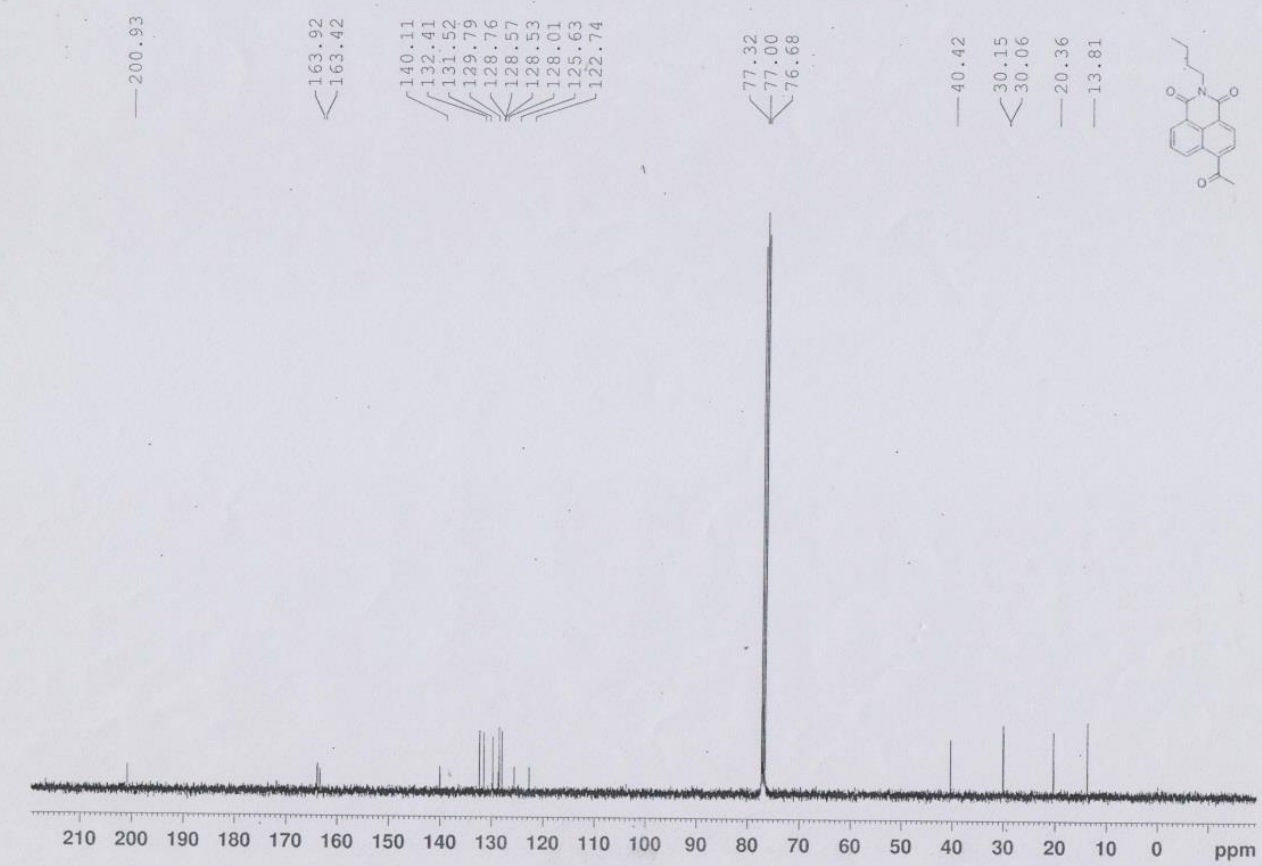

Figure S60 ${ }^{13} \mathrm{C}$ NMR of compound 13. 
Analysis Info

Analysis Name

Method

Sample Name

Comment

D:IDatalyangylnewIMAHUILONG140926_5_01_77. POS_100-1200_For LC.m

MAHUILONG140926

Acquisition Date 9/26/2014 12:39:59 PM

Comment

Intens.

$\times 10^{5}$

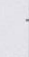

5-

$+1$

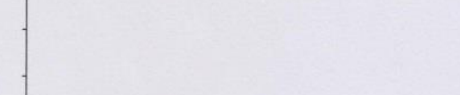

4.

ฐั

$\stackrel{\infty}{m}$

Na

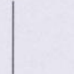

啇

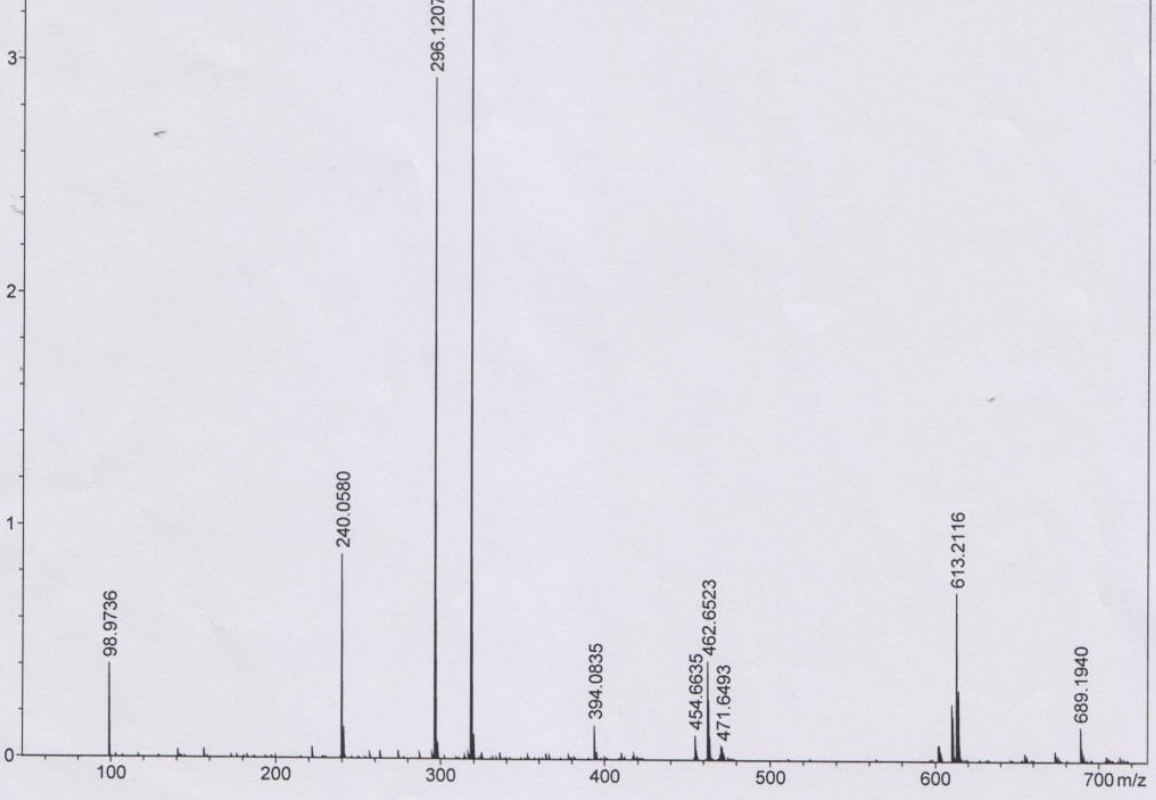

Bruker Compass DataAnalysis 4.1

printed: 9/26/2014 3:37:35 PM

by: LZU

Page 1 of 1

Figure S61 ESI-MS of compound 13. 

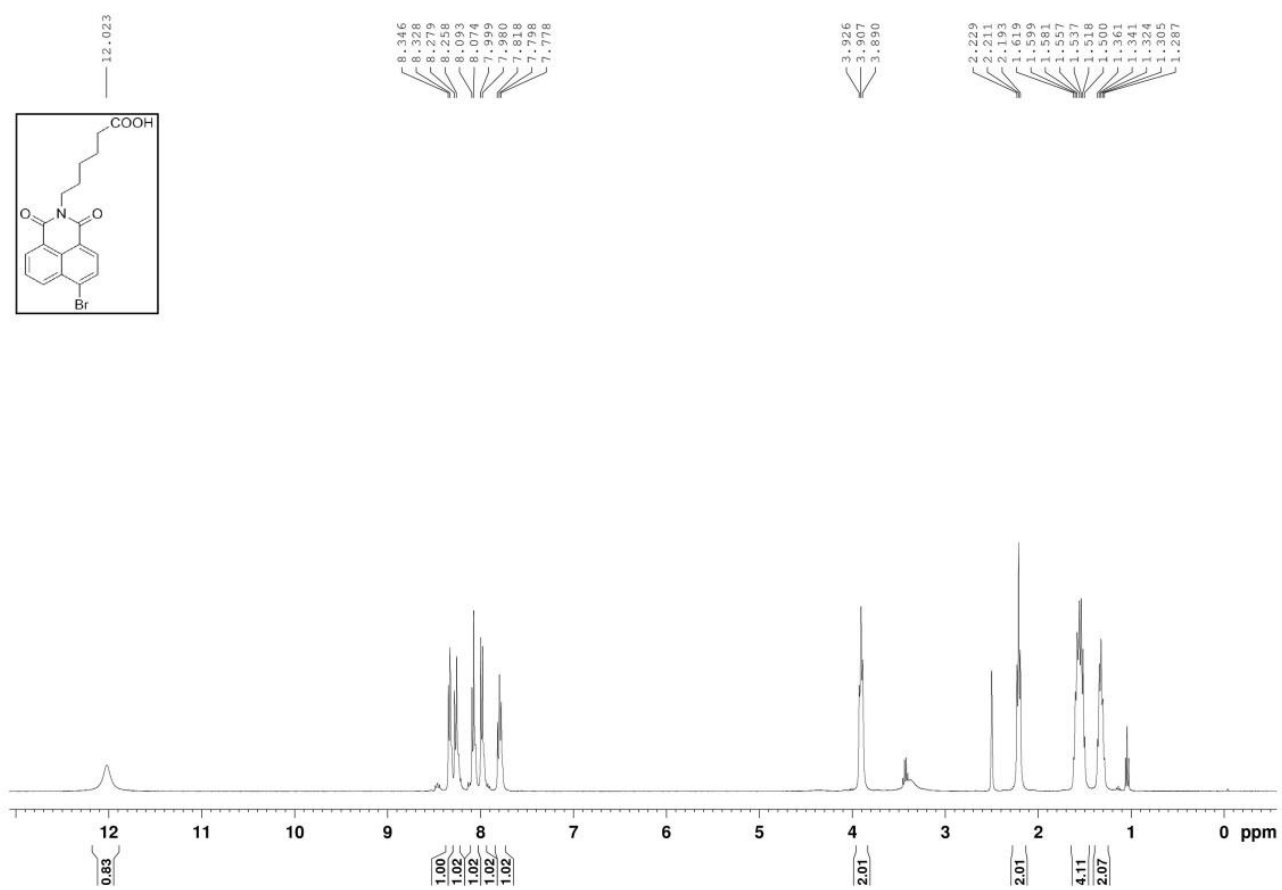

Figure S62 ${ }^{1} \mathrm{H}$ NMR of compound 14.

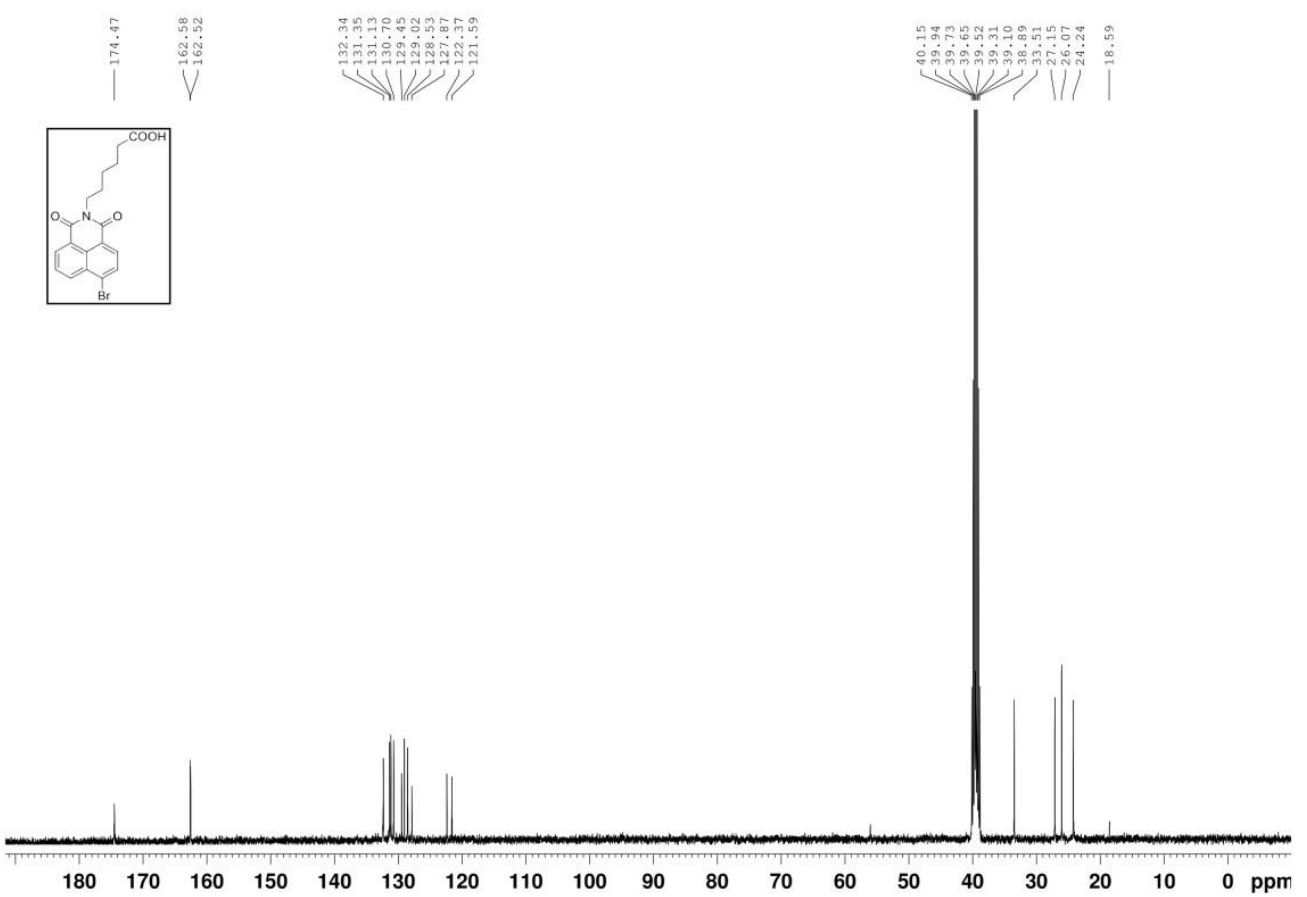

Figure S63 ${ }^{13} \mathrm{C}$ NMR of compound 14 . 


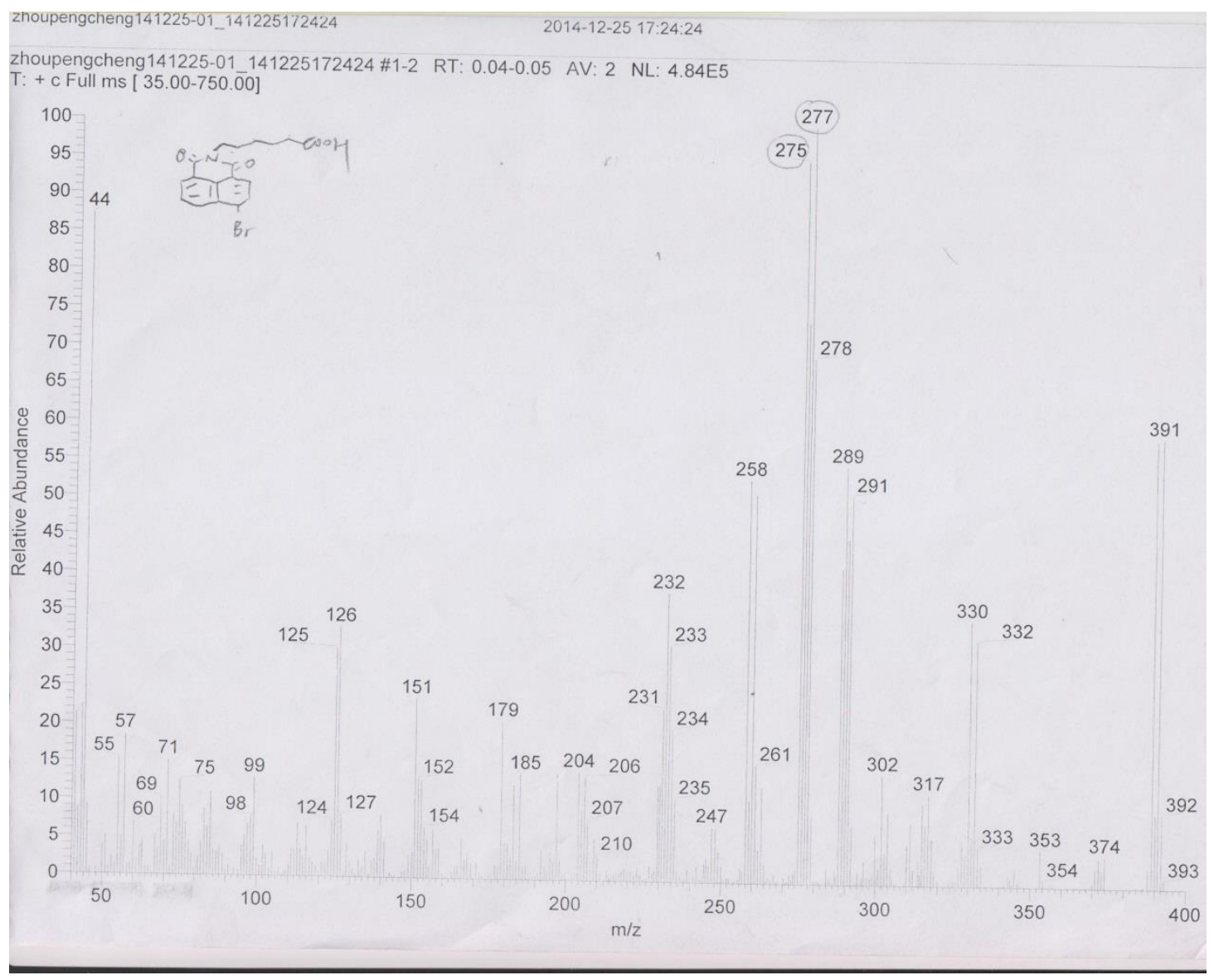

Figure S64 EI-MS of compound 14.

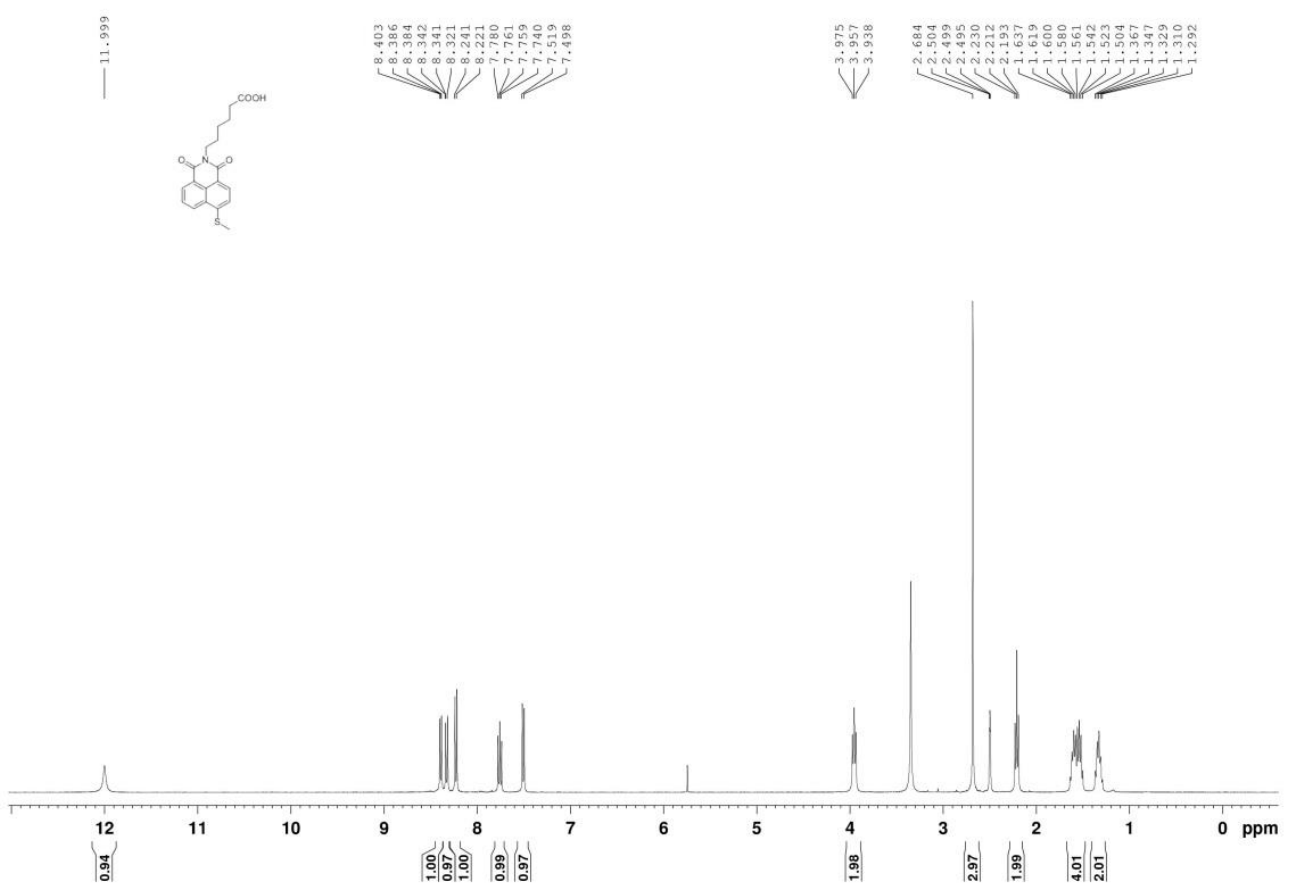

Figure S65 ${ }^{1} \mathrm{H}$ NMR of compound $\mathbf{1 5}$. 


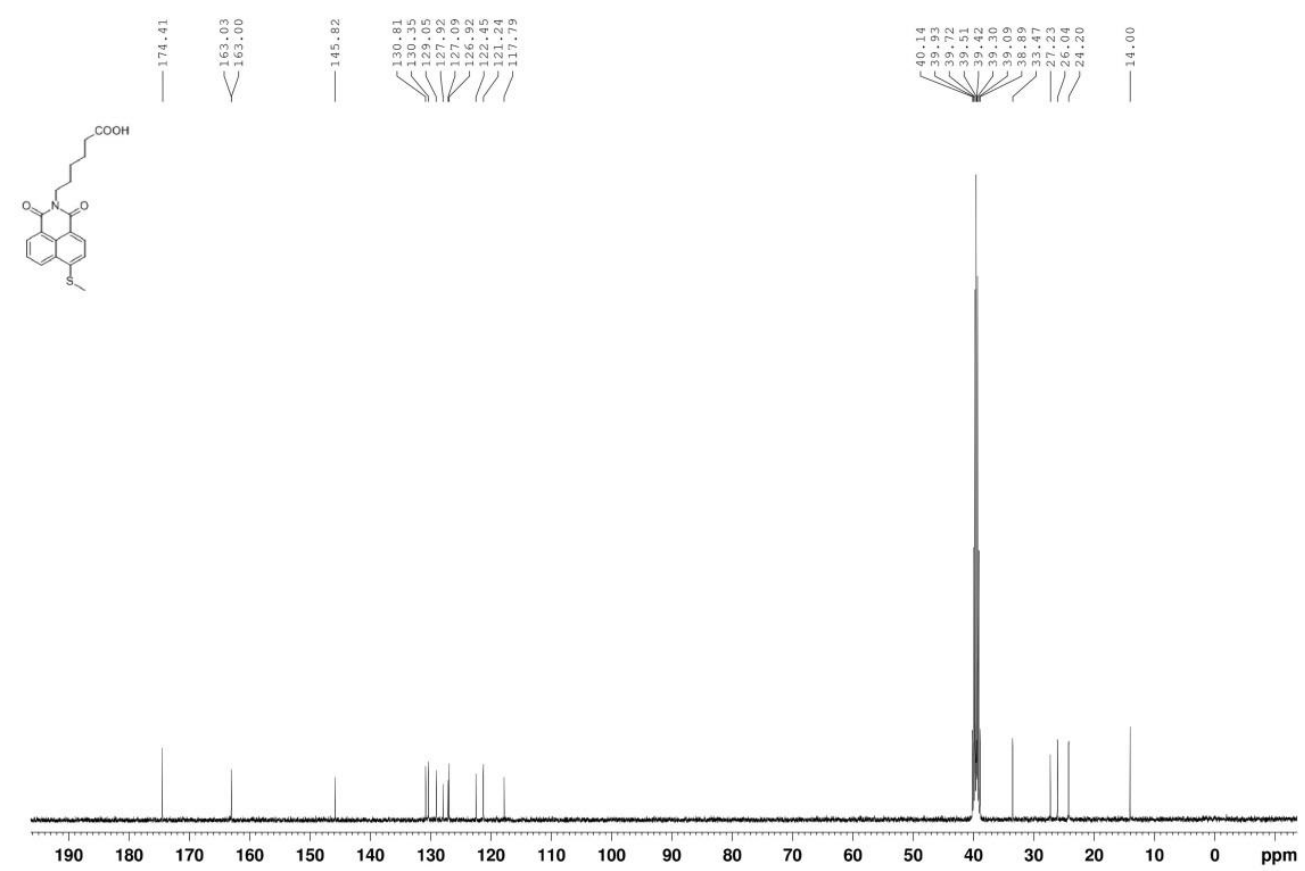

Figure S66 ${ }^{13} \mathrm{C}$ NMR of compound 15 . 


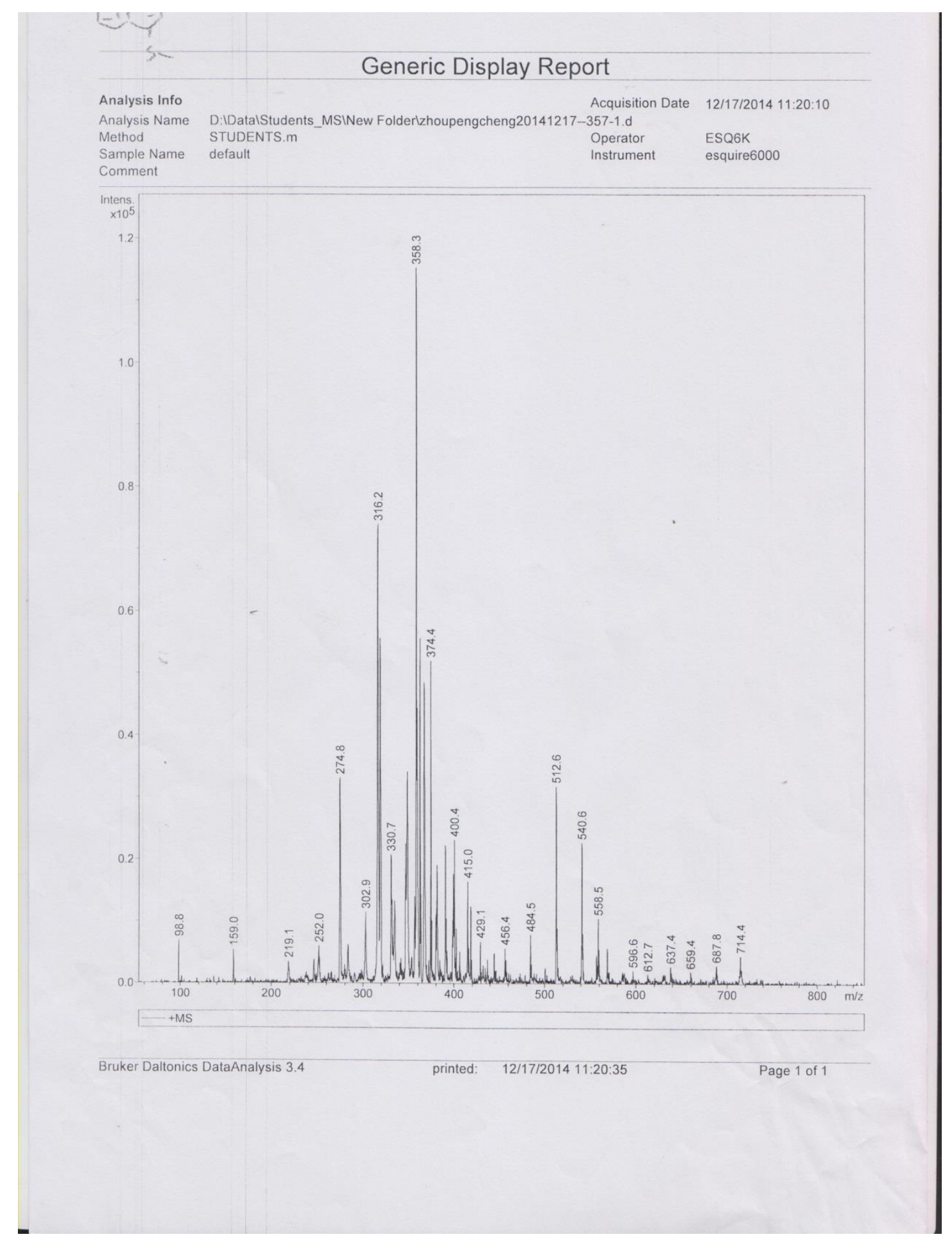

Figure S67 ESI-MS of compound 15. 


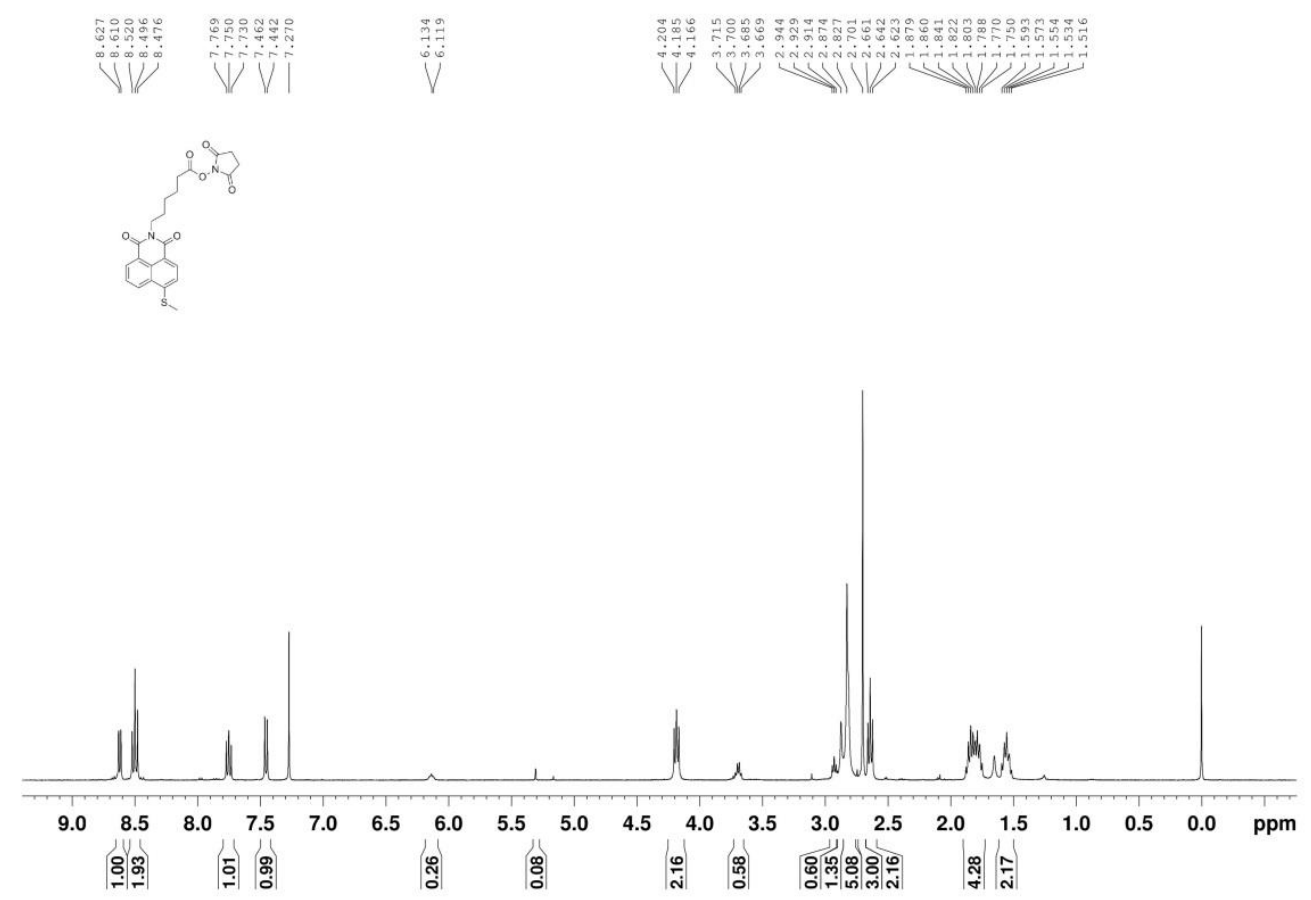

Figure S68 ${ }^{1} \mathrm{H}$ NMR of compound $\mathbf{1 6}$.

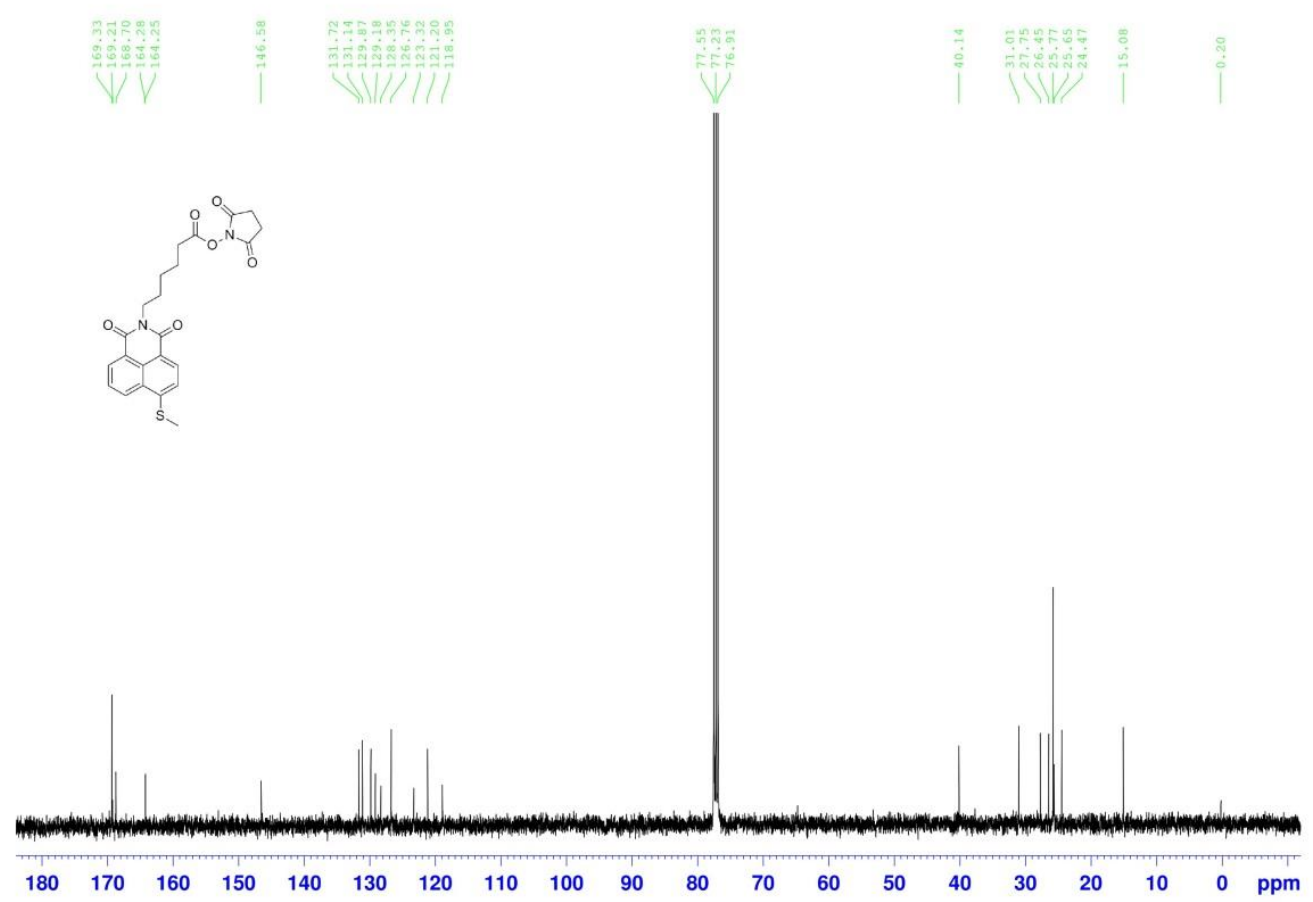

Figure S69 ${ }^{13} \mathrm{C}$ NMR of compound 16 . 


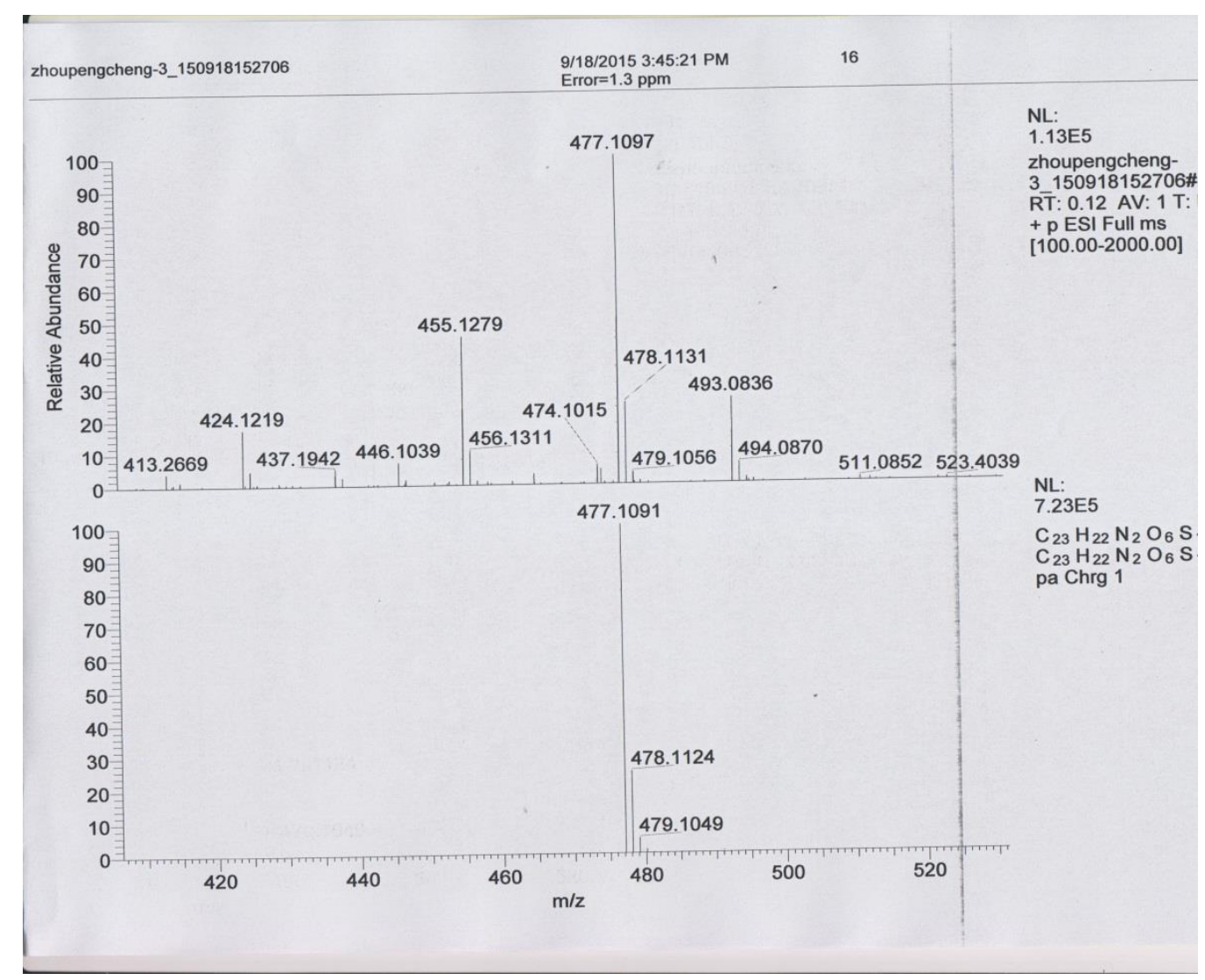

Figure S70 HRMS of compound 16.

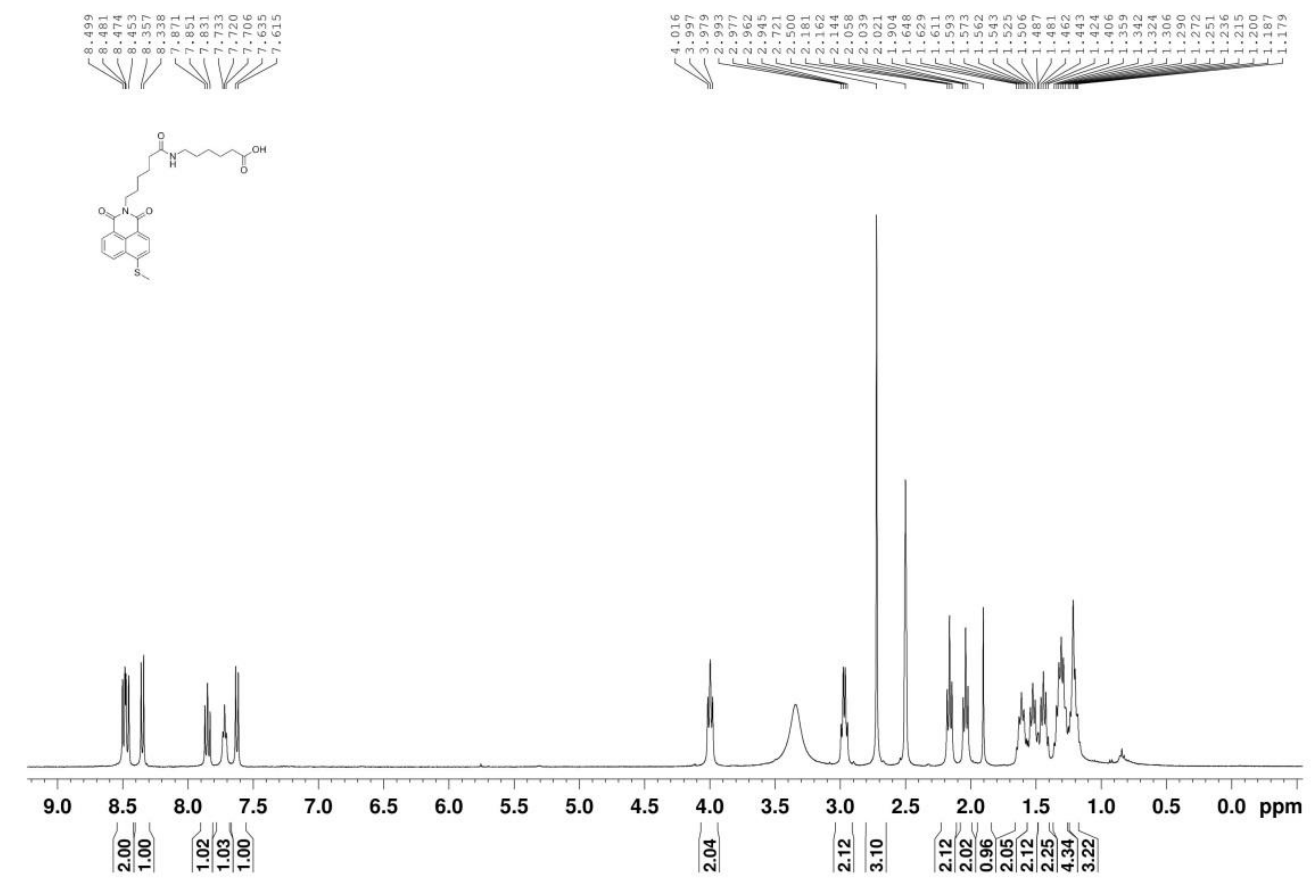

Figure S71 ${ }^{1} \mathrm{H}$ NMR of compound 17. 


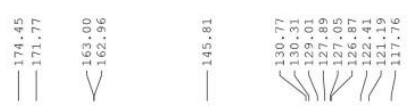

No text available

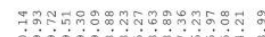

等
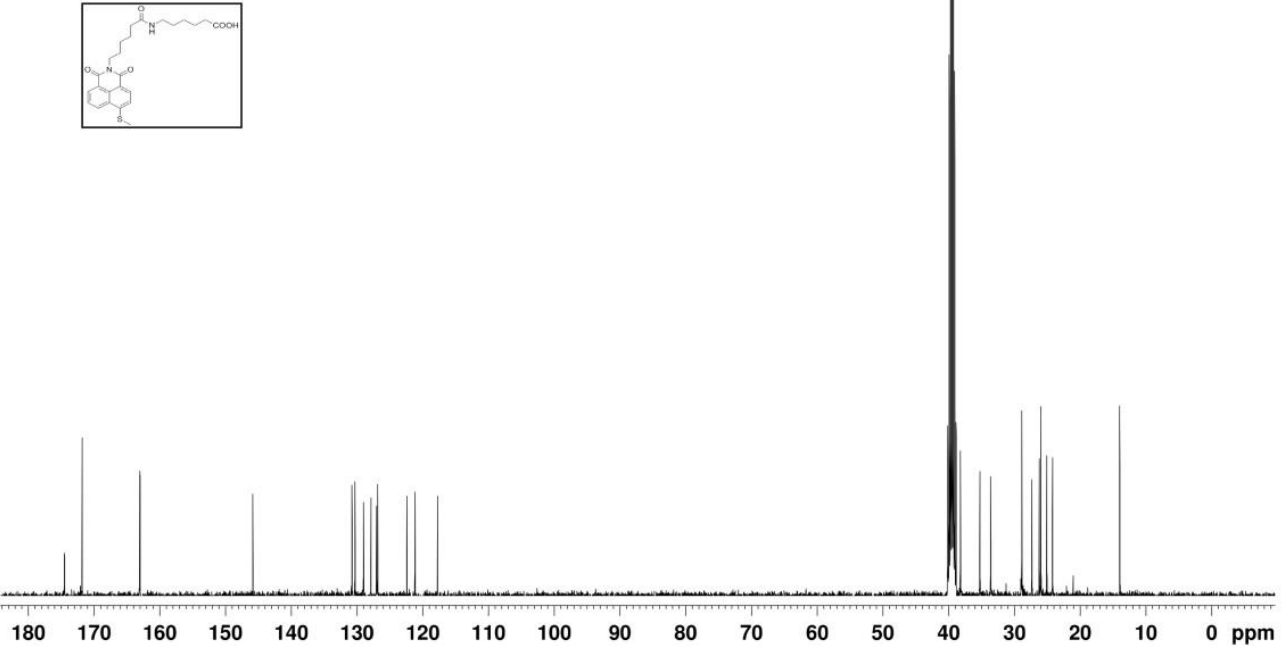

Figure S72 ${ }^{13} \mathrm{C}$ NMR of compound 17 . 


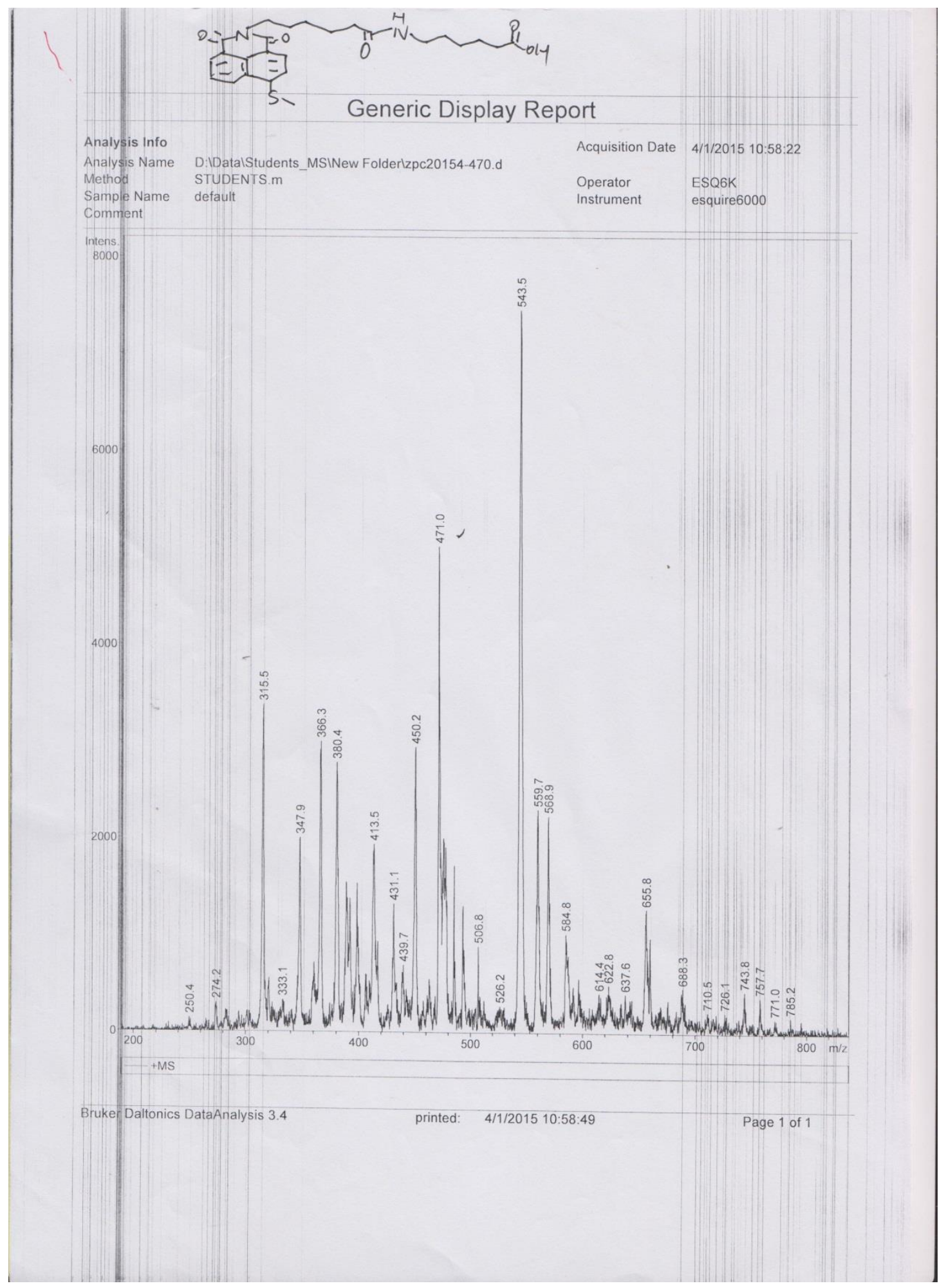

Figure S73 ESI-MS of compound 17. 

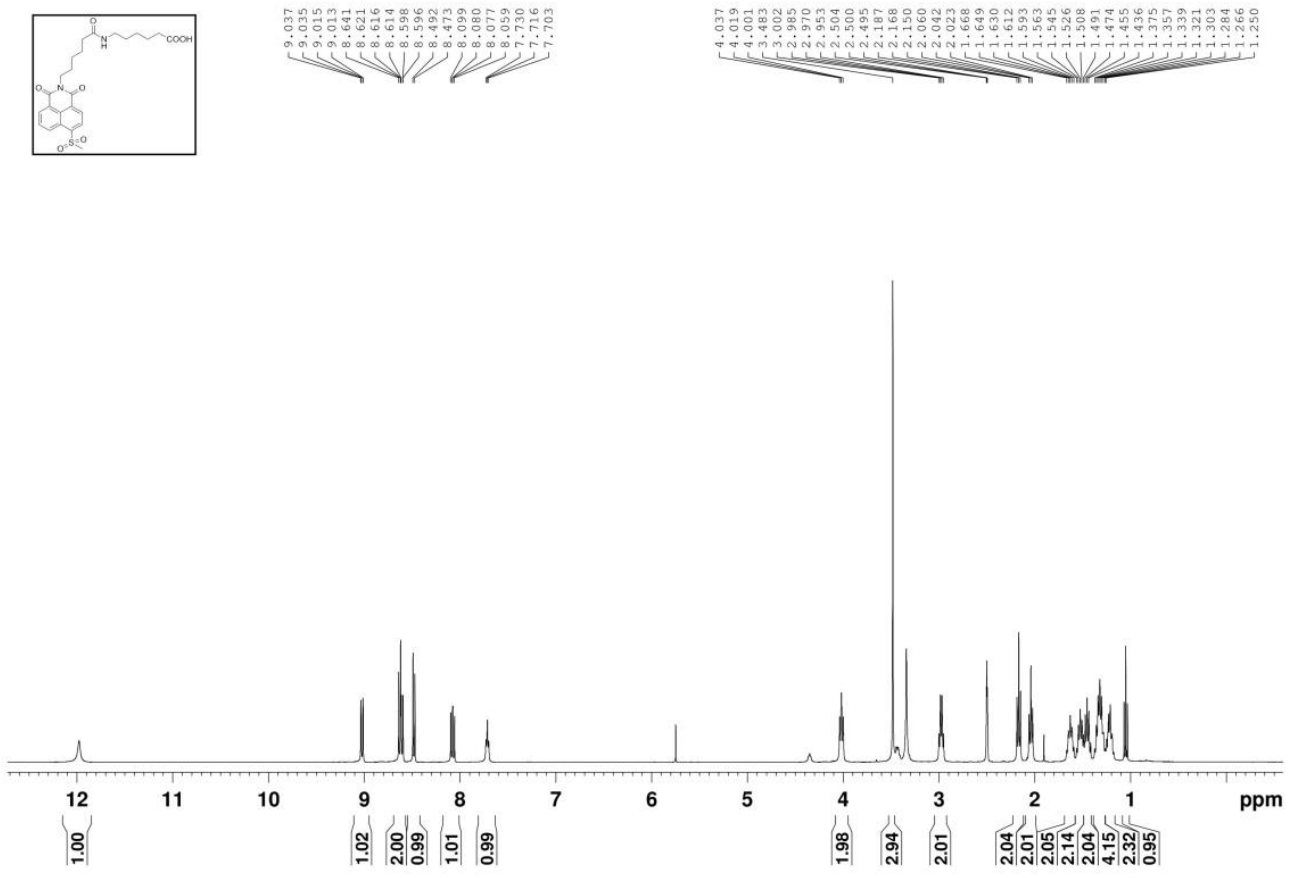

Figure S74 ${ }^{1} \mathrm{H}$ NMR of compound 18 .
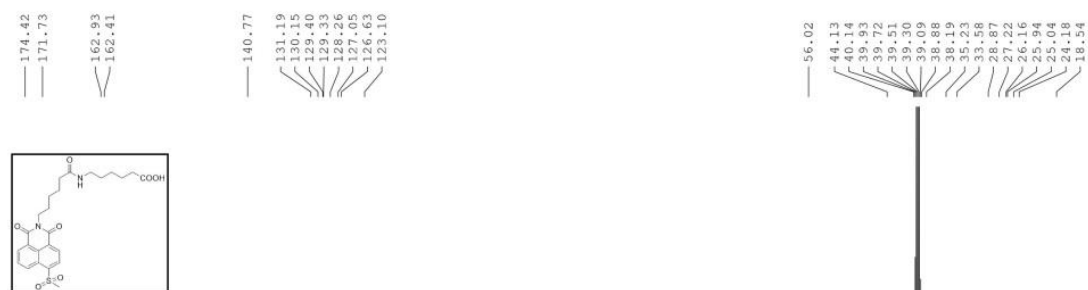

ํำ

1 Nell/lll

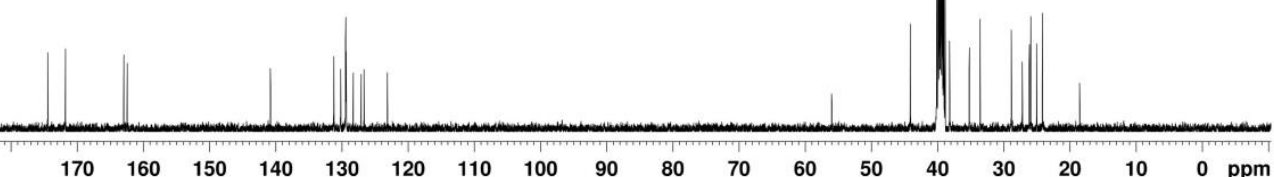

Figure S75 ${ }^{13} \mathrm{C}$ NMR of compound 18 . 


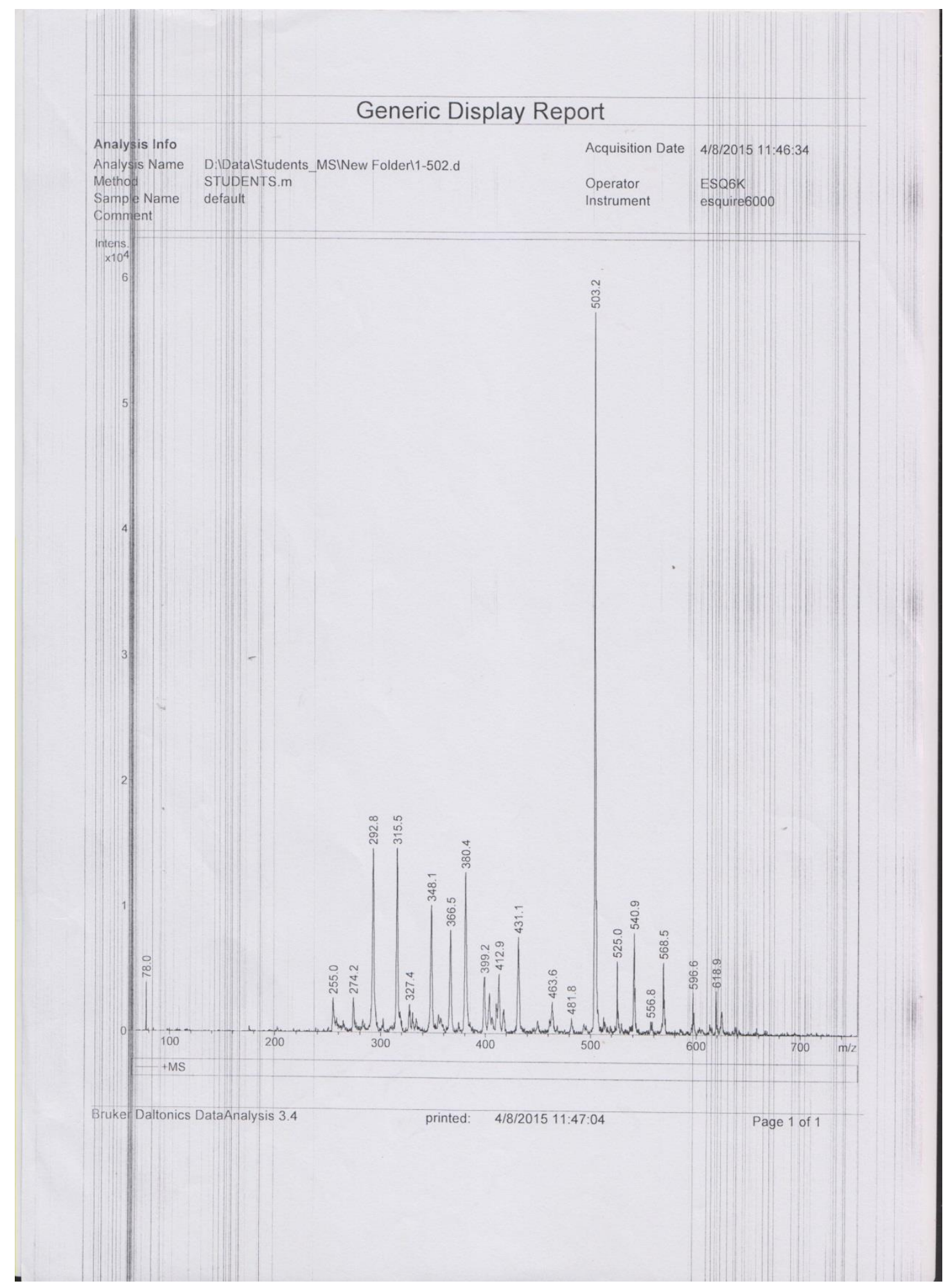

Figure S76 ESI-MS of compound 18. 


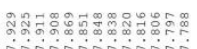

Sogring

nla
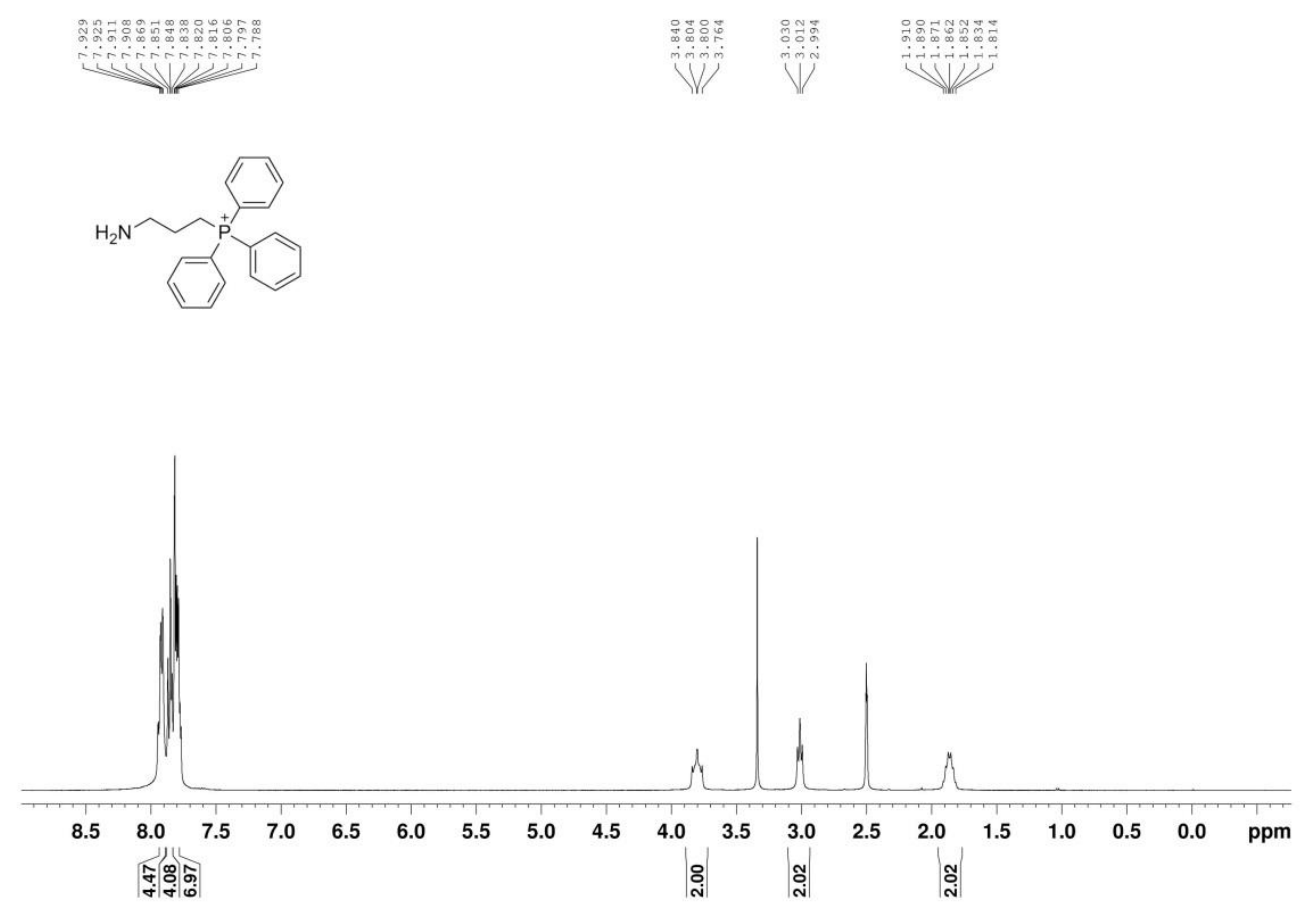

Figure S77 ${ }^{1} \mathrm{H}$ NMR of compound 19.

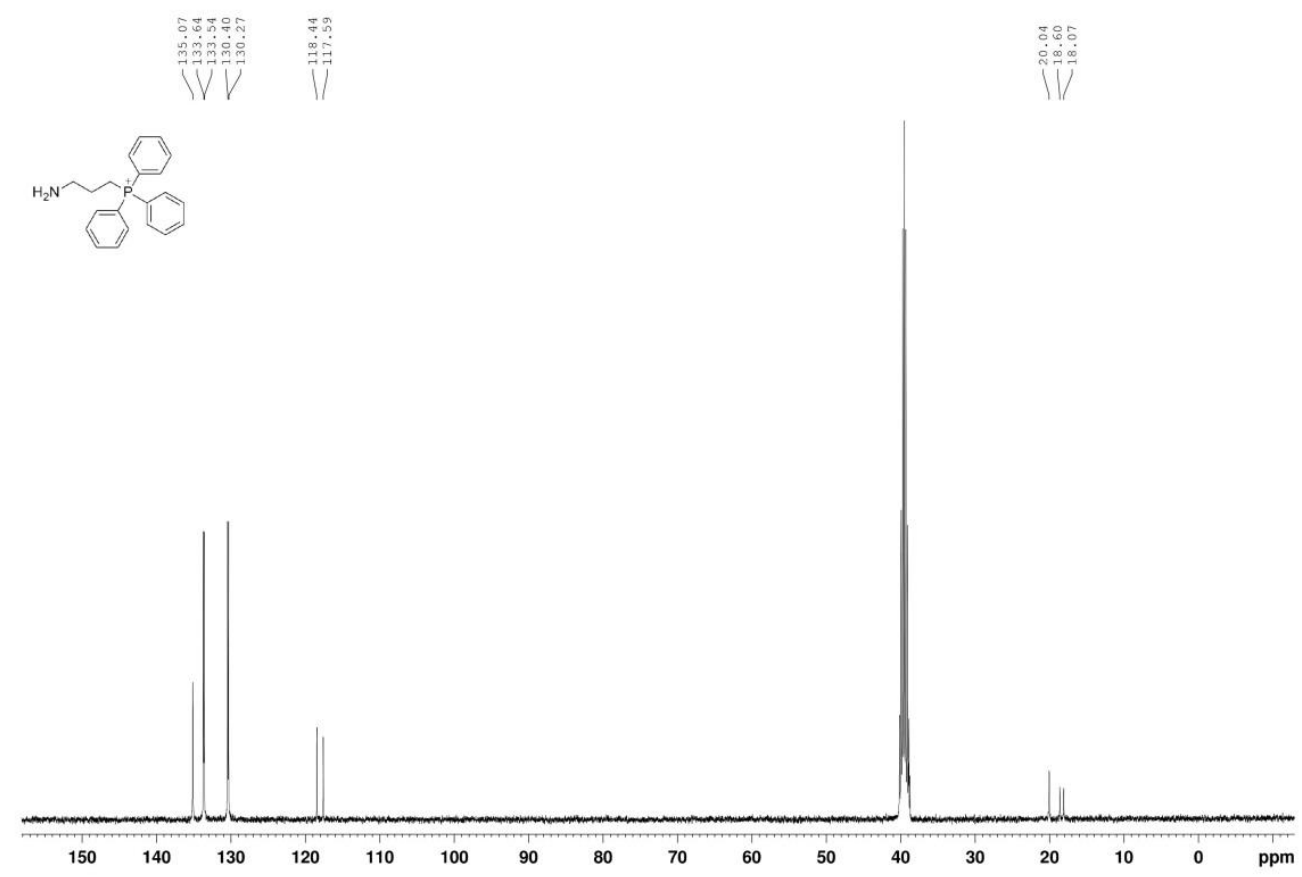

Figure S78 ${ }^{13} \mathrm{C}$ NMR of compound 19. 


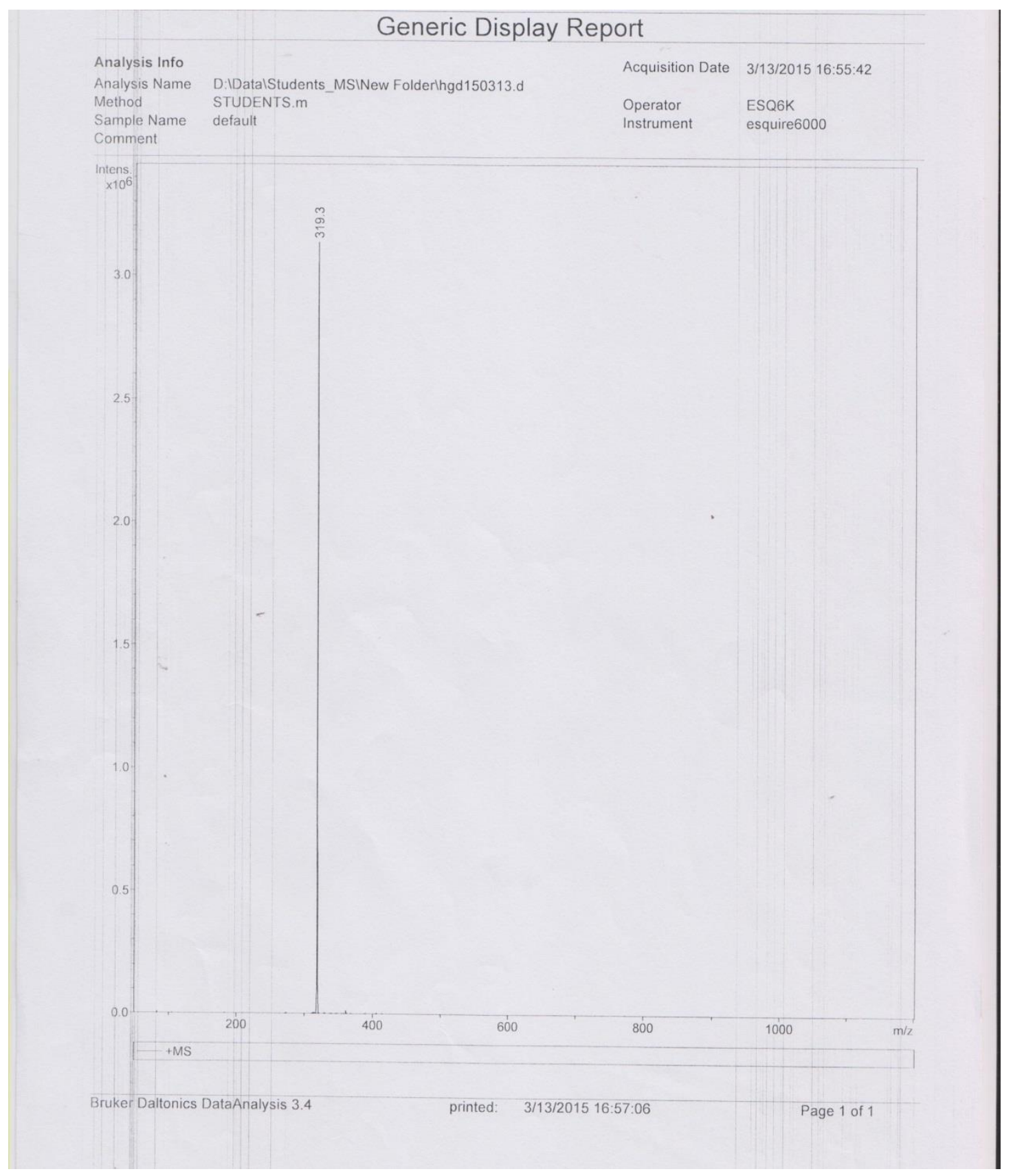

Figure S79 ESI-MS of compound 19. 


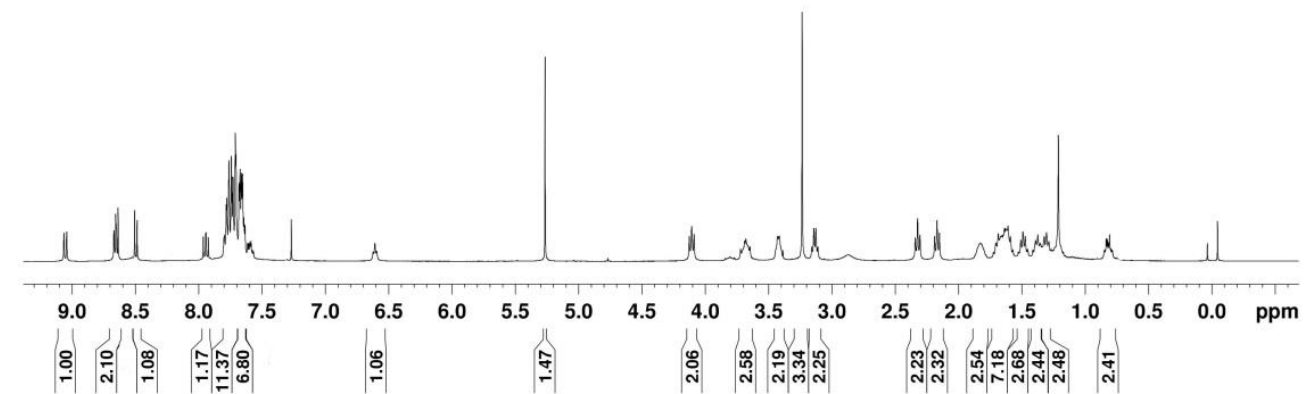

Figure S80 ${ }^{1} \mathrm{H}$ NMR of probe 20.
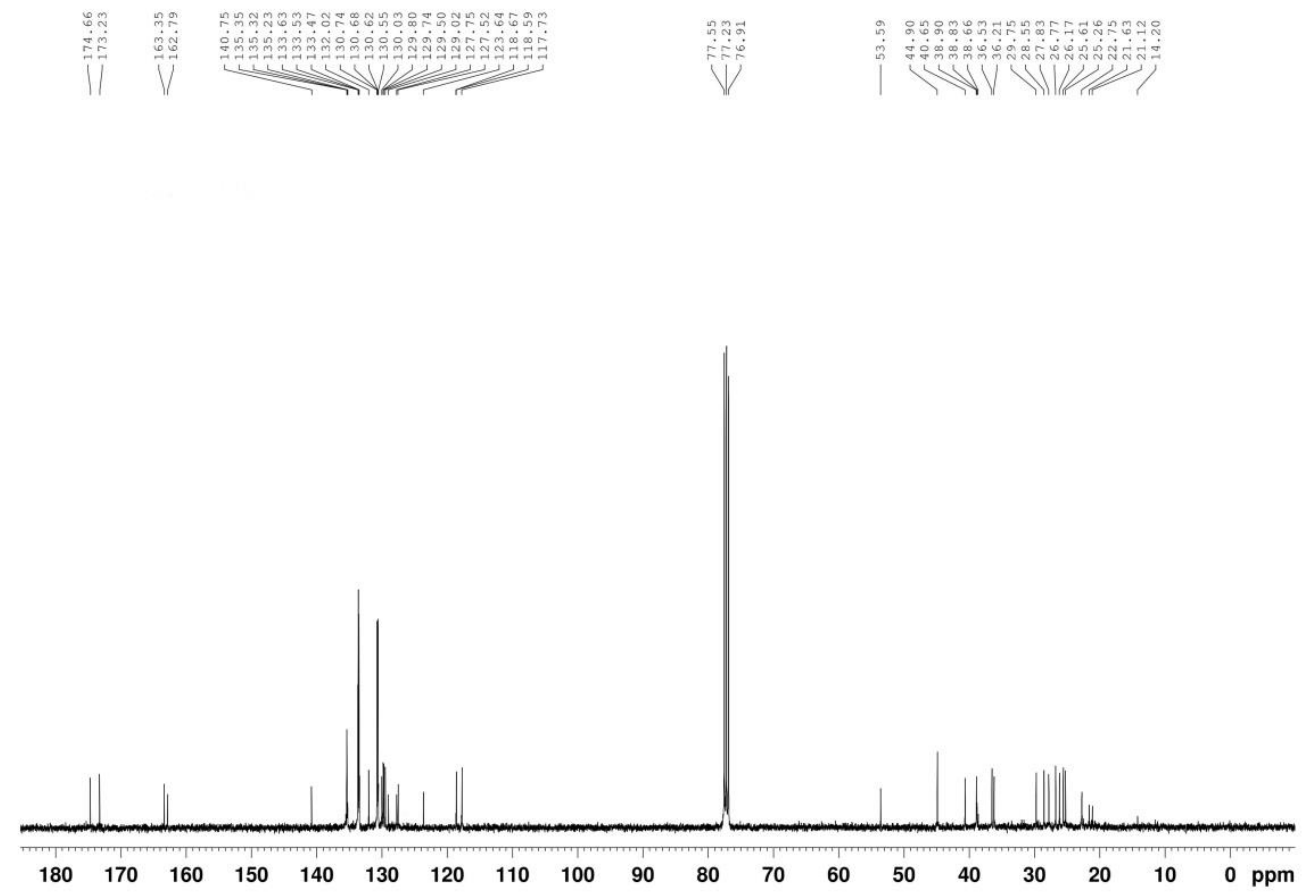

Figure S81 ${ }^{13} \mathrm{C}$ NMR of probe $\mathbf{2 0}$. 


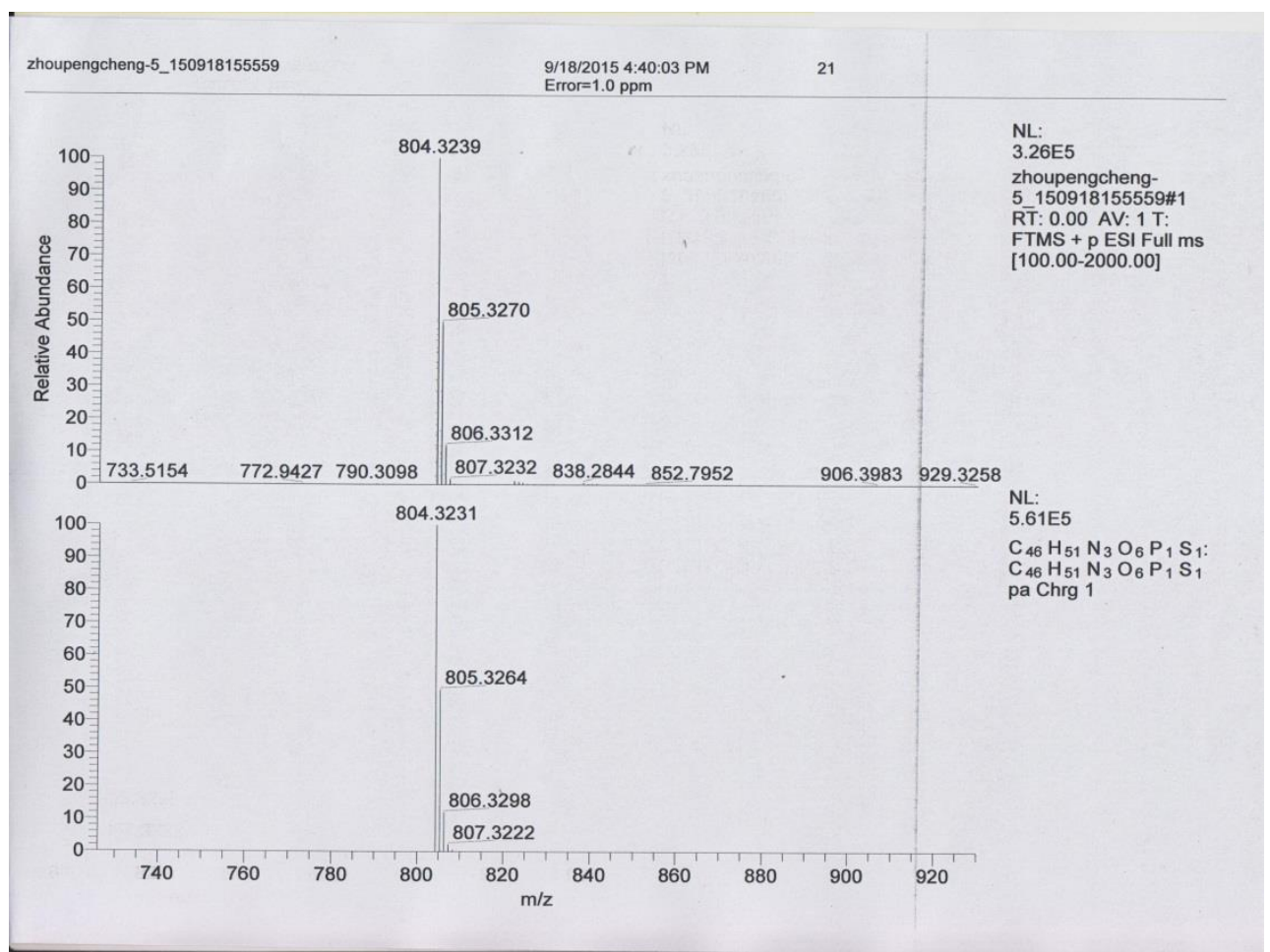

Figure S82 HRMS of compound 20.
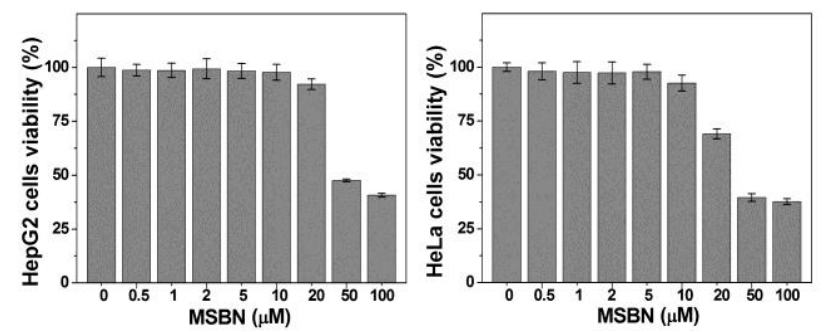

Figure S83 Cytotoxicity of MSBN to HepG2 cells and HeLa cells. The cells were treated with varying concentrations of MSBN for $24 \mathrm{~h}$, and the viability was determined by the MTT assay. 

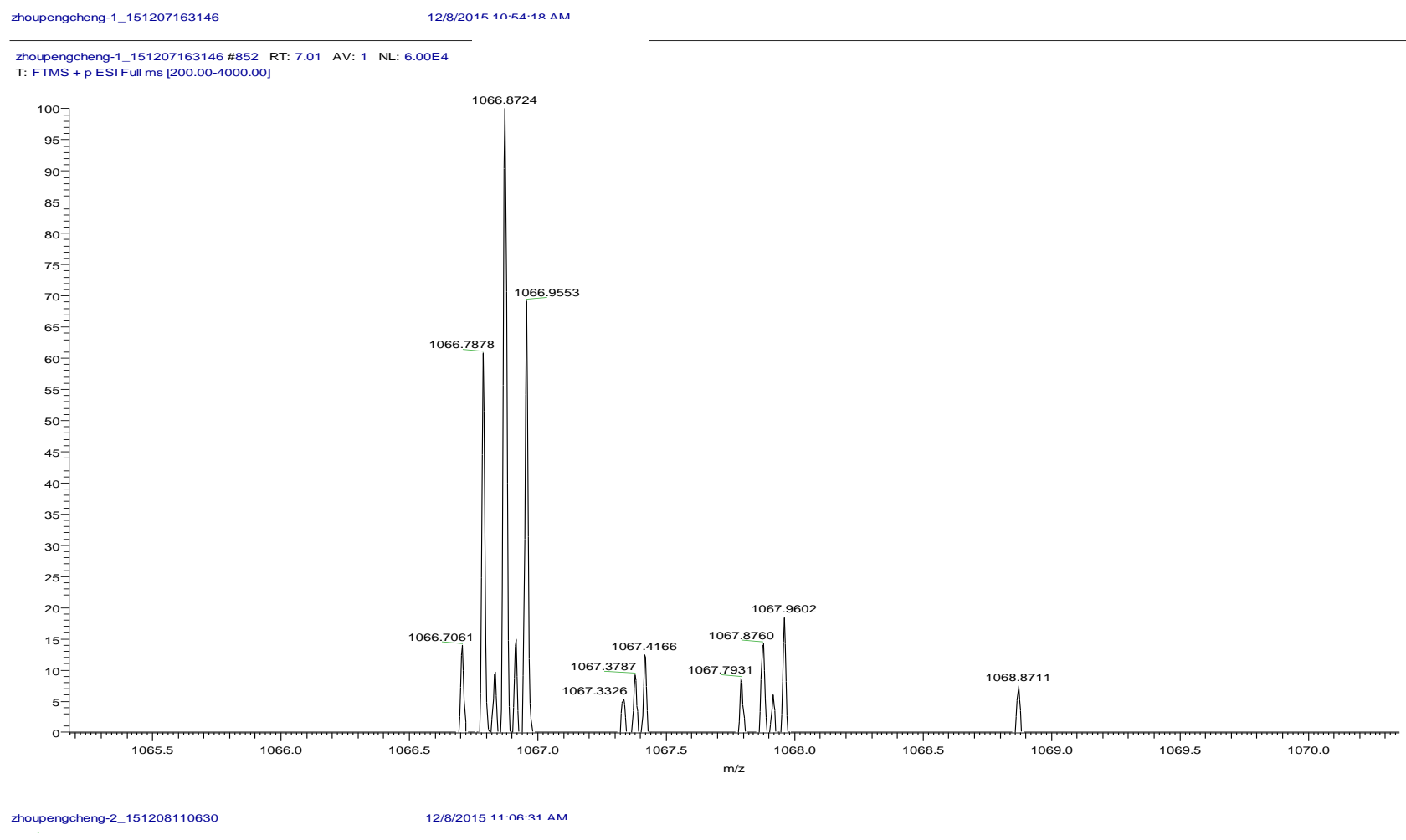

zhoupengcheng-2_151208110630 \#525 RT: 5.53 AV: 1 NL: 3.81E3

T: FTMS + p ESI Full ms [200.00-4000.00]

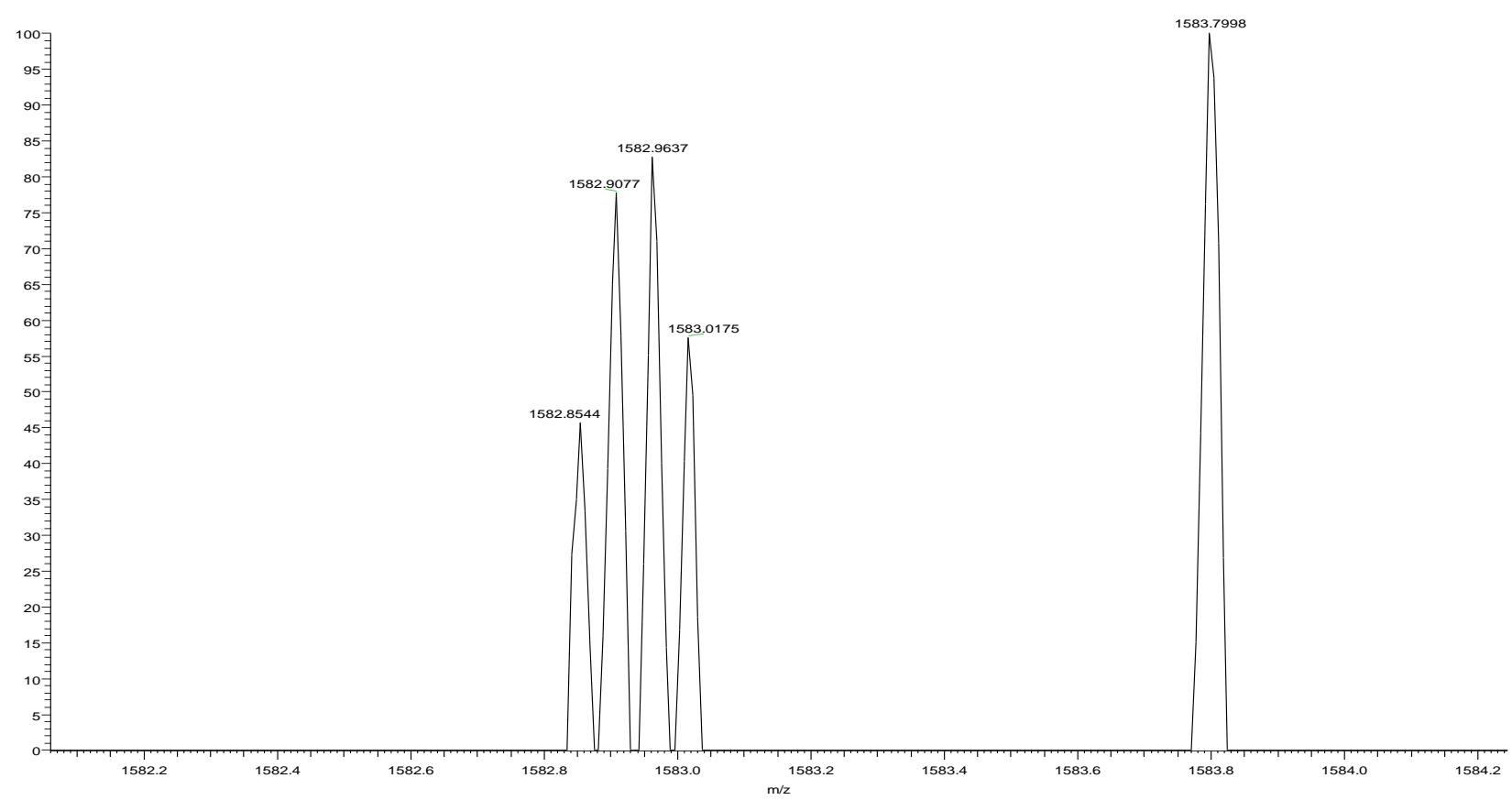

Figure S84 ESI-MS spectra of the E. Coli Trx (top) and the adduct of E. Coli Trx with MSBN-TPP (bottom). The sample in the top panel contains 12 postive charges (12 protons), and the sample in the bottom pannel contains 9 postive charges ( 7 protons +2 charges from MSBN-TPP). Based on the spectra, the molecular weight of $E$. Coli Trx was calculated to be 1066.8724 x $12-12=12790.46$; While the adduct of $E$. Coli Trx with MSBN-TPP was calculated 1582.9637 x $9-7=14239.67$. The mass difference between two samples is $1449.2(14239.67-12790.46)$, which means the protein binds 2 molecules of MSBN-TPP [804.4 x2-158 $\left(2 \mathrm{CH}_{3} \mathrm{SO}_{2}\right)-2(2 \mathrm{H})=1448.8$.]. 


\section{References}

(1) Liu, Y., Duan, D., Yao, J., Zhang, B., Peng, S., Ma, H., Song, Y., and Fang, J. (2014) Dithiaarsanes induce oxidative stress-mediated apoptosis in HL-60 cells by selectively targeting thioredoxin reductase J. Med. Chem. $57,5203-5211$.

(2) Fang, J., Nakamura, T., Cho, D. H., Gu, Z., and Lipton, S. A. (2007) S-nitrosylation of peroxiredoxin 2 promotes oxidative stress-induced neuronal cell death in Parkinson's disease Proc. Natl. Acad. Sci. U S A 104, 18742-18747.

(3) Zhang, L., Duan, D., Liu, Y., Ge, C., Cui, X., Sun, J., and Fang, J. (2014) Highly selective off-on fluorescent probe for imaging thioredoxin reductase in living cells J. Am. Chem. Soc. 136, 226-233.

(4) Triboni, E. R., Artur, J. C., Berci, P., Cuccovia, I. M., and Politi, M. J. (2009) Aromatic nitro substitution reaction between 4-nitro-N-n-butyl-1,8-naphthalimide and n-heptanethiol in water-methanol binary mixtures $J$. Phys. Org. Chem. 22, 703-708.

(5) Chen, R., Lu, H., Liu, C., and Kong, Q. (2015) Novel chemosensors for detection of glutathione by reduction or substitution of naphthalimide derivatives containing sulfoxide or sulfone substituents Bioorg. Med. Chem. Lett. 25, 59-61.

(6) Song, L., Yang, Y., Zhang, Q., Tian, H., and Zhu, W. (2011) Synthesis and photochromism of naphthopyrans bearing naphthalimide chromophore: predominant thermal reversibility in color-fading and fluorescence switch J. Phys. Chem. B 115, 14648-14658.

(7) Lan, H. C., Liu, B., Lv, G. L., Li, Z. H., Yu, X. D., Liu, K. Y., Cao, X. H., Yang, H., Yang, S. P., and Yi, T. (2012) Dual-channel fluorescence "turn on" probe for $\mathrm{Cu}^{2+}$ Sensor Actuat. B-Chem. 173, 811-816.

(8) Xu, C., Luo, W. F., Li, L. J., Yao, S., and Song, H. (2010) Synthesis and Enantiomer Separation of 5-(1-(3,5-Dinitrobenzoylamino)pent-4-enyl)acenaphthene Asian J. Chem. 22, 3923-3928.

(9) Moro, A. J., Schmidt, J., Doussineau, T., Lapresta-Fernandez, A., Wegener, J., and Mohr, G. J. (2011) Surface-functionalized fluorescent silica nanoparticles for the detection of ATP Chem. Commun. 47, 6066-6068.

(10) Li, N., Ramil, C. P., Lim, R. K., and Lin, Q. (2015) A genetically encoded alkyne directs palladium-mediated protein labeling on live mammalian cell surface ACS Chem. Biol. 10, 379-384.

(11) Millard, M., Gallagher, J. D., Olenyuk, B. Z., and Neamati, N. (2013) A selective mitochondrial-targeted chlorambucil with remarkable cytotoxicity in breast and pancreatic cancers J. Med. Chem. 56, 9170-9179. 